\title{
Zur Geschichte der Geowissenschaften im Museum für Naturkunde zu Berlin. Teil 6: Geschichte des Geologisch-Paläontologischen Instituts und Museums der Universität Berlin 1910-2004
}

\author{
Walter Gross $\nmid \&$ Hans-Peter Schultze ${ }^{1}$
}

Mit 14 Abbildungen und 1 Tabelle

\section{Zusammenfassung}

Die Entwicklung des Geologisch-Paläontologischen Instituts und Museums der Universität Berlin von einer Institution, die Geologie zusammen mit Paläontologie als eine Einheit vertrat, über eine Institution, die eine geotektonische Ausrichtung hatte, zu einer auf Paläontologie konzentrierten Institution wird nachvollzogen. Die beiden Institutsdirektoren am Anfang des 20sten Jahrhunderts waren Vertreter der allumfassenden Geologie des 19ten Jahrhunderts, während die beiden folgenden Direktoren eine Geologie ohne Paläontologie vertraten. Das führte zu einer Trennung der beiden Richtungen, und nach der III. Hochschulreform der DDR 1968 verblieb allein die sammlungsbezogene Paläontologie am Museum. Nach der Wiedervereinigung wurde ein Institut für Paläontologie mit biologischer Ausrichtung mit zwei Professuren, einer für Paläozoologie und einer für Paläobotanik, eingerichtet.

Schlüsselwörter: Museum für Naturkunde, Berlin, Geschichte, 20tes Jahrhundert, Geologie, Paläontologie, Deutschland.

\begin{abstract}
The development of the Geologisch-Paläontologisches Institut und Museum of the Museum für Naturkunde at the Humboldt University (formerly Friedrich-Wilhelm-Universität) in Berlin from a geology-paleontology institution to a pure paleontology instution is described. The first two directors of the department in the beginning of the 20th century, Prof. von Branca and Prof. Pompeckj, represented a 19th century concept of a geology, which included paleontology, even vertebrate paleontology as the crown jewel of geology. They fought sometimes vigorously against a separation of paleontology from geology. The next two directors, Prof. Stille and Prof. von Bubnoff, were the leading geologists in Germany; to be a student of Stille was a special trade mark in geology of Germany. They represented a geology centered on tectonics. The separation of paleontology as separate section was prepared. The destructions of the Second World War, the following restaurations and the division of Germany into two States influenced strongly their directorships. The education of geologists at the Museum für Naturkunde ended with the III. University Reform of the German Democratic Republik in 1968. Paleontology was represented by the international renown vertebrate paleontologist, Prof. Dr. W. Gross, up to 1961. Since 1969, paleobotany was strengthened by the inclusion of the paleobotany unit of the Akademie der Wissenschaften into the museum. After reunification of Germany in 1990, the department was rebuild as a Institut für Paläontologie with close connection to biology, a unique situation in Germany. Two professorships, one for paleozoology, Prof. Schultze, and one for paleobotany, Prof. Mai, were established. The number of curators increased to ten from one under the first director of the 20 th century.
\end{abstract}

Key words: Museum of Natural History, Berlin, History, 20th century, Geology, Palaeontology, Germany

\section{Einleitung}

Dieser Artikel setzt die Geschichte der Geologie und Paläontologie im Museum für Naturkunde zu Berlin fort, die von G. Hoppe für die gesamten Geowissenschaften in mehreren Artikeln bis 1910 (Hoppe 2003), von W. O. Dietrich für die geologisch-paläontologischen Sammlungen (Dietrich
1960) und von W. von Branca für das GeologischPaläontologische Institut ebenfalls bis 1910 (Branca 1910a) abgehandelt worden ist. Der Artikel des dritten Direktors des selbstständigen Geologisch-Paläontologischen Instituts und Museums der Universität Berlin, des Geheimrats Prof. Dr. Wilhelm von Branca, umfasst die Zeit von der Gründung der Universität Berlin bis zum Jahre

\footnotetext{
${ }^{1}$ Museum für Naturkunde, Institut für Paläontologie, Invalidenstr. 43, D-10115 Berlin, Germany. - Privat: 2001 Vermont Street, Lawrence, Kansas 66046, USA.

Erhalten Februar 2004, angenommen April 2004
} 
1910, dem Jahr der Jahrhundertfeier der Universität und der geowissenschaftlichen Institute (Lenz 1910). An diese Berichte knüpft die Darstellung der Institutsgeschichte von 1910 bis 2004 an. Die Zeit von 1910 bis zur Gegenwart ist fast so lang wie die vorausgegangenen hundert Jahre, aber nun greifen die Ereignisse zweier Weltkriege in das stille Dasein des Instituts. Im Jahre 1910 waren erst etwas über 20 Jahre seit der räumlichen Trennung des Instituts vom Hauptgebäude der Universität und seiner Verselbstständigung gegenüber dem Mineralogischen Institut vergangen, die Zeit von 1910 bis jetzt umfasst dagegen über 90 Jahre. W. Gross hatte die Geschichte des Instituts anschließend an den Artikel von Branca (1910a) von 1910 bis 1957 in einem Manuskript zusammengefasst, das aber nach Gross's Wechsel in den Westen Deutschlands 1961 nicht mehr publiziert wurde. Dennoch wurde das Manuskript mehrfach zitiert (Daber 1987, 1994, 2002, Jaeger 1992). Das Manuskript von W. Gross, ergänzt vor allem durch Literaturangaben, bildet den ersten Teil dieses Artikels. Der zweite Teil umfasst die Zeit von 1957 bis 2004, für den der zweite Autor verantwortlich zeichnet.

Die Geschichte eines Instituts ist nicht nur Geschichte seiner Persönlichkeiten und ihrer Werke, sondern auch die Geschichte eines Geistes, der in ihm entsteht, lebt, sich verändert und weitergegeben wird. Ein Institut ist fast so etwas wie ein lebender Organismus. der Kräfte gewinnt, seine Kräfte erhält, aber auch seine Kräfte verlieren kann. Eine solche Kraft ist das Ansehen, gewonnen aus den Leistungen seiner führenden Wissenschaftler und Direktoren. Entscheidend ist die Kraft der Persönlichkeit, die sich gegen Widerstände durchzusetzen weiß, die es versteht, Mittel und Wege zu finden, den Ausbau des Instituts vorwärts zu treiben, den Lehrkörper und den Mitarbeiterstab zu vergrößern, jungen Nachwuchswissenschaftlern die Wege zur selbstständigen Forschung und Arbeit zu weisen und zu ebnen. Die Persönlichkeit des Direktors kann eine entscheidende Rolle spielen. Tritt eine Fakultätskommission zusammen, um eine Berufung vorzubereiten, so weiß sie darum, und ihre Sorge gilt der Frage nach den Fähigkeiten des zu Berufenden in bezug auf Forschung Lehre und Direktorat. Die Geschichte eines Instituts ist aber auch weitgehend abhängig vom Wandel in der Aufgabenstellung der jeweiligen Wissenschaft und von der Fähigkeit der Institutsdirektoren, diesen Wandel rechtzeitig zu erkennen.

Die Geschichte wissenschaftlicher Institute ist kein spannender Bericht; die Darstellung des
Wandels im Lehrkörper, in der Assistentenschaft und im Personal, Ausbau und Aufbau der Gebäude und ihrer Räume ist trocken. Sie ist aber notwendig wie alles Tatsachenmaterial als Unterlage einer historischen Betrachtung. Unter den jungen Assistenten treten die Namen auf, die später berühmte Träger wissenschaftlichen Ruhmes sein können. Die vielen kleinen Vorgänge und Änderungen, aus denen sich die Geschichte des Instituts zusammensetzt, gehen so rasch der Erinnerung - auch der Lebenden - verloren, dass sie nicht früh genug festgehalten werden können, um Legendenbildung zu vermeiden. So wird auch in der folgenden Darstellung der trockene Bericht des Tatsachenmaterials den größeren Umfang einnehmen, unterbrochen von den kurzen Schilderungen der Persönlichkeit der einander folgenden Direktoren. Die Geschichte des Instituts innerhalb der Zeit von 1910 bis zur Gegenwart wird eingeteilt in die Direktorate: von Branca (1910-1917), Pompeckj (1917-1930), Solger $\quad(1930-1932), \quad$ Stille (1932-1950), von Bubnoff (1950-1957), Gross (1957-1961), die wechselvolle Zeit zwischen 1961 und 1994 und Schultze (1994-2004).

Leider waren vielfach die notwendigen Unterlagen und Akten über den Personenwechsel in den verschiedenen Dienststellen nicht $\mathrm{zu}$ beschaffen. Alle Institutsakten sind im Jahre 1945 in den letzten Kriegstagen verbrannt. Es bedurfte daher so mancher mühseliger Suche in Universitätsakten und Archiven, so mancher Nachfrage bei Mitarbeitern und Vertretern anderer Dienststellen der Universität. Die Anzahl der Institutsdirektoren ist gering, da sie für viele Jahre in ihr Amt berufen wurden. Auch die Kustoden und Präparatoren sind als Universitätsbeamte durch viele Jahre hindurch tätig. Rascher ist schon der Wechsel der Dozenten, insbesondere der früheren Privatdozenten. Die Assistentenstellen wurden hingegen manchmal in einem Jahr mehrfach besetzt, hier ist der lebhafteste Wechsel festzustellen, namentlich bei der Neuübernahme des Ordinariats (Tabelle 1).

\section{Direktor v. Branca (1894 bis 1917)}

Wir beginnen mit dem Jahre 1911. Das Institut bestand räumlich im gleichen Umfang wie bei seiner Gründung im Jahre 1889; die Anzahl der Mitarbeiter hatte ein wenig zugenommen. Geheimrat Prof. Dr. Wilhelm von Branca (Abb. siehe Hoppe 2003, Abb. 12) leitete seit 1899 das Institut als Direktor und Ordinarius. Er erteilte 
Tabelle 1

Das wissenschaftliche Personal des Geologisch-Paläontologischen Instituts und Museums (1910-1968), des Bereiches Paläontologisches Museum (1969-1993) und des Instituts für Paläontologie (1994-2004) in alphabetischer Reihenfolge auf der Basis von Anonym (1962), Asen (1955), Akten des Instituts, dem Archiv der Humboldt-Universität, Nachrufen und mündlichen Mitteilungen ehemaliger Mitglieder des Instituts.

Abkürzungen: A: Assistent, aplA: außerplanmäßiger Assistent, Asp: Aspirant, aplAsp: außerplanmäßiger Aspirant, Bdk: Bodenkundler, Bot: Botaniker, D: Dozent, Dir: Direktor, Geod: Geodät, Geol: Geologe, Geoph: Geophysiker, gesch.: geschäftsführend, HA: Hilfsassistent (nur teilweise erfasst), Ha: Habilitation, HP: Honorarprofessor, K: Kustos, LA: Lehrauftrag, M: Mitglied, OA: Oberassistent, OK: Oberkustos, oM: ordentliches Mitglied, P: Professor, aoP: außerordentlicher Professor (auch Professor mit Lehrauftrag), aplP: außerplanmäßiger Professor, oP: ordentlicher Professor, Pal: Paläontologe, Palb: Paläobotaniker, PD: Privatdozent, Phil: Philosoph, wiss. Ma: wissenschaftlicher Mitarbeiter.

Institutionen: BfB: Bundesanstalt für Bodenforschung, Hannover, BPM: Bereich Paläontologisches Museum, DAWiss: Deutsche Akademie der Wissenschaften, Geotekt. I: Geotektonisches Institut der Akademie, GLA Krefeld: Geologisches Landesamt Nordrhein-Westfalen, Grad.-kolleg: Graduiertenkolleg, HU: Humboldt Universität zu Berlin, I. Bodenkart: Institut für Bodenkartierung, I. Geol: Institut für Geologie, I. Met. Geoph: Institut für Meteorologie und Geophysik, I. Pal: Institut für Paläontologie, LWGF: Landwirtschaftlich-Gärtnerische Fakultät, MfN: Museum für Naturkunde, PrGLA: Preußische Geologische Landesanstalt (1939 Reichsstelle für Bodenforschung, 1940 Reichsamt für Bodenforschung), TH: Technische Hochschule, TU: Technische Universität Berlin, ZGI: Zentrales Geologisches Institut (1945 Geologische Landesanstalt, 1950 Staatliche Geologische Kommission, 1958 Zentraler Geologischer Dienst, 1961 ZGI).

\begin{tabular}{|c|c|c|c|c|c|c|c|}
\hline Name, Vorname & $\begin{array}{l}\text { Lebens- } \\
\text { jahre }\end{array}$ & Promotion & $\begin{array}{l}\text { Assistent/ } \\
\text { Kustos }\end{array}$ & Lehrkraft & Gebiet & $\begin{array}{l}\text { später tätig } \\
\text { in }\end{array}$ & $\begin{array}{l}\text { Bemerkun- } \\
\text { gen }\end{array}$ \\
\hline Aberhan, Martin & $*^{*} 1959$ & $\begin{array}{l}1992 \\
\text { Würzburg } \\
\text { Ha } 1998 \\
\text { Würzburg }\end{array}$ & $\begin{array}{l}\text { K } 1998-2002 \\
\text { OK seit } 2002\end{array}$ & PD 1999 & Pal & & \\
\hline Ahrens, Helmut & $*_{1933}$ & 1968 Berlin & A $1961-62$ & & Geol & & $\begin{array}{l}\text { LA } 1961 \\
\text { ZGI }\end{array}$ \\
\hline Arratia, Gloria & *1942 & $\begin{array}{l}1966 \text { Santiago } \\
\text { de Chile } \\
1996 \text { Uppsala }\end{array}$ & K seit 1996 & & Pal & & \\
\hline Barthel, Manfred & ${ }^{*} 1934$ & $\begin{array}{l}1960 \text { Halle } \\
\text { Ha } 1968 \\
\text { Berlin }\end{array}$ & K 1968-92 & $\begin{array}{l}\text { D } 1978 \\
\text { aoP } 1981\end{array}$ & Palb & & $\begin{array}{l}\text { Dir. BPM } \\
\text { 1976-78 } \\
\text { Dir. MfN } \\
1981-90\end{array}$ \\
\hline $\begin{array}{l}\text { Becker, Ralph- } \\
\text { Thomas }\end{array}$ & *1959 & $\begin{array}{l}1991 \text { Bochum } \\
\text { Ha } 2001 \mathrm{FU} \\
\text { Berlin }\end{array}$ & $\begin{array}{l}\text { K 1995-99 } \\
\text { OK } \\
1999-2001\end{array}$ & & Pal & $\begin{array}{l}\text { ab } 2001 \\
\text { Münster }\end{array}$ & \\
\hline Behrend, Fritz & $1885-1949$ & $\begin{array}{l}1908 \text { Berlin } \\
\text { Ha } 1924 \\
\text { Berlin }\end{array}$ & & $\begin{array}{l}\text { PD 1924-35 } \\
\text { aplP 1935-45 }\end{array}$ & Geol & & $\begin{array}{l}\text { PrGLA } \\
1928-29 / 30 \\
\text { Südafrika }\end{array}$ \\
\hline Beyer, Erich & ${ }^{*} 1926$ & 1963 Berlin & Asp 1958-62 & & Geol & & LA 1961-67 \\
\hline Böhme, Gottfried & ${ }^{*} 1934$ & 1979 Berlin & K 1976-99 & & Pal & & $\begin{array}{l}\text { wiss. Sekre- } \\
\text { tär 1969-74 }\end{array}$ \\
\hline $\begin{array}{l}\text { Branca, } \\
\text { Wilhem von }\end{array}$ & $1844-1928$ & $\begin{array}{l}1876 \\
\text { Heidelberg }\end{array}$ & & oP $1899-1917$ & $\begin{array}{l}\mathrm{Pal}+ \\
\mathrm{Geol}\end{array}$ & & $\begin{array}{l}\text { Dir. } \\
1899-1917 \\
\text { oM DAWiss } \\
1900\end{array}$ \\
\hline Bubnoff, Serge von & $1888-1957$ & $\begin{array}{l}1912 \\
\text { Heidelberg } \\
\text { Ha } 1921 \\
\text { Breslau }\end{array}$ & & oP 1950-57 & Geol & & $\begin{array}{l}\text { oM DAWiss } \\
1949-57 \\
\text { Dir. 1950-57 } \\
\text { National- } \\
\text { preisträger }\end{array}$ \\
\hline $\begin{array}{l}\text { Chrobok, Siegfried } \\
\text { Martin }\end{array}$ & $1930-1999$ & 1963 Berlin & $\begin{array}{l}\text { A } 1957-60 \\
\text { OA } 1960-68\end{array}$ & & Geol & $\begin{array}{l}\text { Geograph. } \\
\text { Inst. HU }\end{array}$ & LA $1961-67$ \\
\hline Daber, Rudolf & *1929 & $\begin{array}{l}1954 \text { Berlin } \\
\text { Ha } 1957 \text { Berlin }\end{array}$ & Asp 1952-57 & $\begin{array}{l}\text { D 1958-61 } \\
\text { P 1961-69 } \\
\text { oP 1969-94 }\end{array}$ & Palb & $\begin{array}{l}1983-86 \\
\text { Mosambik }\end{array}$ & $\begin{array}{l}\text { LA 1953-55 } \\
\text { Dir. Inst. Pal } \\
1962-68 \\
\text { Dir. BPM } \\
1969-70 \text {, } \\
1987-90 \\
\text { Dir. MfN } \\
1969-72\end{array}$ \\
\hline
\end{tabular}


Tabelle 1 (Fortsetzung)

\begin{tabular}{|c|c|c|c|c|c|c|c|}
\hline Name, Vorname & $\begin{array}{l}\begin{array}{l}\text { Lebens- } \\
\text { jahre }\end{array} \\
\end{array}$ & Promotion & \begin{tabular}{|l} 
Assistent/ \\
Kustos \\
\end{tabular} & Lehrkraft & Gebiet & $\begin{array}{l}\text { später tätig } \\
\text { in }\end{array}$ & Bemerkungen \\
\hline Dahlgrün, Fritz & $1894-1954$ & 1921 Göttingen & & HP 1933-1939 & Geol & $\begin{array}{l}1946-54 \\
\text { Clausthal- } \\
\text { Zellerfeld }\end{array}$ & PrGLA \\
\hline de Terra, Hellmut & $1900-1981$ & $\begin{array}{l}1924 \\
\text { München }\end{array}$ & aplA 1929-30 & & Pal & $\begin{array}{l}\text { Yale Univ., } \\
\text { New Haven }\end{array}$ & \\
\hline Denner, Julius & $1895-?$ & $\begin{array}{l}1922 \\
\text { Tubingen }\end{array}$ & & & Geol & & $\begin{array}{l}\mathrm{P} \text { in } \mathrm{LWGF} \\
\mathrm{LA} 1949-51\end{array}$ \\
\hline Deubel, Fritz & $1898-1966$ & 1922 Jena & & aplP $1952-54$ & Geol & oP Univ Jena & \begin{tabular}{|l|} 
LA 1951 \\
oM DaWiss \\
1953 \\
Nationalpreis- \\
träger \\
\end{tabular} \\
\hline Diebel. Kurt & $1915-1981$ & 1939 Berlin & $\begin{array}{l}\text { A } 1947-50 \\
\text { K } 1951-80\end{array}$ & & Pal & & LA 1952-67 \\
\hline Diener, Siegfried & $1926-1992$ & - & A $1956-59$ & & Geol & & \begin{tabular}{|l} 
LA 1956-59 \\
ZGI
\end{tabular} \\
\hline $\begin{array}{l}\text { Dietrich, Wilhelm } \\
\text { Otto }\end{array}$ & $1881-1964$ & 1903 Tübingen & $\begin{array}{l}\text { A } 1911-27 \\
\text { OA } 1927-44 \\
\text { K } 1944-59\end{array}$ & P 1943 & Pal & & \\
\hline Dittrich, W. Georg & $\div 1929$ & $\begin{array}{l}1958 \\
\text { Bergakad. } \\
\text { Freiberg }\end{array}$ & & & Geod & & \begin{tabular}{|l|} 
ZGI \\
LA $1960-67$
\end{tabular} \\
\hline Dolezalek, Berthold & $1917-2000$ & 1950 Berlin & $\begin{array}{l}\text { HA } 1946 \\
\text { A } 1947-53\end{array}$ & & Geol & Krefeld & \\
\hline Fahlbusch, Klaus & $* 1927$ & 1955 Berlin & $\begin{array}{l}\text { HA } 1947-52 \\
\text { A } 1953-55\end{array}$ & & Pal & $\begin{array}{l}1955 \text { TU Berlin } \\
\text { TH Darmstadt }\end{array}$ & \\
\hline $\begin{array}{l}\text { Fanselau, Gerhard } \\
\text { Rudolf }\end{array}$ & $1904-1982$ & $\begin{array}{l}1927 \text { Berlin } \\
\text { Ha } 1935 \text { Berlin }\end{array}$ & & & Geoph & & $\begin{array}{l}\text { I.Met.Geoph. } \\
\text { LA 1952-56 }\end{array}$ \\
\hline Fischer, Georg & $1899-?$ & $\begin{array}{l}\text { 1924 München } \\
\text { Ha } 1927 \\
\text { München }\end{array}$ & & $\begin{array}{l}\text { PD 1936-39 } \\
\text { D 1939-44 } \\
\text { apl P 1944 }\end{array}$ & Geol & & PrGLA \\
\hline Fischer, Karlheinz & *1932 & $\begin{array}{l}1962 \\
\text { Halle }\end{array}$ & \begin{tabular}{|l|} 
wiss. Ma \\
$1962-70$ \\
K 1970-97 \\
\end{tabular} & & Pal & & LA $1966-67$ \\
\hline Fischer, Olaf & $* 1962$ & 1991 Berlin & A $1990-91$ & & Palb & & \\
\hline Funke, Klaus-Peter & $1938-2000$ & $\begin{array}{l}973 \\
\text { Berlin } \\
\end{array}$ & A $1961-68$ & & Geol & & \\
\hline Gothan, Walter & $1879-1954$ & $\begin{array}{l}\text { 1904 Jena } \\
\text { Ha } 1908 \\
\text { Bergakad. } \\
\text { Berlin } \\
\end{array}$ & & $\begin{array}{l}\text { HP 1927-45 } \\
\text { aplP 1946 } \\
\text { P 1947-53 }\end{array}$ & Palb & & $\begin{array}{l}\text { PrGLA } \\
\text { oM DAWiss } \\
1949 \\
\text { LA 1953-54 }\end{array}$ \\
\hline Gross, Walter & $1903-1974$ & $\begin{array}{l}1929 \text { Berlin } \\
\text { Ha } 1935 \\
\text { Frankfurt }\end{array}$ & $\begin{array}{l}\text { aplA 1932. } \\
1937 \\
\text { A } 1938-44\end{array}$ & $\begin{array}{l}\text { PD 1937-43 } \\
\text { aplP 1943-44 } \\
\text { aoP 1944-45, } \\
1949 \\
\text { oP + Direktor } \\
1950-61\end{array}$ & Pal & \begin{tabular}{|l|}
$1961-69$ \\
Tübingen
\end{tabular} & $\begin{array}{l}\text { gesch. Dir. } \\
\text { 1957-61 }\end{array}$ \\
\hline $\begin{array}{l}\text { Haarmann, Erich } \\
\text { Otto }\end{array}$ & $1882-1945$ & $\begin{array}{l}1908 \text { Berlin } \\
\text { Ha } 1914 \text { Berlin }\end{array}$ & HA $1915-22$ & $\begin{array}{l}\text { PD 1915-22 } \\
\text { aplP 1922-45 }\end{array}$ & Geol & & \\
\hline Hampe, Oliver & *1961 & $\begin{array}{l}\text { 1991 Mainz } \\
\text { Ha } 2003 \text { Berlin }\end{array}$ & $\begin{array}{l}\text { A 1996-2000 } \\
\text { K 2000- }\end{array}$ & PD 2003 & Pal & & \\
\hline Hartung, Wolfgang & $1907-94$ & $\begin{array}{l}1933 \text { Berlin } \\
\text { Ha } 1938 \text { Berlin }\end{array}$ & A 1933 & & Palb & & LA $1940-45$ \\
\hline $\begin{array}{l}\text { Heck, } \\
\text { Herbert-Lothar }\end{array}$ & $1904-1967$ & 1927 Göttingen & & $\begin{array}{l}\text { P } 1963-66 \\
\text { oP 1966-67 }\end{array}$ & Geol & & PrGLA \\
\hline $\begin{array}{l}\text { Heinrich, } \\
\text { Wolf-Dieter }\end{array}$ & *1941 & $\begin{array}{l}1968 \text { Berlin } \\
\text { Ha } 1979 \text { Berlin }\end{array}$ & $\begin{array}{l}\text { HA } 1964 \\
\text { Asp. } 1966-72 \\
\text { A } 1975-76 \\
\text { K } 1976-94 \\
\text { OK seit } 1994\end{array}$ & & Pal & & $\begin{array}{l}\text { gesch. Dir. I. } \\
\text { Pal. 1992-94 }\end{array}$ \\
\hline
\end{tabular}


Tabelle 1 (Fortsetzung)

\begin{tabular}{|c|c|c|c|c|c|c|c|}
\hline Name, Vorname & \begin{tabular}{|l} 
Lebens- \\
jahre
\end{tabular} & Promotion & $\begin{array}{l}\text { Assistent/ } \\
\text { Kustos }\end{array}$ & Lehrkraft & Gebiet & $\begin{array}{l}\text { später tätig } \\
\text { in }\end{array}$ & Bemerkungen \\
\hline Helms, Jochen & $* 1932$ & 1961 Berlin & $\begin{array}{ll}\text { A } 1957-69 \\
\text { K } 1969-97\end{array}$ & & $\mathrm{Pal}$ & & $\begin{array}{l}\text { LA 1961-67 } \\
\text { Dir. BPM } \\
1978-86\end{array}$ \\
\hline Hennig, Edwin & $1882-1977$ & $\begin{array}{l}1906 \text { Berlin } \\
\text { Ha } 1913 \text { Berlin }\end{array}$ & A $1906-17$ & $\begin{array}{l}\text { PD 1915-17 } \\
\text { P } 1916\end{array}$ & $\mathrm{Pal}$ & \begin{tabular}{|l|}
$1917-46$ \\
Tübingen
\end{tabular} & $\begin{array}{l}1909-11 \\
\text { Leiter } \\
\text { Expedition } \\
\text { Tendaguru }\end{array}$ \\
\hline Herbst, Georg & 1911-? & 1938 Berlin & A 1937 & & & & \\
\hline Herrmann, Rolf & $* 1928$ & 1968 Berlin & $\begin{array}{l}\text { OA } 1968 \\
\text { K 1971-75 }\end{array}$ & & Geol & Heilbronn & \\
\hline Herneck, Friedrich & $1909-1993$ & $\begin{array}{l}1941 \text { Prag } \\
\text { Ha } 1961 \\
\text { Berlin }\end{array}$ & & & Phil & & LA $1962-67$ \\
\hline $\begin{array}{l}\text { Hinz-Schallreuter, } \\
\text { Ingelore }\end{array}$ & ${ }^{*} 1957$ & \begin{tabular}{|l|}
1986 Bonn \\
Ha 1996 \\
Hamburg \\
\end{tabular} & A $1995-2000$ & PD 1998-2000 & Pal & $\begin{array}{l}2000 \\
\text { Greifswald }\end{array}$ & \\
\hline $\begin{array}{l}\text { Hyde, Herbert P. T. } \\
\text { (früher Rohieder) }\end{array}$ & & $\begin{array}{l}1926 \\
\text { München }\end{array}$ & & & Geol & & LA 1961-64 \\
\hline Jaeger, Hermann & $1929-1992$ & \begin{tabular}{|l|}
1958 Berlin \\
Ha 1966 Berlin
\end{tabular} & $\begin{array}{l}\text { HA 1951-55 } \\
\text { A 1956-59 } \\
\text { K 1959-92 }\end{array}$ & D 1966-67 & $\mathrm{Pal}$ & & \begin{tabular}{|l|} 
LA $1961-66$ \\
Dir. BPM \\
$1970-75$ \\
$1990-92$ \\
M Leopoldina
\end{tabular} \\
\hline Jäger, Klaus-Dieter & *1936 & 1965 Jena & wiss. Ma 1967 & & & $\begin{array}{l}\text { Frankfurt/Oder } \\
\text { Halle }\end{array}$ & \\
\hline Jähnichen, Hellmut & *1919 & 1964 Berlin & $\begin{array}{l}\text { A } 1964-68 \\
\text { K } 1968-91 \\
\end{array}$ & & Palb & & \\
\hline $\begin{array}{l}\text { Janensch, } \\
\text { Werner Ernst Martin }\end{array}$ & $1878-1969$ & 1901 Straßburg & $\begin{array}{l}\text { A } 1901-06 \\
\text { K } 1906-50\end{array}$ & P 1912 & $\mathrm{Pal}$ & & $\begin{array}{l}\text { 1909-1911 } \\
\text { Tendaguru } \\
\text { 1928/29 } \\
\text { Südafrika } \\
\end{array}$ \\
\hline Jubitz, Karl Bernhard & $* 1925$ & 1953 Münster & & & Geol & & \begin{tabular}{|l|} 
Geotekt. I. \\
DAWiss \\
LA 1954-55 \\
\end{tabular} \\
\hline Kahlert, Eberhard & *1931 & - & \begin{tabular}{|l|} 
wiss. Ma \\
$1994-96$
\end{tabular} & & Palb & & \\
\hline Karrenberg, Herbert & $1909-1983$ & $\begin{array}{l}1933 \\
\text { Göttingen }\end{array}$ & $\begin{array}{l}\text { HA 1933 } \\
\text { A 1934-37 }\end{array}$ & & Geol & & \begin{tabular}{|l|} 
PrGLA \\
GLA Krefeld
\end{tabular} \\
\hline Kautzsch, Eberhard & $1905-1986$ & $\begin{array}{l}1931 \text { München } \\
\text { Ha } 1955 \text { Berlin }\end{array}$ & & $\begin{array}{l}\text { PD } 1955 \\
\text { aplP 1956-61 } \\
\text { oP 1962-68 }\end{array}$ & Geol & & $\begin{array}{l}\text { LA 1954-62 } \\
\text { Dir. I. Geol. } \\
1962-68 \\
\text { oM DAWiss }\end{array}$ \\
\hline Kießling, Wolfgang & *1965 & 1995 Erlangen & A seit 2001 & & Pal & & $\begin{array}{l}1999-2000 \\
\text { Grad.-kolleg }\end{array}$ \\
\hline Klinghardt, Franz & $1882-1956$ & $\begin{array}{l}\text { 1911 Freiburg } \\
\text { Ha } 1914 \\
\text { Greifswald }\end{array}$ & & $\begin{array}{l}\text { aoP 1935-1939 } \\
\text { aplP 1939-44 }\end{array}$ & Pal & & \\
\hline Knape, Helmuth & *1931 & $\begin{array}{l}1962 \text { Berlin } \\
\text { Ha } 1970 \text { Berlin }\end{array}$ & & & Geol & & \begin{tabular}{|l|} 
ZGI \\
LA 1964-67
\end{tabular} \\
\hline Kölbel, Heinrich & $1910-1984$ & 1938 Berlin & HA 1937 & & & & \begin{tabular}{|l|} 
PrGLA, ZGI \\
LA 1962-67
\end{tabular} \\
\hline Kolp, Otto & *1918-1990 & $\begin{array}{l}1953 \text { Rostock } \\
\text { Ha } 1965 \\
\text { Leipzig }\end{array}$ & & D $1966-67$ & Geol & & $\begin{array}{l}\text { Warnemünde } \\
\text { LA 1964/65 }\end{array}$ \\
\hline Kordiuk, Bohdan & $1908-?$ & 1938 Berlin & aplA 1939-40 & & Geol & & \\
\hline Korn, Dieter & *1958 & 1996 Tübingen & K seit 2002 & & Pal & & \\
\hline Kronecker, Wilhelm & 1884-? & 1910 Berlin & $\begin{array}{l}\text { HA 1908 } \\
\text { A 1909-11 }\end{array}$ & & Geol & & \\
\hline
\end{tabular}


Tabelle 1 (Fortsetzung)

\begin{tabular}{|c|c|c|c|c|c|c|c|}
\hline Name, Vorname & $\begin{array}{l}\text { Lebens- } \\
\text { jahre }\end{array}$ & Promotion & $\begin{array}{l}\text { Assistent/ } \\
\text { Kustos }\end{array}$ & Lehrkraft & Gebiet & $\begin{array}{l}\text { später tätig } \\
\text { in }\end{array}$ & Bemerkungen \\
\hline Krutzsch, Wilfried & $\% 1928$ & \begin{tabular}{|l|}
1956 Halle \\
Ha 1964 Berlin
\end{tabular} & K 1983-93 & D $1966-67$ & Palb & & \begin{tabular}{|l} 
ZGI \\
LA 1961-67
\end{tabular} \\
\hline Krzywicki, Erwin & $1910-?$ & 1939 Berlin & HA 1937 & & Geol & & \\
\hline Lazarus, David & *1954 & $\begin{array}{l}1984 \text { Columbia, } \\
\text { New York }\end{array}$ & K seit 1995 & & Pal & & \\
\hline Lewien, Erich & $1905-?$ & 1933 Aachen & & & Geol & & $\begin{array}{l}\text { PrGLA } \\
\text { ZGI } \\
\text { LA } 1956\end{array}$ \\
\hline Lindert, Wolfgang & $* 1938$ & 1967 Berlin & A $1963-68$ & & Geol & & $\mathrm{ZGI}$ \\
\hline Litke, Reinhold & $* 1932$ & 1964 Berlin & K $1968-71$ & & Palb & & \\
\hline Locker, Sigurd & $\mid 1940-1997$ & 1967 Berlin & $\begin{array}{l}\text { Asp 1963-72 } \\
\text { A 1972-82 }\end{array}$ & & Pal & 1983 Univ. Kiel & \\
\hline Lotze, Franz & $1903-1971$ & $\begin{array}{l}\text { 1926 Göttingen } \\
\text { Ha 1929 } \\
\text { Göttingen }\end{array}$ & A $1932-41$ & $\begin{array}{l}\text { PD 1932-35 } \\
\text { aplP 1935-38 }\end{array}$ & Geol & $\begin{array}{l}\text { 1941-68 } \\
\text { Wien, Münster }\end{array}$ & $\begin{array}{l}1938-41 \\
\text { (beurlaubt) } \\
\text { Bergbaugeo- } \\
\text { loge }\end{array}$ \\
\hline Ludwig, Gerhard & $* 1927$ & & & & Geol & & $\begin{array}{l}\text { ZGI } \\
\text { LA 1953-55 }\end{array}$ \\
\hline Mai, Dieter & $* 1934$ & $\begin{array}{l}1963 \text { Jena } \\
\text { Ha } 1983 \text { Berlin }\end{array}$ & & oP 1993-2000 & Palb & & \begin{tabular}{|l|} 
Leiter Paläo- \\
botanik \\
1993-2000
\end{tabular} \\
\hline Martin, Hans & $1899-1990$ & $\begin{array}{l}1925 \text { Jena } \\
\text { Ha } 1935 \text { Jena } \\
\end{array}$ & & & Geoph & P. Univ. Jena & LA $1952-55$ \\
\hline $\begin{array}{l}\text { Meier, Rudolf Erich } \\
\text { Arnold }\end{array}$ & *1932 & 1965 Berlin & A $1959-67$ & & Geol & \begin{tabular}{|l} 
DA Wiss \\
Potsdam
\end{tabular} & LA $1966-67$ \\
\hline Möbus, Günter & $\% 1922$ & \begin{tabular}{|l|}
1954 Berlin \\
Ha 1963 Berlin \\
\end{tabular} & & D $1963-68$ & Geol & 1968 Greifswald & LA $1955-67$ \\
\hline Mohr, Barbara A. R. & *1953 & $\begin{array}{l}1983 \text { Bonn } \\
\text { Ha } 2000 \text { Berlin }\end{array}$ & K seit 1995 & PD 2000 & Palb & & \\
\hline Neumann, Christian & \%1965 & $\begin{array}{l}1999 \\
\text { FU Berlin }\end{array}$ & K seit 2001 & & Pal & & \\
\hline Neumann, Werner & *1923 & 1955 Berlin & HA $1951-52$ & & & & LA 1955 \\
\hline Peters, Günter & $* 1932$ & $\begin{array}{l}1960 \text { Berlin } \mathrm{Ha} \\
1972 \text { Berlin }\end{array}$ & & & Zool & & \begin{tabular}{|l|} 
LA 1961-67 \\
P 1975 (Zool)
\end{tabular} \\
\hline Pietrzeniuk, Erika & $* 1935$ & 1966 Berlin & $\begin{array}{l}\text { Asp 1962-70 } \\
\text { K 1970-2000 }\end{array}$ & & Pal & & \\
\hline Pilger, Andreas & $1910-1997$ & $\begin{array}{l}1937 \text { Berlin } \\
\text { Ha } 1943 \text { Berlin }\end{array}$ & $\begin{array}{l}\text { HA } 1937 \\
\text { aplA } 1937-38 \\
\text { A } 1938-45\end{array}$ & PD 1943-45 & Geol & \begin{tabular}{|l|}
1951 Krefeld \\
$1956-1979$ \\
Clausthal- \\
Zellerfeld
\end{tabular} & \\
\hline Pompeckj, Josef Felix & $1867-1930$ & \begin{tabular}{|l}
1885 \\
Königsberg \\
Ha 1894 \\
München
\end{tabular} & & oP 1917-30 & $\begin{array}{l}\mathrm{Pal}+ \\
\text { Geol }\end{array}$ & & \begin{tabular}{|l|} 
Direktor \\
$1917-30$ \\
Rektor Univ. \\
$1925 / 26$ \\
oM DAWiss \\
1920 \\
\end{tabular} \\
\hline Potonié, Henry & $1857-1913$ & \begin{tabular}{|l|}
1884 Berlin \\
Ha 1901 Berlin \\
\end{tabular} & & PD $1901-13$ & Palb & & $\begin{array}{l}\text { PrGLA } \\
\text { LA } 1901-13\end{array}$ \\
\hline Prauss, Michael & $* 1955$ & \begin{tabular}{|l|}
1988 Göttingen \\
Ha 1998 \\
Göttingen \\
\end{tabular} & & PD 2002-04 & Palb & & $\begin{array}{l}\text { Vertretung P. } \\
\text { Paläobotanik }\end{array}$ \\
\hline Quenstedt. Werner & $1893-1960$ & $\begin{array}{l}\text { 1922 München } \\
\text { Ha } 1929 \text { Berlin }\end{array}$ & A $1923-37$ & $\begin{array}{l}\text { PD 1928-35 } \\
\text { aoP 1935 aplP } \\
1935-44\end{array}$ & Pal & $\begin{array}{l}\text { ab } 1944 \\
\text { Achenkirch/ } \\
\text { Tirol }\end{array}$ & LA 1937 \\
\hline Range. Paul & $1879-1952$ & $\begin{array}{l}1903 \text { Leipzig } \\
\text { Ha } 1921 \text { Berlin }\end{array}$ & & $\begin{array}{l}\text { PPD 1921-32 } \\
\text { aoP 1932-39 } \\
\text { aplP 1939-45 }\end{array}$ & Geol & & $\begin{array}{l}\text { M Leopoldina } \\
1940 \\
\text { M DAKMü }\end{array}$ \\
\hline
\end{tabular}


Tabelle 1 (Fortsetzung)

\begin{tabular}{|c|c|c|c|c|c|c|c|}
\hline Name, Vorname & $\begin{array}{l}\text { Lebens- } \\
\text { jahre }\end{array}$ & Promotion & $\begin{array}{l}\text { Assistent/ } \\
\text { Kustos }\end{array}$ & Lehrkraft & Gebiet & $\begin{array}{l}\text { später tätig } \\
\text { in }\end{array}$ & Bemerkungen \\
\hline Reck, Hans & $1886-1937$ & 1909 München & $\begin{array}{l}\text { HA 1909-15 } \\
\text { A } 1919-1930\end{array}$ & aplP $1920-1930$ & Geol & \begin{tabular}{l|}
1914 Deutsch- \\
Ostafrika \\
ab 1931 \\
Forschungs- \\
reisen in Afrika
\end{tabular} & $\begin{array}{l}\text { 1912-1913 } \\
\text { Tendaguru }\end{array}$ \\
\hline Remy, Winfried & 1924-1995 & $\begin{array}{l}\text { 1951 Tübingen } \\
\text { Ha } 1955 \text { Berlin }\end{array}$ & HA 1951 & & Palb & \begin{tabular}{|l|}
$1961-89$ \\
Münster
\end{tabular} & \begin{tabular}{|l} 
ZGI, DAWiss. \\
LA 1955-61
\end{tabular} \\
\hline $\begin{array}{l}\text { Richter, Gerhard } \\
\text { (Richter-Bernburg) }\end{array}$ & $1907-1990$ & $\begin{array}{l}1929 \text { Göttingen } \\
\text { Ha } 1941 \text { Berlin }\end{array}$ & apl.A 1932-34 & & Geol & & \begin{tabular}{|l} 
PrGLA \\
BfB
\end{tabular} \\
\hline Rüffle, Ludwig & ${ }^{*} 1931$ & 1961 Berlin & K 1969-96 & & Palb & & \\
\hline $\begin{array}{l}\text { Schellenberg, } \\
\text { Hans-Georg }\end{array}$ & $* 1938$ & - & A $1961-68$ & & & & \\
\hline $\begin{array}{l}\text { Schindewolf, } \\
\text { Otto Heinrich }\end{array}$ & $1886-1971$ & $\begin{array}{l}1919 \text { Marburg } \\
\text { Ha } 1921 \\
\text { Marburg }\end{array}$ & & $\begin{array}{l}\text { aplP } 1946 \text { oP } \\
1947-48\end{array}$ & $\mathrm{Pal}$ & $\begin{array}{l}\text { 1948-63 } \\
\text { Tübingen }\end{array}$ & PrGLA \\
\hline Schirarend, Carsten & *1956 & 1985 Berlin & apl A 1984-89 & & $\begin{array}{l}\text { Bot } \\
\text { (Palb) }\end{array}$ & & \\
\hline Schlegel, Ernst & $* 1925$ & - & A $1958-60$ & & Geol & & \\
\hline Schmidt, Klaus & $1928-1983$ & $\begin{array}{l}1954 \text { Berlin } \\
\text { Ha } 1957 \text { Berlin }\end{array}$ & $\begin{array}{l}\text { A } 1952-54 \\
\text { OA } 1954-60\end{array}$ & D $1958-60$ & Geol & $\begin{array}{l}\text { ab } 1960 \text { Mün- } \\
\text { ster, München }\end{array}$ & LA $1957-60$ \\
\hline $\begin{array}{l}\text { Schmidt-Thomé, } \\
\text { Paul }\end{array}$ & 1911-1997 & \begin{tabular}{|l|}
1936 Bonn \\
Ha 1943 Berlin
\end{tabular} & $\begin{array}{l}\text { aplA 1941-43 } \\
\text { A } 1943-45\end{array}$ & PD 1943-45 & Geol & $\begin{array}{l}\text { ab } 1946 \text { Mün- } \\
\text { chen }\end{array}$ & \\
\hline Schoch, Rainer & $* 1970$ & 1998 Tübingen & A $2001-2002$ & & Pal & 2002 Stuttgart & \\
\hline $\begin{array}{l}\text { Schönenberg, } \\
\text { Reinhard Hugo }\end{array}$ & $1914-1996$ & $\begin{array}{l}1944 \text { Berlin } \\
\text { Ha } 1950 \text { Berlin }\end{array}$ & A $1944-48$ & & Geol & $\begin{array}{l}\text { ab } 1949 \mathrm{FU} \\
\text { Berlin } 1957 / 58 \\
\text { Clausthal- } \\
\text { Zellerfeld } \\
\text { 1959 Tübingen }\end{array}$ & 1948 DAWiss \\
\hline Schroeder, Erich & $* 1930$ & \begin{tabular}{|l|}
1956 Berlin \\
Ha 1965 Berlin
\end{tabular} & $\begin{array}{l}\text { HA } 1951-53 \\
\text { A } 1953-57\end{array}$ & & Geol & & \begin{tabular}{|l|} 
Geotekt. I. \\
DAWiss. \\
1957 \\
LA $1960-67$ \\
\end{tabular} \\
\hline Schultka, Stephan & $* 1952$ & 1988 Münster & $\begin{array}{l}\text { K } 1995-2000 \\
\text { OK seit } 2000\end{array}$ & & Pal & & \\
\hline Schultze, Hans-Peter & *1937 & $\begin{array}{l}\text { 1965 Tübingen } \\
\text { Ha } 1971 \\
\text { Göttingen }\end{array}$ & & oP 1994-2004 & Pal & & $\begin{array}{l}\text { Direktor } \\
1994-2004 \\
\text { Dir. MfN } \\
2000-04\end{array}$ \\
\hline Schust, Friedrich & *1923 & 1963 Berlin & A $1956-58$ & & Geol & & $\overline{Z G I}$ \\
\hline Schwan, Werner & $1917-2002$ & $\begin{array}{l}1949 \text { Berlin } \\
\text { Ha } 1954 \text { Berlin }\end{array}$ & $\begin{array}{l}\text { HA 1945-46 } \\
\text { A } 1947-49\end{array}$ & $\begin{array}{l}\text { D 1955-61 } \\
\text { aplP } 1960\end{array}$ & Geol & $\begin{array}{l}1961 \text { Münster } \\
1964 \text { Erlangen }\end{array}$ & $\begin{array}{l}\text { Geotekt. I. } \\
\text { DAWiss. } \\
\text { 1949-61 } \\
\text { LA 1952-61 }\end{array}$ \\
\hline Siemens, Günther & $1901-?$ & 1935 TH Berlin & & & Geoph. & & $\begin{array}{l}\text { PrGLA, ZGI, } \\
\text { LA 1956 } \\
\text { LA 1961-64 }\end{array}$ \\
\hline $\begin{array}{l}\text { Solger, Friedrich } \\
\text { Ernst Adalbert }\end{array}$ & $1877-1965$ & $\begin{array}{l}1902 \text { Berlin } \\
\text { Ha } 1907 \text { Berlin }\end{array}$ & $\begin{array}{l}\text { HA } 1899 \\
\text { A } 1900-1903\end{array}$ & $\begin{array}{l}\text { PD 1907-09 } \\
\text { aplP 1921-53 }\end{array}$ & Geol & & $\begin{array}{l}\text { 1914-20 } \\
\text { China, Japan } \\
\text { stellv. Dir. } \\
\text { 1930-1932 } \\
\text { LA 1953-65 }\end{array}$ \\
\hline Stach, Erich & $1896-1987$ & $\begin{array}{l}923 \text { Berlin } \\
\text { Ha } 1929 \text { Berlin }\end{array}$ & & $\begin{array}{l}\text { PD 1929-40 } \\
\text { aplP 1941-45 }\end{array}$ & Geol & & \begin{tabular}{|l|} 
PrGLA \\
$1947-61$ \\
GLA Krefeld \\
\end{tabular} \\
\hline Staff, Johannes von & $1883-1915$ & $\begin{array}{l}1906 \text { Breslau } \\
\text { Ha } 1909 \text { Berlin } \\
\end{array}$ & A $1909-11$ & $\begin{array}{l}\text { PD 1909-14 } \\
\text { P } 1914\end{array}$ & Geol & $\begin{array}{l}\text { 1914-15 } \\
\text { SW-Afrika } \\
\end{array}$ & $\begin{array}{l}1911 \\
\text { Tendaguru } \\
\end{array}$ \\
\hline $\begin{array}{l}\text { Stappenbeck, } \\
\text { Richard }\end{array}$ & $1880-1963$ & \begin{tabular}{|l|}
1905 Berlin \\
Ha 1926 Berlin
\end{tabular} & aplA $1930-32$ & $\begin{array}{l}\text { PD 1926-36 } \\
\text { aplP 1936-37 }\end{array}$ & $\begin{array}{l}\mathrm{Pal}+ \\
\text { Geol }\end{array}$ & $\begin{array}{l}1937 \\
\text { TH Berlin }\end{array}$ & \\
\hline
\end{tabular}


Tabelle 1 (Fortsetzung)

\begin{tabular}{|c|c|c|c|c|c|c|c|}
\hline Name, Vorname & $\begin{array}{l}\text { Lebens- } \\
\text { jahre }\end{array}$ & Promotion & $\begin{array}{l}\text { Assistent/ } \\
\text { Kustos }\end{array}$ & Lehrkraft & Gebiet & $\begin{array}{l}\text { später tätig } \\
\text { in }\end{array}$ & Bemerkungen \\
\hline Stieler, Karl & $1890-?$ & 1919 Berlin & A $1920-1923$ & & $\mathrm{Pal}$ & & \\
\hline Stille, Hans & $1876-1966$ & $\begin{array}{l}1899 \text { Göttingen } \\
\text { Ha } 1904 \text { Berlin }\end{array}$ & & $\begin{array}{l}\text { PD 1904-08 } \\
\text { oP 1932-50 }\end{array}$ & Greol & $\begin{array}{l}1908-32 \\
\text { Hannover, } \\
\text { Göttingen }\end{array}$ & \begin{tabular}{|l|} 
Direktor \\
$1932-50$ \\
oM DAWiss \\
1933 \\
Dr. h.c. HU \\
1960
\end{tabular} \\
\hline Stock, Fritz & $* 1913$ & 1939 Breslau & & & Geol & & $\begin{array}{l}\text { LA } \\
1951-1953\end{array}$ \\
\hline Stremme, Hermann & $1879-1961$ & $\begin{array}{l}1903 \text { Berlin } \\
\text { Ha } 1908 \text { Berlin }\end{array}$ & A $1903-12$ & $\begin{array}{l}\text { PD 1908-14 } \\
\text { aoP } 1912\end{array}$ & $\begin{array}{l}\text { Geol + } \\
\text { Pal }\end{array}$ & $\begin{array}{l}1914-45 \\
\text { Danzig }\end{array}$ & $\begin{array}{l}1947-59 \\
\text { I. Bodenkart. } \\
\text { Berlin }\end{array}$ \\
\hline Süß, Herbert & $*^{*} 1920$ & $\begin{array}{l}1955 \text { Potsdam } \\
\text { Ha } 1970 \\
\text { Potsdam }\end{array}$ & $\begin{array}{ll}\text { A } 1971 \\
\text { K } 1971-85\end{array}$ & & Palb & & \\
\hline $\begin{array}{l}\text { Teichmüller. } \\
\text { Rolf Otto Gotthard }\end{array}$ & $1904-1983$ & $\begin{array}{l}1928 \text { Göttingen } \\
\text { Ha } 1935 \text { Berlin }\end{array}$ & HA $1933-38$ & & Palb & \begin{tabular}{|l|}
$1938-39$ \\
Dienstst. \\
Erforschg. \\
Bodens \\
$1939-45$ \\
PrGLA \\
1945-69 Bonn, \\
Bochum, \\
Krefeld \\
\end{tabular} & \\
\hline $\begin{array}{l}\text { Teschke. } \\
\text { Hans-Jürgen }\end{array}$ & $* 1922$ & $\begin{array}{l}1972 \\
\text { Greifswald }\end{array}$ & $\begin{array}{l}\text { HA } 1953-54 \\
\text { A } 1956-57\end{array}$ & & Geol & & $\begin{array}{l}\text { Geotekt. I. } \\
\text { DAWiss } 1957 \\
\text { LA } 1962\end{array}$ \\
\hline Trénel, Max & $1889-1966$ & $\begin{array}{l}1922 \text { Berlin } \\
\text { Ha } 1927 \text { Berlin }\end{array}$ & & & Bodk & & $\begin{array}{l}\text { PrGLA } \\
\text { LA } 1949 \\
1955-58 \\
\text { oP in LWGF } \\
\text { ab } 1947\end{array}$ \\
\hline Unwin, David & *1959 & 1991 Reading & K seit 1998 & & $\mathrm{Pal}$ & & \\
\hline Vogel, Edgar & & & & & Geol & & \begin{tabular}{|l} 
ZGI \\
LA 1956
\end{tabular} \\
\hline $\begin{array}{l}\text { Wahnschaffe, Gustav } \\
\text { Albert Bruno Felix }\end{array}$ & *1851-1914 & $\begin{array}{l}\text { 1875 Jena } \\
\text { Ha } 1886 \text { Berlin }\end{array}$ & & PD $1886-14$ & Geol & & PrGLA \\
\hline Wegener, Helmut & $1922-?$ & 1952 Berlin & A $1952-53$ & & Geol & & ZGI \\
\hline $\begin{array}{l}\text { Wiegank, } \\
\text { Friedrich-Manfred }\end{array}$ & $* 1936$ & 1968 Berlin & $\begin{array}{l}\text { apl Asp } \\
1964-66\end{array}$ & & Geol & & \\
\hline Wienholz, Roland & $* 1930$ & 1964 Berlin & & & Geol & VEB Erdöl & LA 64/65 \\
\hline Zeuch, Richard & *1927 & - & & & Geoph & & $\begin{array}{l}\text { ZGI } \\
\text { LA 1961-64 }\end{array}$ \\
\hline $\begin{array}{l}\text { Zöllich, } \\
\text { Martin Sylvester }\end{array}$ & $1913-1940$ & 1938 Berlin & $\begin{array}{l}\text { HA } 1937 \\
\text { aplA } 1938-39\end{array}$ & & Greol & $\begin{array}{l}1939-40 \\
\text { Göttingen }\end{array}$ & \\
\hline Zwanzig, Michael & $* 1953$ & - & $\begin{array}{l}\text { wiss. Ma } \\
1983-84\end{array}$ & & Palb & & \\
\hline
\end{tabular}

den Unterricht in Geologie und Paläontologie. Unterstützt wurde er im Unterricht von Prof. Dr. Henry Potonié (bis 1913), der Paläobotanik las, und von Privatdozent Dr. Hermann Stremme. Einziger Kustos war Dr. Werner Janensch; eine weitere Kustodenstelle, die unbedingt erforderlich war, konnte v. Branca trotz aller Bemühun- gen seit seiner Amtsübernahme vom Ministerium nicht erlangen. Stets ist es leichter, größere Sondermittel zu erhalten, als die Bewilligung einer Beamtenstelle, die für den Staat eine Dauerausgabe bedeutet. Assistenten waren Privatdozent Dr. Hans von Staff, Dr. Edwin Hennig und seit 1911 Dr. Wilhelm Otto Dietrich. Dr. Ja- 
nensch und Dr. Hennig führten seit 1909 Ausgrabungen in der Südostecke der ehemaligen Kolonie Deutsch-Ostafrika am Tendaguru-Berg durch, Dr. v. Staff stieß 1911 zu den Ausgrabungen, wo in diesem Jahr bis zu 500 Ortsansässige beschäftigt wurden. Dr. Dietrich übernahm die große und wichtige Aufgabe, die systematische Hauptsammlung neu zu ordnen. Dr. Hans Reck wurde als Hilfsassistent eingestellt. Als Präparator arbeitete Gustav Borchert (seit 1908) und als Institutsgehilfe Ewald Siegert (ab 1912).

Seit 1909 stand das Institut im Zeichen der großen Sauriergrabung am Tendaguru-Berg (siehe Mayer 2003 für ausführliche Darstellung). Im letzten großen Grabungsjahr (1912/13) arbeiteten bis zu 150 Ortsansässige unter der Leitung von Dr. Reck und seiner Frau Ina an der Ausgrabung und der Bergung der fossilen Skelette. Die Kosten der Expedition beliefen sich auf über 230000 Mark. Im Institut entstand nach dem Eintreffen des Grabungsmaterials großer Raummangel, der noch Jahre hindurch fortdauern sollte. Die großen versteinerten Knochen lagen überall im Institut in Fluren und Gängen, in Sammlungssälen und in Kellern. Auf einen derartig großen Materialzuwachs (zwischen 15-20000 Einzelknochen) war das Institut nicht vorbereitet. Die Saurier standen damals im Mittelpunkt der Paläontologie der Wirbeltiere. Das allgemeine Interesse an den Riesensauriern war erwacht. Am 14. 3. 1912 besichtigte Kaiser Wilhelm II. den von Carnegie geschenkten und 1908 aufgestellten Gipsabdruck des amerikanischen Riesensauriers Diplodocus (Oberer Jura), erste präparierte Knochen der Saurier von Tendaguru (Oberer Jura) und zwei unvollständige Skelette des Halberstädter Plateosaurus (Obere Trias). Das ganze Institut, vom Direktor bis zum Institutsdiener, war in die Aufgabe der Saurierforschung eingespannt. Gleich nach der Beendigung der Expedition setzte eine lebhafte wissenschaftliche Arbeit ein. Es begann die große Reihe der Veröffentlichungen über die Ergebnisse der Tendaguru-Expedition, zu denen Prof. Dr. Janensch den Hauptbeitrag lieferte. Dr. Reck war mit seiner Frau in Ostafrika verblieben, im Herbst 1913 entdeckte er die ersten Menschenreste in der Olduvai-Schlucht. Bei dieser Aktivität blieb keine Zeit für die obertriassischen Saurier von Halberstadt, die Prof. O. Jaekel, Greifswald, für das Museum für Naturkunde ausgrub und dann auch noch in Greifswald präparieren ließ (Böhme 1989).

Der Direktor des Instituts war ein ebenso begeisterter Paläontologe wie Geologe, er gehörte $\mathrm{zu}$ derjenigen Geologengeneration, die beiden Wissenschaften in gleicher Weise zugewandt war. Die paläontologische Sammlung, die größte Deutschlands, bestimmte das Gesicht des Instituts, wie es auch ihr Gründer, Ernst Beyrich, gewollt hat. Die Paläontologie stand auch im Vordergrund bei der Raumverteilung im Institut und bei der Arbeit des wissenschaftlichen und technischen Personals. Nur im Unterricht trat sie zugunsten der Geologie zurück.

Von Branca war Institutsdirektor bis zu seiner Emeritierung im Jahre 1917. In den sieben Jahren seit 1910 änderte sich äußerlich nur wenig im Institut. Der Krieg bedingte, dass die 1914 erwogenen Pläne, das Museum für Naturkunde mit seinen Instituten nach Dahlem zu verlegen, scheiterten. Ein neuer und moderner Bau sollte der Raumnot steuern. Im alten Gebäude in der Invalidenstraße konnten keine durchgreifenden Veränderungen vorgenommen werden; der Platzmangel und die ungünstigen Lichtverhältnisse in einem großen Teil der Schausammlungen blieben bestehen.

Die Anzahl der Lehrkräfte und der Mitarbeiter erhielt sich etwa auf gleichem Stand. Der Unterricht und die wissenschaftlichen Arbeiten wurden bis in den Krieg unvermindert fortgesetzt; im Verlauf des Krieges wurden aber immer mehr Mitarbeiter zum Kriegsdienst eingezogen. In aller Kürze seien die Änderungen, die im Verlauf der Jahre von 1910 bis 1917 eintraten, aufgeführt. Der Kustos Dr. Janensch (1912) und der erste Assistent Privatdozent Dr. v. Staff (1913) erhielten Professorentitel. Der Hilfsassistent Dr. Reck ging nach Afrika und setzte die Ausgrabungen am Tendaguru-Berg fort. Im Kriege geriet er in englische Gefangenschaft, aus der er 1919 entlassen wurde. Privatdozent Prof. Dr. v. Staff wurde im März 1914 Regierungsgeologe in Deutsch-Südwestafrika, wo er im Kriege am 8.6.1915 an Typhus starb. Prof. Dr. Friedrich Solger, seit 1910 Geologe in Peking, wurde in China vom Kriege überrascht und geriet 1914 als deutscher Offizier in Tsingtau in japanische Kriegsgefangenschaft, aus der er 1920 entlassen wurde. 1913 habilitierte sich der Assistent Dr. Hennig für Geologie und Paläontologie; 1916 erhielt Hennig den Professortitel. 1914 folgte die Habilitation von Dr. Erich Haarmann, ebenfalls für Geologie und Paläontologie. Der Assistent Dr. Dietrich ordnete nach und nach große Teile der Hauptsammlung der Wirbellosen, Kustos Prof. Dr. Janensch Teile der Wirbeltiersammlung. 1916 wurden Knochen des Sauriers Dicraeosaurus im Lichthof aufgestellt. 
Ende 1916 wurden Prof. Janensch und Dr. Hennig zum Heeresdienst eingezogen.

Im April 1917 ließ sich Geheimrat v. Branca im Alter von 73 Jahren emeritieren. Bis zur Besetzung des Lehrstuhles führte der einzige noch anwesende Assistent, Dr. Dietrich, die Verwaltungsgeschäfte des Instituts. Am 1.11. 1917 übernahm der neuberufene Ordinarius, Prof. Dr. Josef Felix Pompeckj, die Leitung des Geologisch-Paläontologischen Instituts. Der Mitarbeiterstab war sehr zusammengeschmolzen; Kustos, Assistenten und Privatdozenten standen zum größten Teil an der Front oder waren in den Kolonien in Gefangenschaft geraten. Vor der Schilderung des Direktorats Pompeckjs wollen wir bei der Persönlichkeit Brancas kurz verweilen.

Die Lebensdaten und die akademische Laufbahn: geboren am 9.9.1844 in Potsdam als Wilhelm Branco, gestorben am 12.3.1928 in München als Wilhelm von Branca. Dr. phil. in Heidelberg 1876; Habilitation 1881 bei Beyrich. Privatdozent in Berlin 1881, in Aachen 1881, und wiederum in Berlin von 1882 bis 1887: zugleich Landesgeologe an der Preußischen Geologischen Landesanstalt in Berlin; 1887 Ordinarius für Geologie an der Universität Königsberg, ab 1890 an der Universität Tübingen; 1894 Amtsniederlegung infolge Überarbeitung. 1895 bereits erneute Berufung als Ordinarius für Geologie an die Landwirtschaftliche Akademie in Hohenheim in Württemberg; seit 1895 von Branco. 1899 bis 1917 Ordinarius für Geologie und Paläontologie an der Universität Berlin; 1907 Namensänderung in von Branca; im April 1917 Emeritierung (Pompeckj 1928, Hennig 1928, Reck 1929).

Branca war ein allseitig interessierter, ausgezeichneter Forscher und Gelehrter, ein hervorragender Lehrer und ein interessierter und angesehener Direktor. Nur für rein praktische Fragen hatte er weniger Verständnis. Durch seine mit Feuereifer betriebene Organisierung der Tendaguru-Expedition (Mayer 2003) hat er sich ein bedeutendes Denkmal gesetzt. Seine Prägung als Wissenschaftler und Geologe erhielt er noch in einer Zeit, in der die einzelnen Richtungen der Geologie und Paläontologie nicht so weit auseinandergestrebt waren, dass ein einzelner sie nicht mehr vollständig übersehen konnte. So hat v. Branca neben seinen bedeutenden vulkanologischen Arbeiten (z. B. Branco 1894, 1895) auch rein paläontologische Untersuchungen angestellt; besonders bekannt und grundlegend ist seine Arbeit über die Anfangskammern der Cephalopoden (z. B. Branco 1879, 1880). Aber v. Branca hat auch über andere Tiergruppen gearbeitet, besonders über Wirbeltiere (z. B. Branca 1916a), deren Erforschung er durch die ungemein tatkräftig betriebene Organisierung der TendaguruExpedition nachdrücklich befördert hat. Neben der Vulkanologie beschäftigten ihn fernerhin Fragen der allgemeinen, der historischen und der angewandten Geologie.

Aus dieser allseitigen Beherrschung des Stoffes entstand bei ihm die Vorstellung, dass auch in Zukunft die verschiedenen Disziplinen der Geologie und der Paläontologie von den Geologen der Universitäten mühelos vertreten werden könnten. Auch sah er in der paläontologischen Sammlung, insbesondere in der Wirbeltiersammlung, den wertvollsten Teil des Instituts, den der Ordinarius und Direktor unter gar keinen Umständen aus der Hand geben dürfte. Er litt an der Befürchtung, dass die reinen Paläontologen die Hände nach der paläontologischen Sammlung und dem paläontologischen Unterricht ausstrecken könnten. Die allgemeine Geologie glaubte er mit Nachdruck gegen die Geographen verteidigen zu müssen (Branca 1913). Als aber immer häufiger Pläne einer Trennung der Fächer Geologie und Paläontologie erörtert wurden, wollte v. Branca den Trennungsstrich so führen, dass die historische Geologie und die Paläontologie vereinigt blieben, die allgemeine Geologie aber zum selbstständigen Fach erhoben würde. Mit Leidenschaft, und oft ungemein persönlich werdend, verteidigte er seine Vorstellungen (Branca 1910b, 1916b), besonders gegen den hochbegabten, verdienstvollen aber leider auch ein wenig zu phantasiereichen Paläontologen Prof. Dr. Jaekel, Ordinarius für Geologie und Paläontologie an der Universität Greifswald, Gründer der Paläontologischen Gesellschaft. Jaekel sah die Zukunft der Wissenschaften Geologie und Paläontologie klarer als v. Branca, aber er konnte sich nicht gegen die Autorität der Person und Stellung v. Brancas durchsetzen. Branca hat damit unbeabsichtigt und vom besten Willen beseelt die Entwicklung der deutschen Paläontologie stark gehemmt. Es kam nicht zu der Einrichtung eines oder mehrerer selbstständiger paläontologischer Museen oder Institute in Deutschland, zu der damals die Voraussetzung bestanden hat.

Diese Fragen traten erneut hervor, als nach der Emeritierung v. Brancas ein Nachfolger gesucht wurde. Anfänglich wurde die Absicht erwogen, das Institut - ähnlich wie in München in zwei Institute aufzuteilen, ein Institut für Historische Geologie und Paläontologie und ein 
weiteres für Allgemeine Geologie. Für jedes dieser Institute waren schon die Berufungslisten mit jeweils zwei Kandidaten zusammengestellt worden. Infolge der Kriegslage verzichtete man schließlich auf diese Pläne und begnügte sich mit dem Fortbestand des einheitlichen Instituts. Doch wurden zwei der damaligen Kandidaten nacheinander Direktoren des Instituts Pompeckj und Stille. Direktor des einheitlich verbliebenen Instituts wurde Prof. Dr. Josef Felix Pompeckj, der ursprünglich als erster Kandidat für den Posten des Direktors eines Instituts für Historische Geologie und Paläontologie genannt worden war. Branca hatte in Pompeckj denjenigen Wissenschaftler gefunden, der das Gesamtinstitut in seinem Sinne lenken konnte.

\section{Direktorat Pompeckj (1917 bis 1930)}

Geheimrat Prof. Dr. Pompeckj (Abb. 1) übernahm mitten im ersten Weltkrieg die Institutsleitung. Es war natürlich nicht möglich, bei den Berufungsverhandlungen die Durchführung von Vergrößerungen des Instituts und seines Personals zu erreichen. Die anschließenden Nachkriegs- und Inflationsjahre blockierten weiterhin

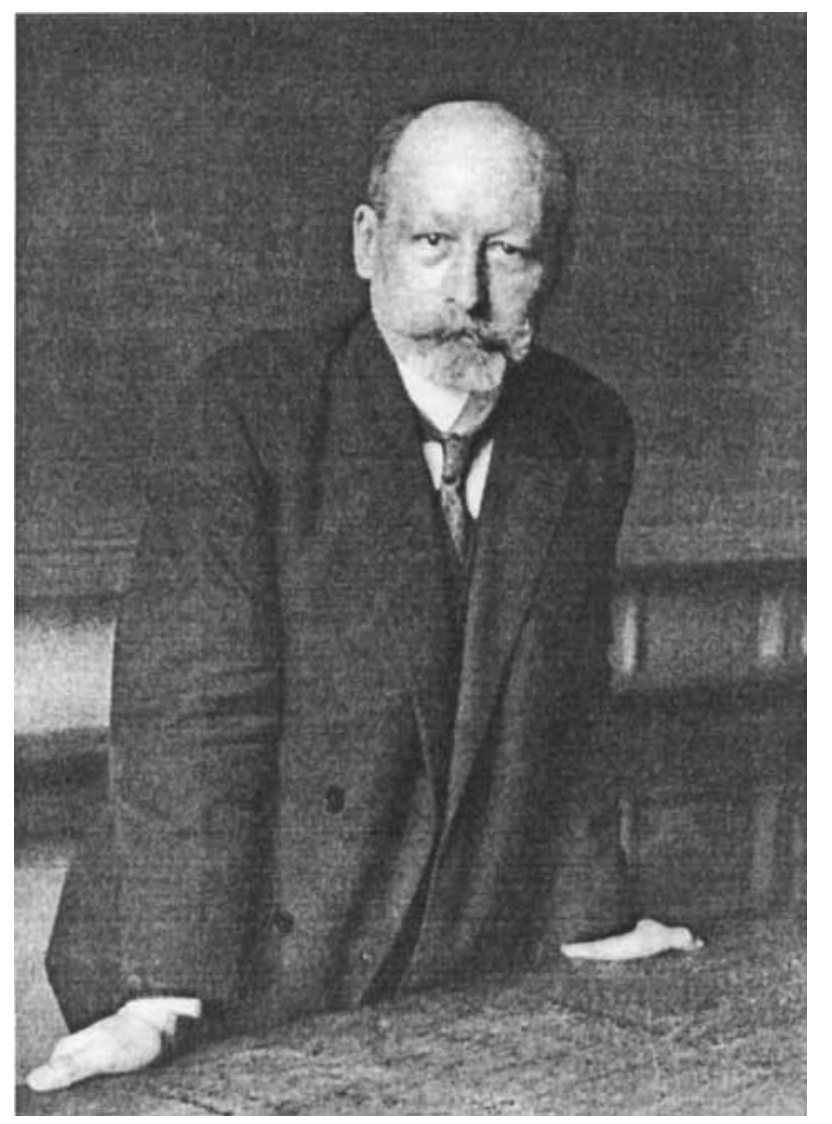

Abb. 1. Prof. Dr. J. F. Pompeckj (Aufnahme aus dem Nachruf Diedrich 1930). alle derartigen Pläne. Pompeckj besaß nicht die Gabe diplomatischer Verhandlungsführung, so dass es ihm auch in den Jahren nach der Inflation nicht gelang, das Institut zu modernisieren und den wachsenden Aufgaben entsprechend umzugestalten und zu vergrößern.

Pompeckj war Direktor vom 1.11.1917 bis zu seinem Tode am 8. 7.1930. Einziger Kustos blieb innerhalb dieser Zeit Prof. Dr. Janensch. Als Ordinarius stand Prof. Dr. Pompeckj an der Spitze des Lehrkörpers. 1927 wurde der bekannte Paläobotaniker Prof. Dr. Walter Gothan Honorarprofessor für Paläobotanik. 1917 waren am Institut zwei Privatdozenten tätig, Prof. Dr. Hennig, der 1917 als Ordinarius an das Geologisch-Paläontologische Institut der Universität Tübingen berufen wurde, und Dr. Haarmann, der 1922 den Professorentitel erhielt. Der 1920 aus der japanischen Kriegsgefangenschaft heimgekehrte Prof. Dr. Solger wurde wieder Privatdozent. Eine weitere Privatdozentur erhielt 1921 Dr. Paul Range, der 1932 zum a. o. Professor ernannt wurde. Es habilitierten sich und wurden Privatdozenten: 1921 Dr. Range, 1924 Dr. Fritz Behrend, 1926 Dr. Stappenbeck, 1929 Dr. Quenstedt und Dr. Erich Stach; von ihnen gehörte nur Dr. Quenstedt dem Institut als Assistent an.

Als Präparator arbeitete von 1908 bis 1927 Präparator Gustav Borchert, der 1928 von Oberpräparator Ewald Siegert abgelöst wurde. Vor seiner Pensionierung wurde Borchert noch zum Oberpräparator ernannt. Präparator Hans Schober, der im Angestelltenverhältnis stand, arbeitete nach der Entlassung aus dem Kriegsdienst weiter an der Präparation und Montage der Saurier der Tendaguru-Expedition. Institutsgehilfe wurde 1928 Fritz Marquardt.

Während des Direktorats von Pompeckj wurde mit vielen Kräften an der Präparation der Tendaguru-Saurier weitergearbeitet. Pompeckj bemühte sich auch mit Erfolg um die Einwerbung wertvoller und schöner Skelette aus dem Lias von Holzmaden, die alsbald ihre Aufstellung in der Schausammlung fanden (Plesiosaurus, Ichthyosaurus, Stenopterygius, Mystriosaurus, Dorygnathus, Leptopterygius und Pelagosaurus, ferner Pentacrinus subangularis, ein Riesencrinoid). Die ersten Vorarbeiten für die Montage der großen Saurier begannen. Von den kleineren Tendaguru-Sauriern wurde 1925 Kentrurosaurus und Elaphrosaurus, und 1930 Dicraeosaurus aufgestellt. 1927 wurden im Keuper von Halberstadt von Oberpräparator Siegert unter Aufsicht von Dr. Janensch Skelette des Sauriers Plateosaurus geborgen, wertvolles und schönes Material. 
Janensch konnte 1929 in Südafrika Aufsammlungen in der Karroo-Formation durchführen, diese wurden 1932 und 1937 von Reck weitergeführt, so dass bedeutende Funde von Cotylosauriern und Therapsiden ans Museum kamen.

Josef Felix Pompeckj wurde am 10.5.1867 in Groß-Köllen (Ostpreußen) geboren, er starb am 8. 7. 1930 in Berlin. Promotion in Königsberg bei Branco 1889; Habilitation bei Zittel 1894 in München; 1903 a. o. Professor in München; 1904 bis 1907 o. Professor an der Landwirtschaftlichen Hochschule in Hohenheim: 1907 a. o. Professor in Königsberg; 1908 a. o. Professor in Göttingen; 1908 bis 1913 Ordinarius für Geologie in Göttingen, 1913 bis 1917 in Tübingen, 1917 bis 1930 in Berlin (Janensch 1930, Hennig 1930. Dietrich 1931, Kohring 1998).

Wie sein Lehrer v. Branca gehörte Pompeckj noch zu der Generation mit umfassenden Interessen und vielseitiger Arbeitsrichtung. Pompeckj war ein hervorragender Gelehrter mit einem allseitigen Wissen, er beherrschte weitgehend die Paläontologie, die historische Geologie und die regionale Geologie. Er verknüpfte die Ergebnisse aller Richtungen zu einer Gesamtschau, zu dem ein einzelner heute bei der ungemein angewachsenen Kenntnisfülle gar nicht mehr in der Lage ist. Man muss mit dem Entstehen dieser Erkenntnisse aufgewachsen sein, dann kann man sie noch übersehen und zusammenfassen. Bei Pompeckj finden wir Ansätze zu Studien und Arbeiten, die wir uns auch heute noch dringend wünschten: Übersichten der Lebewelt ganzer Epochen und ihrer Fossilisationsbedingungen. Wo sind die Lagerstätten fossiler Tiere? Warum sind sie hier vorhanden und fehlen anderswo? Für alle phylogenetischen Betrachtungen sind derartige Übersichten von größtem Wert, besonders wenn nicht nur eine Begründung für die Überlieferung der ehemaligen Organismen, sondern auch für ihr jeweiliges Fehlen in bestimmten Schichten gegeben wird. Solche Übersichten erfordern eine gewaltige Gelehrtenarbeit, eine Beherrschung der gesamten Literatur, eine kritische Beurteilung aller geologischen und paläontologischen Angaben. Dieses Vermögen besaß Pompeckj; aber zu den erhofften Werken ist es leider nicht gekommen. Sein unerwartet früher Tod im dreiundsechzigsten Lebensjahr hat vermutlich die Ausführung so mancher großer Pläne zunichte gemacht, aber noch mehr hinderte ihn sein Charakter. Seine Gelehrtennatur mit ihrer Forderung nach allumfassender Beherrschung des Stoffes stand seiner Forschernatur im Wege; der Anspruch auf Vollständigkeit und Aus- gereiftheit der Ergebnisse war zu hoch. Pompeckj vermochte außerordentlich klar und gut zu beschreiben. Er hatte lebhaftes Interesse für paläozoologische Untersuchungen, für die Lebewelt ganzer Epochen und Kontinente in Verbindung mit dem Wandel in der Ausdehnung des Festlandes und des Meeres, dem Wechsel des Klimas und der Lebensbedingungen. Ihn reizten die großen Zusammenhänge in der Geschichte des Lebens und der Erde. Aber über Teillösungen ist er nicht hinausgekommen. Die Aufgaben der historischen Geologie sah er - ähnlich wie v. Branca - in der Darstellung der Geschichte des Lebens, weniger in der Geschichte der Erde mit ihren gewaltigen tektonischen Wandlungen und Geschehnissen, mit ihren allgemeinen Gesetzen. Er sah nicht eine neue Geologie heraufziehen, der die Tektonik im Vordergrund stand, die eine Geschichte der Erde darzustellen bestrebt war, die weit über eine Geschichte des Lebens hinausgriff.

Pompeckj ist ein großartiger Herausgeber geologischer und paläontologischer Zeitschriften gewesen. Die Mehrzahl der bedeutenden Fachzeitschriften standen unter seiner Schriftleitung, hier hat er in rastloser Arbeit jahrelang Bedeutendes geleistet.

Als Mensch konnte Pompeckj von großer Herzlichkeit und Hilfsbereitschaft sein, es war nicht seine Art, kühl und zurückhaltend zu bleiben. Wen er mochte und schätzte, dem half er und trat ihm menschlich nah, aber ebenso wenig verbarg er seine Abneigung, wenn jemand seine Gunst verscherzte oder nicht zu gewinnen vermochte. - Pompeckjs große Pläne zur Neugestaltung des Instituts und Museums sind nicht zur Verwirklichung gekommen. Das lag nicht nur an der Ungunst der Zeit und am vorzeitigen Tod, sondern vielmehr an seiner Wesensart. Diplomatisches und geduldiges Verhandeln, die Gewinnung und Überzeugung der leitenden Personen in Ministerium oder Verwaltung lagen ihm gar nicht. Er hatte keinen Sinn für moderne Technik und modernes Organisieren, ihm fehlte die praktische Begabung. So konnte es kommen, dass eine so bedeutende Persönlichkeit und ein so umfassender Gelehrter das Institut in einem Zustand hinterließ, der zu scharfer Kritik geradezu herausforderte. Keine modernen optischen Instrumente waren vorhanden, keine Präparationsgeräte, keine Laboratorien, die Räumlichkeiten waren völlig unzureichend, größte Beengung herrschte in jeder Hinsicht. Viele Provinzuniversitäten hatten ungleich modernere und besser ausgestattete geologische Institute. Aus eigenem 
Erleben hat W. Gross diese Zustände als Doktorand mit Verwunderung wahrgenommen, zugleich aber die menschliche Herzlichkeit und Hilfsbereitschaft Pompeckjs dankbar erlebt, der jeden strebsamen und interessierten Nachwuchswissenschaftler förderte. Nach außen hin gab Pompeckj dem Institut durch seine glänzende Persönlichkeit Ansehen und Beachtung. Der Rückstand in technischer und organisatorischer Beziehung war kein unüberwindliches Übel, wie sein bedeutender Nachfolger alsbald beweisen sollte.

\section{Direktorat Solger (i. V. 1930 bis 1932)}

Nach dem Tode Pompeckj's wurde bis zur Berufung eines neuen Ordinarius Prof. Dr. Friedrich Solger (Abb. 2) zum Direktor in Vertretung ernannt. Die Lebensdaten und die akademische Laufbahn: geboren am 8.10.1877 in Berlin; gestorben am 29.11. 1965 in Berlin; 1902 Promotion in Berlin; 1907 Habilitation in Berlin unter v. Branca; 1910 bis 1913 Professor der Geologie in Peking; von 1914 bis 1920 als deutscher Offizier in japanischer Gefangenschaft; seit 1921 als nichtbeamteter a. o. Professor mit Lehrauftrag für „Geologie Norddeutschlands“ an der Berliner Universität. Als stellvertretender Direktor leitete

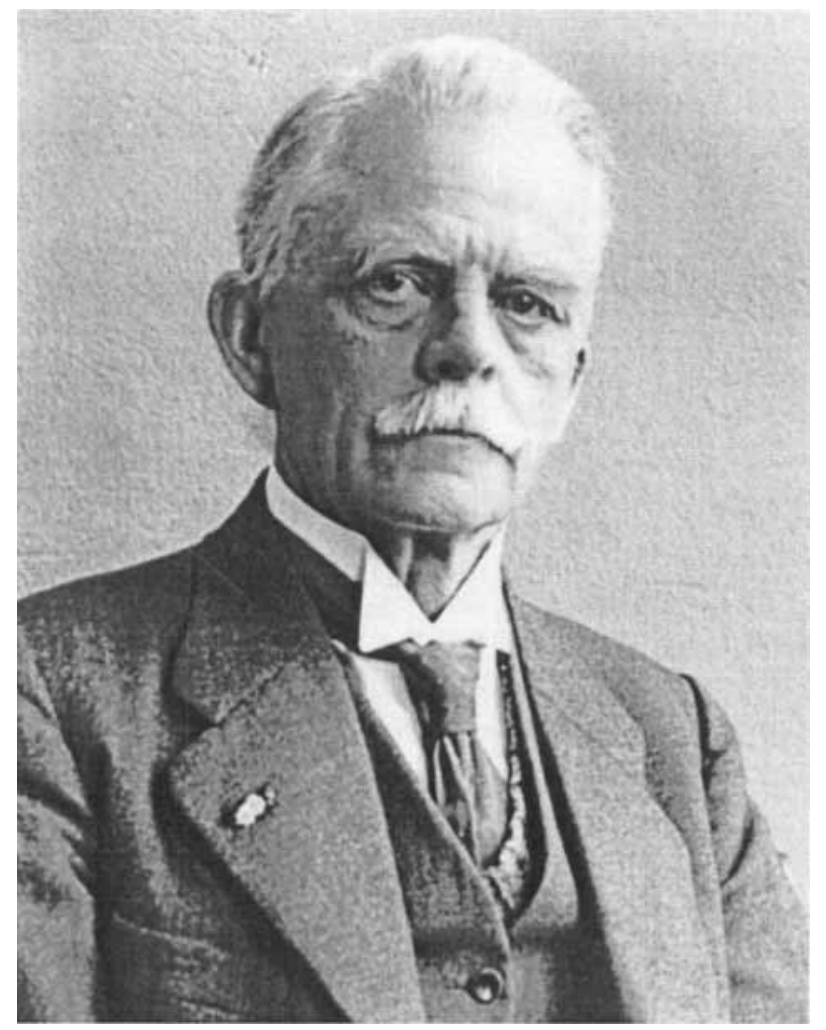

Abb. 2. Prof. Dr. F. E. A. Solger (Archiv des Museums für Naturkunde).
Solger das Institut vom Herbst 1930 bis zum Herbst 1932 (Heck 1966, Faden 1967).

In dieser kurzen Zwischenzeit konnten im Institut keine größeren Änderungen vorgenommen werden, man wollte nicht dem zukünftigen Direktor vorgreifen. Im Mai 1932 ging der apl. Assistent Dr. Stappenbeck nach Südamerika; an seine Stelle trat bis zum Oktober 1932 Dr. Walter Gross, der seit seiner Doktorprüfung im Herbst 1929 als Stipendiat der Notgemeinschaft der Deutschen Wissenschaft Mitarbeiter des Instituts gewesen war. Die Vertretung des Direktors durch Prof. Solger endete am 20.9.1932; Prof. Solger setzte seine Lehrtätigkeit als nichtbeamteter a.o. Professor mit Lehrauftrag bis 1953 und nach seiner Pensionierung bis 1965 fort.

\section{Direktorat Stille (1932 bis 1950)}

Als Prof. Dr. Hans Stille (Abb. 3) im Herbst 1932 Göttingen verließ und die Leitung des Berliner Instituts übernahm, beherrschte die Wirtschaftskrise alles Denken und Planen. Überall wurde im Haushalt und im Stellenplan gespart. Durch kluge und energische Berufungsverhand-

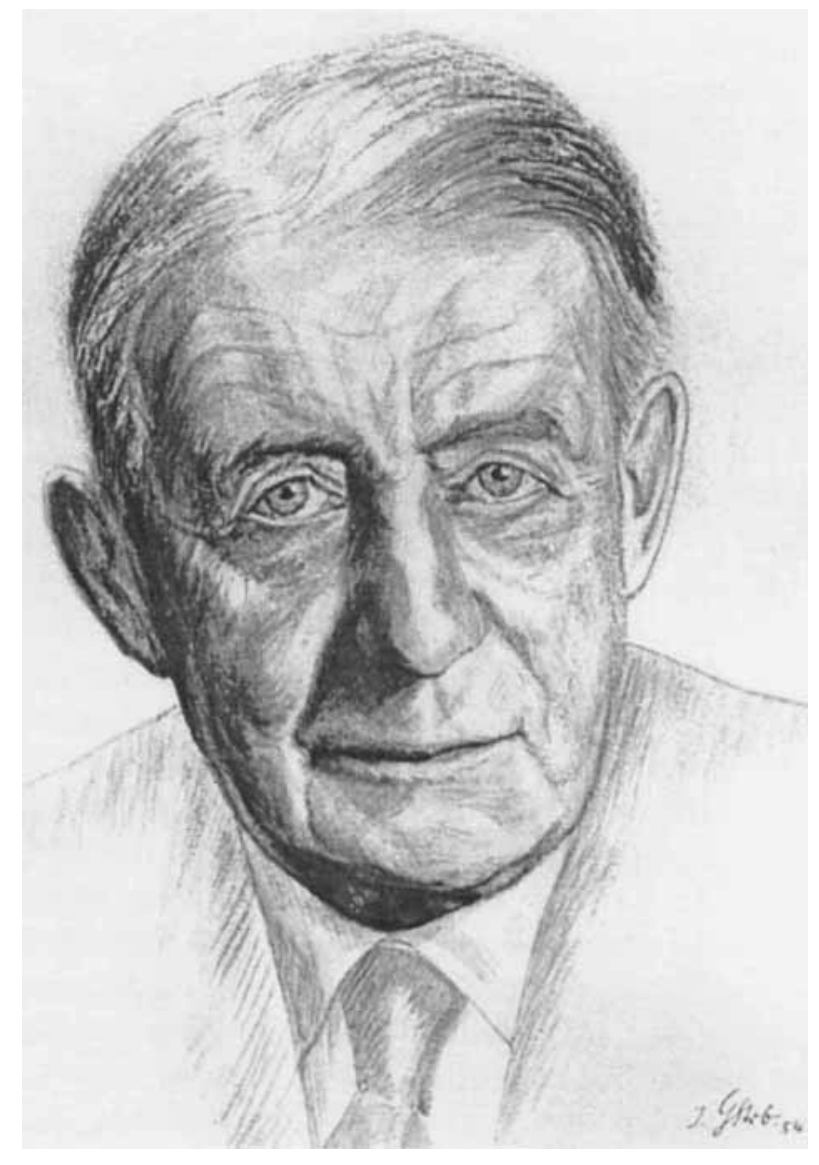

Abb. 3. Prof. Dr. H. Stille (Archiv des Museums für Naturkunde). 
lungen gelang es Stille dennoch, in großem Umfang Veränderungen zum Besten des Instituts und Museums durchzuführen. Das Institut wurde sehr vergrößert und modernisiert, die Anzahl der Planstellen wurde erhöht. Das gewissermaBen in Dornröschenschlaf verfallene Institut wurde zum größten und modernsten in Deutschland und stellte sich in der Ausbildung des Geologennachwuchses an die Spitze aller deutschen geologischen Institute.

Im Institut erfolgten wesentliche Neubauten und Umbauten. Der Hörsaal wurde zum großen Bibliothekssaal umgewandelt, der Bestand an Büchern und Zeitschriften wurde beträchtlich vermehrt. Das Zoologische Museum trat einen Sammlungssaal ab, der nun zum großen Hörsaal mit 212 Sitzen eingerichtet wurde. Vom Hörsaal wurde ein kleiner Vorbereitungsraum abgetrennt, der die Demonstrationssammlung aufnahm, und ein größerer, mit Glasschränken ausgestatteter Raum für die Sammlung großer und wertvoller Saurierreste, der sogenannte „Reptilsaal“. Der niedrige, nach Norden gelegene Bodenraum über dem Südflügel wurde ausgebaut und nahm nun 10 Doktorandenzimmer auf, in denen jeweils zwei Doktoranden oder ein Assistent bequem arbeiten konnten. Diese Neuerung war für die Doktoranden und Assistenten von großem Nutzen; bisher hatten sie in einzelnen größeren Räumen eng zusammengedrängt und sich gegenseitig behindernd Unterkunft gefunden. Die Räume auf der Ostseite des Bodens über dem Ostflügel wurden als Zeichensaal, Dunkelkammer und photographischer Projektionsraum eingerichtet und mit modernen Geräten ausgestattet. Die zwei bisherigen Bibliothekszimmer und das Direktorzimmer, alle im Ostflügel des zweiten Stockwerkes, wurden zu Praktikantenzimmern, sogenannten „Kinderzimmern“ umgestaltet. Zum Direktorzimmer, Vorzimmer des Direktors und Sekretariat wurde das bisherige große Doktorandenzimmer (noch früher Hörsaal) der Südostecke des zweiten Stockwerks ausgebaut. Das Mineralogische Institut trat einen größeren Raum des zweiten Stockwerks ab, der nun als kleiner Hörsaal und Übungsraum diente. Der entsprechende Raum vor der neuen Bibliothek nahm große, aus geologischen Kartenblättern zusammengesetzte geologische Wandkarten und größere geologische Modelle und Salzsammlungen auf. Das Mineralogische Institut erhielt als Ausgleich den großen Raum im ersten Stockwerk südlich des Lichthofes. Der Lichthof des Naturkundemuseums wurde in den folgenden Jahren gänzlich dem Paläontologischen Museum zugewiesen, für die bisher in ihm aufgestellten Walskelette sollte eine neue Halle anschließend an den Fischsaal errichtet werden. Vier Kellerräume, die bisher Dienstwohnung des Oberpräparators gewesen waren, nahmen nun Präparationsräume, Schleifzimmer und Schmiede auf. Die Säle der Hauptsammlung und der Schausammlung wurden renoviert und mit elektrischem Licht versehen. Das Institut erhielt an Stelle des bisher einzigen Fernsprechapparates nun zahlreiche Außen- und Innenapparate.

Folgende Stellen wurden neu geschaffen: ein Sekretariat mit Chefsekretärin, eine Stelle für einen technischen Assistenten, der die Zeichenund Photoarbeiten auszuführen hatte, und eine neue Hilfsassistentenstelle für die Bibliothek. Alle diese neuen Kräfte unterstanden unmittelbar dem Direktor. - In der Folgezeit war Stille bemüht, in Anpassung an die Wandlungen der geologischen Forschungsrichtungen, den Lehrkörper des Instituts zu vervollständigen.

Die Geschichte des Instituts unter Leitung von Stille ist viel mehr als die der vergangenen Jahrzehnte entscheidend beeinflusst worden von dem politischen Geschehen: Zu Anfang die Auswirkungen der großen Wirtschaftskrise, danach die Machtübernahme durch die Nationalsozialistische Partei, die das Leben an der Universität vielfach änderte. Es folgte der zweite Weltkrieg, in dessen Verlauf die Bombenangriffe und die Endkämpfe um Berlin dem Institut schwersten Schaden zufügten. Die Jahre nach dem zweiten Weltkrieg standen zunächst ganz im Zeichen des Wiederaufbaues der Universität und des Instituts. So ist die Geschichte des Direktorats Stille viel bewegter als die seiner Vorgänger und ungleich schwereren Belastungen ausgesetzt gewesen. Mit der gleichen Tatkraft, mit der Stille das Institut bei seiner Amtsübernahme neu gestaltet hat, ergriff er auch nach dem zweiten Weltkrieg die Initiative zum Wiederaufbau und zur Wiederingangsetzung des Unterrichtes und der Forschung.

In Kürze sei nun der Bestand des Instituts an Kustoden, Lehrkräften, Assistenten und Präparatoren im Jahre 1932 aufgeführt. Im Herbst 1932 war Prof. Janensch nach wie vor der einzige Kustos. In seiner Arbeit wurde er aufs beste unterstützt von dem Oberassistenten Dr. Dietrich, der zugleich auch die Bibliothek verwaltete. PlanmäBige Assistenten waren Dr. Werner Quenstedt und Dr. Franz Lotze, der als Privatdozent und Assistent von Göttingen nach Berlin gekommen war. Die außerplanmäßige Assistentenstelle, die vorher mehrere Jahre lang Privatdozent Dr. Ri- 
chard Stappenbeck und ganz kurze Zeit Dr. Walter Gross innegehabt hatten, erhielt Dr. Gerhard Richter, ebenfalls aus Göttingen übernommen. Dr. Richter hat sich besondere Verdienste um die Planung des Umbaus und die Neueinrichtung erworben. Dr. Gross wurde wieder wissenschaftlicher Mitarbeiter als Stipendiat der Notgemeinschaft der deutschen Wissenschaft. Im Bestand der Präparatoren blieb es bei der bisherigen Besetzung: Oberpräparator Siegert und Präparator Schober. Institutsgehilfe blieb ebenfalls F. Marquardt.

Neben dem Ordinarius, Prof. Stille, lehrten 1932 am Institut Prof. Dr. Walter Gothan als Honorarprofessor für Paläobotanik und Prof. Dr. Friedrich Solger (Geologie Norddeutschlands), Prof. Dr. Erich Otto Haarmann (Wirtschaftsgeologie), Geheimrat Dr. Paul Range (Geologie der Kolonien), Dr. Fritz Behrend (Geochemie), Dr. Richard Stappenbeck (Lagerstättenkunde), Dr. Werner Quenstedt (Paläontologie), Dr. Erich Stach (Kohlengeologie) und Dr. Franz Lotze (Tektonische Geologie und Grenzgebiete) als Privatdozenten.

Bei diesem Bestand blieb es nicht. In den folgenden Jahren trat vielfacher Wechsel im Lehrkörper und unter den Institutsbeamten ein. Im Jahre 1933 wurden der Bezirksgeologe an der PreuBischen Geologischen Landesanstalt, Dr. Fritz Dahlgrün, zum Honorarprofessor für Geologie (Geologie Mitteleuropas) und Geheimrat Dr. Range bereits 1932 zum nichtbeamteten a. 0 . Professor ernannt. 1935 erfolgte die Ernennung der Herren Dr. Quenstedt, Dr. Behrend und Dr. Lotze zu nichtbeamteten a. o. Professoren, 1936 die von Dr. Stappenbeck. Einen Lehrauftrag für „Geologie, Paläontologie und diluviale Vorgeschichte" erhielt 1935 Professor Dr. Franz Klinghardt.

Eine Änderung der Habilitationsbestimmungen wurde im Jahre 1934 für die deutschen Universitäten erlassen. Das Habilitationsverfahren endete mit der Ernennung zum Dr. habil. Eine Dozentur konnte nur nach Bedarf verliehen werden, die Privatdozenturen sollten nach und nach verschwinden. Die Dozenturen wurden zu besoldeten Stellen, etwa einer Assistentenstelle gleichwertig. Doch konnten unbezahlte Dozenturen nach wie vor an solche habilitierten Doktoren oder Professoren verliehen werden, die als Beamte oder Angestellte festes Gehalt bezogen.

1938 wurde Dr. Gross, der sich 1935 in Frankfurt a. M. habilitiert und dort eine Dozentur für Geologie und Paläontologie erhalten hatte, Dozent in gleicher Eigenschaft an der Berliner Uni- versität, nachdem er 1937 als Assistent an die Berliner Universität zurückgekehrt war. 1935 habilitierte sich Dr. Rudolf Teichmüller, ohne Dozent zu werden. 1937 schied Prof. Dr. Stappenbeck als Dozent aus und übernahm das Ordinariat für Lagerstättenkunde an der Technischen Hochschule in Berlin-Charlottenburg. 1937 starb in Laurenco Marques, PortugiesischOstafrika (heute Mosambik), der Mitarbeiter des Instituts und frühere langjährige Assistent Prof. Dr. Hans Reck. 1938 habilitierte sich Dr. Wolfgang Hartung, der 1940 einen Lehrstuhl für Paläobotanik erhielt. 1941 wurde der Dozent Dr. Stach zum nichtbeamteten a. o. Professor ernannt. Im gleichen Jahr schied Prof. Dr. Lotze aus und übernahm als Regierungsdirektor die Zweigstelle Wien der Reichsstelle für Bodenforschung. Am 30. 1.1943 erhielt Dr. W. O. Dietrich den Professorentitel. Im Januar habilitierten sich die Assistenten Dr. Andreas Pilger und Dr. Paul Schmidt-Thomé, beide Herren wurden Dozenten mit Gehalt als Assistenten. 1943 erhielt Dr. Gross einen Ruf nach Göttingen (Ordinariat für Paläontologie), den er jedoch nicht annahm, da zugleich Berufungsverhandlungen auf den Posten einer 1937 geschaffenen, aber einstweilen nicht besetzten beamteten außerordentlichen Professur für Paläontologie an der Berliner Universität begannen. 1943 wurde Gross eingezogen, Prof. Stille nahm die Fortführung der Berufungsverhandlungen auf. 1943 wurde Dr. Gross zum nichtbeamteten a. o. Professor ernannt. 1944 konnte Prof. Gross die Berufungsverhandlungen abschließen und den Berufungsvertrag, der einen gesonderten kleinen eigenen Etat vorsah, unterzeichnen. Durch die Kriegsereignisse zögerte sich die Unterzeichnung der Urkunde bis in den Januar 1945 hinaus. Die Ernennung zum beamteten außerordentlichen Professor auf Lebenszeit erfolgte rückwirkend zum 1.11.1944. Gleichzeitig erfolgte die Ernennung zum ständigen Vertreter des Direktors und zum Direktor der Paläontologischen Abteilung.

Der Wechsel der Assistenten ist lebhafter als der der Dozenten. Oberassistent blieb von 1932 bis 1937 Dr. Dietrich. 1937 wurde die Oberassistentenstelle in ein beamtetes Extraordinariat für Paläontologie umgewandelt, das aber vorerst nicht besetzt wurde. Dr. Dietrich wurde weiterhin aus dem unbesetzten Extraordinariat bezahlt. Die bereits 1937 geplante zweite Kustodenstelle wurde erst 1944 errichtet und mit Dr. Dietrich besetzt; dadurch wurde das Extraordinariat für Paläontologie frei. 1934 schied der Assistent Dr. G. Richter aus und ging an die Preußische Geo- 
logische Landesanstalt; seine Stelle wurde mit Dr. Herbert Karrenberg besetzt, der die Stelle bis zum Jahre 1937 behielt; danach folgte er seinem Vorgänger als Geologe an die Preußische Geologische Landesanstalt, die 1939 in die Reichsstelle für Bodenforschung umgewandelt wurde. 1937 kehrte Dr. Gross aus Frankfurt a. M. zurück. Er trat an die Stelle des bisherigen Assistenten Prof. Dr. Quenstedt, der 1937 einen bezahlten Lehrauftrag für Paläontologie erhalten hatte. 1939 wurde Prof. Quenstedt außerplanmäBiger Professor mit Lehrauftrag für Geologie und Paläontologie (Mutschlechner 1961, Weisbach 1961). Nachfolger von Dr. Karrenberg wurde für kurze Zeit Dr. Georg Herbst, den noch im selben Jahr (1937) Dr. Andreas Pilger ablöste. Hilfsbibliotheks-Assistentenstellen wechselten recht häufig, doch liegen hierüber keine Unterlagen vor. 1938 wurde Dr. Martin Zöllich außerplanmäßiger Assistent, alsbald folgte ihm Dr. Bohdan Kordiuk, den 1941 Dr. Paul SchmidtThomé ablöste.

Bis zum Kriegsende blieben als Präparatoren tätig: Oberpräparator Siegert und Präparator Schober. Neben dem Institutsgehilfen Marquardt wurde 1936 als zweiter Institutsgehilfe Robert Nicodem eingestellt.

Das Ende des zweiten Weltkriegs brachte eine völlige Veränderung im Lehrkörper und im Mitarbeiterbestand des Instituts. Am Ende des Krieges befanden sich folgende Institutsangehörige und Lehrkräfte im Felde oder in Gefangenschaft: die Institutsgehilfen Marquardt und Nicodem, Assistent Dozent Dr. Pilger, Prof. Dr. Gross, Privatdozent Prof. Dr. Behrend, Assistent Dozent Dr. Schmidt-Thomé und der Lehrbeauftragte Dr. Hartung. Prof. Dr. Fritz Dahlgrün erhielt 1946 einen Ruf an die Bergakademie Clausthal-Zellerfeld. Dr. Pilger wechselte an das Geologische Landesamt von Nordrhein-Westfalen in Krefeld.

Die Arbeiten im Museum gingen seit der Übernahme des Direktorats durch Stille rasch weiter. Die Neuaufstellung der Schausammlung begann mit der Neuordnung der paläobotanischen Sammlung und ihrer Ausstattung mit Texten und Bildern durch Dr. Hartung im Jahre 1933. Teile der paläontologischen Schausammlung wurden laufend modernisiert. 1934 begann die Neuaufstellung der geologischen Schausammlung, die Dr. Lotze plante und in Angriff nahm. Er vollendete die Aufstellung der allgemeingeologischen Schausammlung. Die Neuaufstellung der Schausammlung für historische Geologie wurde nach den Richtlinien von Prof. Stille entworfen. Mit der Durchführung wurden nach-

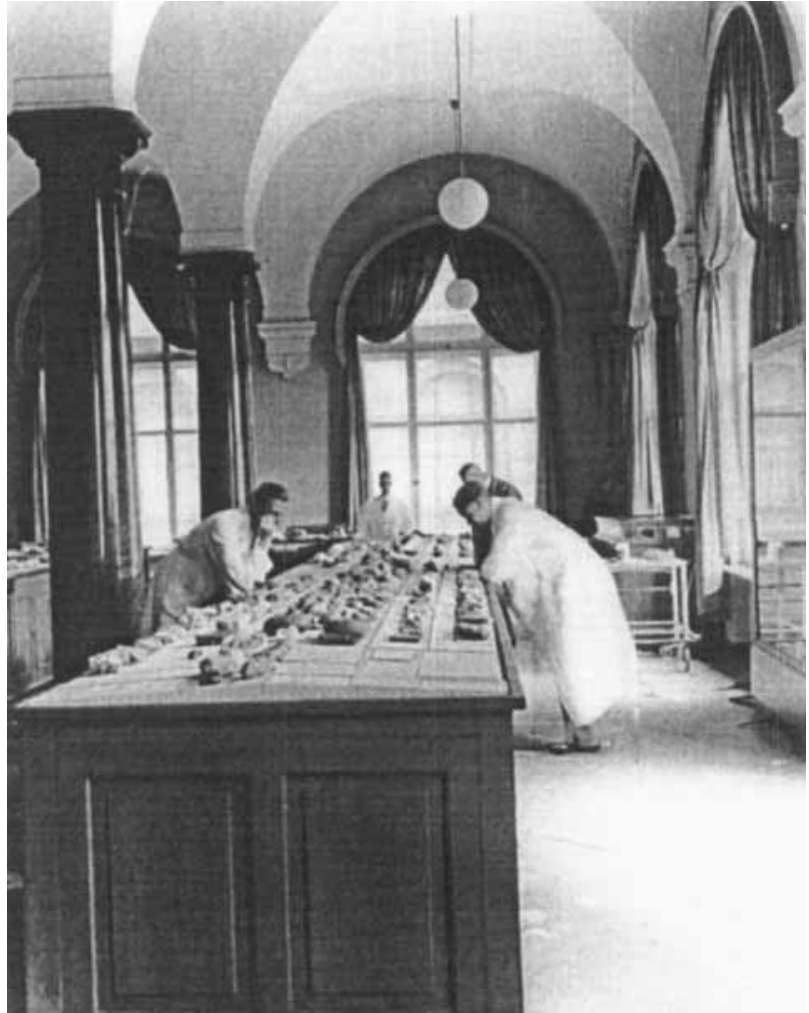

Abb. 4. Aufbau der Schausammlung Historische Geologie; v 1. n. r.: Dr. Karrenberg, Dr. Gross, Oberassistent Dr. Dietrich. Dr. Herbst (1937). (Archiv des Museums für Naturkunde).

einander die Assistenten Dr. Karrenberg, Dr. Herbst, Oberassistent Dr. Dietrich und Dr. Gross beauftragt (Abb. 4). Die Eröffnung erfolgte im Juli 1937. An der Aufstellung des sogenannten "Tektonischen Zimmers" arbeitete seit 1937 Dr. Pilger; die Neuaufstellung war bei Kriegsende noch nicht abgeschlossen, da Dr. Pilger bald eingezogen wurde.

Unter Leitung von Kustos Prof. Dr. Janensch begannen 1934 die Vorarbeiten zur Aufstellung des Skelettes des Riesensauriers Brachiosaurus. Die Präparationsarbeiten und die Nachbildung verschiedener Skeletteile führte in der Hauptsache Oberpräparator Siegert aus, die Vorbereitung der schweren Knochen für die Montage war das Werk von Präparator Schober, ebenso die Konstruktion des Montagegerüstes (Abb. 5). 1937 wurde der Lichthof für die Aufstellung geräumt und neu gestrichen. Die endgültige Aufstellung des Skelettes durch Präparator Schober im Lichthof erfolgte 1937 (Abb. 6), und im gleichen Jahr wurde der Lichthof feierlich eröffnet. Damit erfuhr die wissenschaftliche Lebensarbeit von Prof. Janensch eine auch nach außen weit hervorragende Krönung. Berlin war um eine bedeutende Sehenswürdigkeit bereichert, wie sie kein anderes Museum der Welt in dieser impo- 


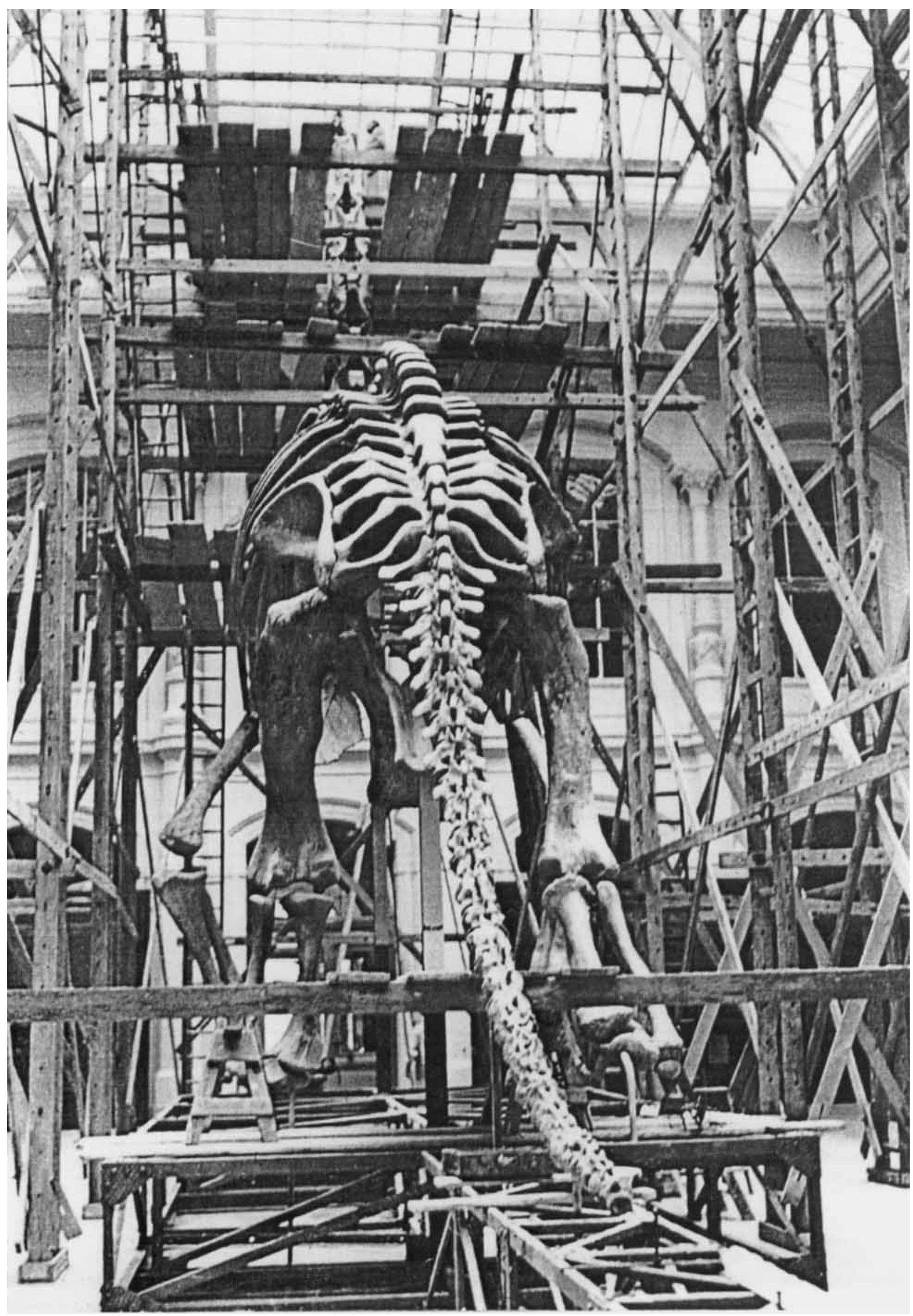

Abb. 5. Aufbau des Brachiosaurus (1937) (Archiv des Museums für Naturkunde). 


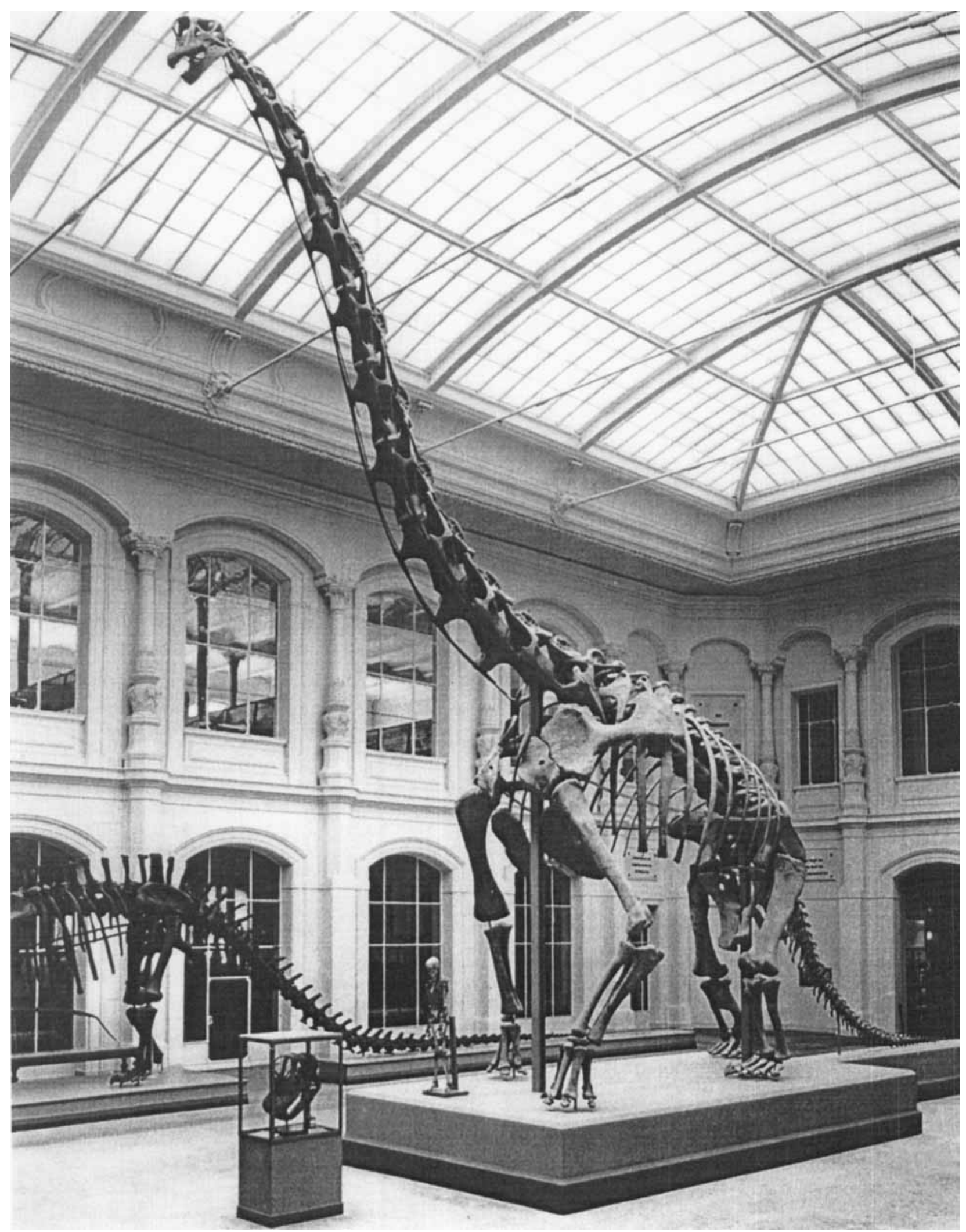

Abb. 6. Das fertig aufgestellte Skelett des Brachiosaurus brancai im Vergleich mit einem menschlichen Skelett; davor das Original des Kopfes, links der hintere Teil der Skelettkopie des Diplodocus. (Archiv des Museums für Naturkunde).

nierenden Größe und Höhe aufzuweisen hatte. 1939 folgte im Lichthof die Aufstellung einer großen Vitrine mit hervorragenden Präparaten von Schädeln und Skeletten südafrikanischer Pareiasaurier und Theromorphen. - Die Lehr- sammlung für die historische Geologie und die allgemeine Geologie wurden laufend vervollständigt und erhielten ihren Platz im Flur des Ostflügels (2. Stockwerk) und im Praktikantenzimmer II. 
Außer den schon erwähnten Aufsammlungen Reck's in Südafrika kamen pleistozäne Säugetiere aus dem Njarasa-Graben und der Serengeti aufgesammelt von L. Kohl-Larsen 1934-1937 ans Institut. In den 30er Jahren vergrößerte Gross die Sammlung devonischer Fische durch Aufsammlungen in Overath bei Köln und in Lettland beträchtlich.

Der Krieg brachte in seinem Verlauf viele Zerstörungen über das Institut. Bis 1943 waren keine merklichen Schäden durch die immer massiver werdenden Luftangriffe eingetreten. Vorsorglich wurde bereits $1943 \mathrm{mit}$ der Verlagerung der wertvollen Originale und Typen der systematischen Hauptsammlung und der Schausammlung der Invertebraten begonnen. Sie wurden im Alvensleben-Stollen des Kalkwerkes Rüdersdorf bei Berlin untergebracht, Wirbeltierreste wurden nur im geringen Umfang verlagert. Im Juli 1943 wurde die Bibliothek ausgeräumt und in der Hauptsammlung im ersten Stock untergebracht, der nicht so unmittelbar durch Brandbomben gefährdet war. Erste Zerstörungen durch Luftangriffe entstanden am 3. und 4. September 1943. Daraufhin wurde das Skelett des Brachiosaurus abmontiert und im Keller untergebracht. Sehr schwere Schäden entstanden durch Luftangriffe am 12.11.1943, denen der große Hörsaal, das Vorlesungs-Vorbereitungszimmer und der Reptilsaal gänzlich zum Opfer fielen; die Räume brannten aus. Die eisernen Türen zu diesen Räumen hatten aber ein Übergreifen des Brandes auf den Ostflügel des Instituts verhindert. Neue Angriffe erfolgten am 17. 11. 1943. Unmittelbar vor Kriegsende wurde am 2. und 3. Mai durch Granatenbeschuss auf das Naturkundemuseum das Dachgeschoss des Südflügels und des Ostflügels zerstört, die Dächer wurden vernichtet, die Zimmer mit ihren Einrichtungen brannten aus. Stark beschädigt und unbenutzbar wurden auch die Zimmer im zweiten Stock des Südflügels. Besonders schädlich wirkten sich die alsbald eingetretenen Wassereinbrüche aus. Das Wasser drang bis ins Erdgeschoss, sobald es heftiger regnete. Die Wasserschäden setzten sich noch jahrelang nach Kriegsende fort, ihre Beseitigung gelang erst in den Jahren 1947 bis 1949, zum Teil noch später.

Ein besonders harter Verlust für die Sammlung trat unmittelbar nach dem Kriegsende ein: alle in den Alvensleben-Stollen in den Muschelkalkwerken von Rüdersdorf verlagerten Fossilien, die wertvollen Typen und Originale, verschwanden nach Russland, kehrten aber 1958 nach Berlin zurück. Wertvolle große Werke und
Zeitschriftenserien, die 1943 in den Schacht Hadmersleben der Salzwerke Westeregeln zu Egeln bei Magdeburg ausgelagert worden waren, konnten nicht wiedererlangt werden. Nach dem zweiten Weltkrieg kam bereits 1946 wieder eine große Sammlung, die P. Bamberg-Sammlung (Plesiosaurier-Skelett und Invertebraten), und 1948 die A. Nehring-Sammlung der ehemaligen Landwirtschaftlichen Hochschule (pleistozäne Säugetiere) ans Institut.

Gleich nach Kriegsende begann, wenn auch zögernd, die Ingangsetzung des Unterrichts und der Institutsarbeit. Die Zahl der Institutsmitglieder und der Lehrkräfte war ungemein stark zurückgegangen, viele befanden sich in Gefangenschaft oder in ganz anderen Gegenden Deutschlands, andere waren als ehemalige Mitglieder der NSDAP sofort entlassen worden. Im Juni 1945 bestand das Personal des Instituts aus folgenden Mitgliedern: Prof. Stille, Direktor und Ordinarius, Prof. Dr. Janensch, erster, und Prof. Dr. Dietrich, zweiter Kustos; Dr. Reinhard Schönenberg, Assistent, Oberpräparator Siegert und Präparator Schober. Präparator Schober erlag im Dezember 1945 einer Lungenentzündung. Von ehemals dreizehn Lehrkräften war die Anzahl auf eine zurückgegangen.

Von dieser traurigen Grundlage aus begann der Wiederaufbau des Unterrichts und der Personalbesetzung des Instituts und Museums. Im Jahre 1946 wurde der Paläontologie-Unterricht wieder aufgenommen; Prof. Dr. Otto Heinrich Schindewolf, ehemals Landesgeologe am Reichsamt für Bodenforschung in Berlin, erhielt zunächst einen Lehrauftrag für Paläontologie und im Jahre 1947 die Professur mit Lehrauftrag für Paläontologie, die er bis zu seinem Ausscheiden im Jahre 1948 innehatte. 1948 nahm Prof. Dr. Schindewolf die Berufung zum Ordinarius für Geologie und Paläontologie an die Universität Tübingen an (Erben 1971). Prof. Dr. Gothan wurde 1946 zum Professor mit Lehrauftrag und 1947 zum Professor mit vollem Lehrauftrag für Paläobotanik ernannt, Prof. Dr. Solger zum Professor mit Lehrauftrag. Ein Lehrauftrag für Bodenkunde wurde Prof. Dr. Max Trénel, Professor in der Landwirtschaftlichen Fakultät, und für Hydrogeologie 1949 Prof. Dr. Julius Denner erteilt. 1949 wurde Prof. Dr. Gross wieder nach Berlin berufen, und zwar nun als Professor mit vollem Lehrauftrag für Paläontologie. 1950 erfolgte die Ernennung zum Professor mit Lehrstuhl für Paläontologie und zum Leiter der Paläontologischen Abteilung des Geologisch-Paläontologischen Instituts und Museums. 
Prof. Dr. Stille beantragte 1949 seine Emeritierung. $\mathrm{Zu}$ seinem Nachfolger als Ordinarius und Direktor wurde Prof. Dr. Roland Brinkmann, Ordinarius in Rostock, berufen, der seinen Dienst jedoch nicht antreten konnte. Dadurch sah sich Prof. Stille genötigt, noch für ein weiteres Jahr Direktor des Instituts zu bleiben und erneute Berufungsverhandlungen in Gang $\mathrm{zu}$ bringen. Als Nachfolger gewählt wurde Prof. Dr. Serge von Bubnoff, Ordinarius für Geologie in Greifswald. Noch vor Antritt seines Amtes am 1. 10. 1950 hatte Prof. v. Bubnoff bereits die groBen Vorlesungen am Berliner Institut übernommen. Am 17. 7. 1950 hielt Stille seine letzte Vorlesung und verabschiedete sich vom Institut. Während des letzten Jahres hatte sich Prof. Stille in Verwaltungsangelegenheiten weitgehend von Prof. Gross vertreten lassen. Danach wohnte Prof. Stille in seiner Heimatstadt Hannover.

Von 1944 bis 1948 war Dr. Reinhard Schönenberg Assistent. Als weiterer Assistent wurde 1947 Dr. Kurt Diebel eingestellt. Im gleichen Jahr erhielten auch die Dipl.-Geologen Werner Schwan und Berthold Dolezalek Assistentenstellungen. Nach seiner Promotion schied Dr. Schwan im Herbst 1949 aus und ging an das geotektonische Institut der Deutschen Akademie der Wissenschaften zu Berlin.

Am Museum blieben nach wie vor im Amt die Kustoden Prof. Dr. Janensch und Prof. Dr. Dietrich. Dasselbe gilt für Oberpräparator Siegert. An Stelle des verstorbenen Präparators Schober trat 1947 Präparator Günter Neubauer. Die früheren Institutsgehilfen nahmen ihren Dienst wieder auf, R. Nicodem im Jahre 1947, F. Marquardt im Jahre 1949, nach sieben- bzw. zehnjähriger Unterbrechung durch Krieg und Nachkriegszeit.

In der Zeit von 1945 bis 1950 haben keine Habilitationen stattgefunden.

Das Leben im Institut wurde durch die Zerstörungen des Krieges sehr erschwert. Nur ganz wenige Zimmer waren völlig frei von Wassereinbrüchen bei Regen- und Schneeschmelze. Die Dampfheizung des Naturkundemuseums war auBer Betrieb, überall mussten Öfen aufgestellt werden, deren Beschaffung große Schwierigkeiten verursachte; in den ersten Jahren war die Menge an Holz und Kohlen sehr gering. Die Sammlungssäle und viele andere Räume waren im Winter nicht benutzbar. Der Wiederaufbau begann 1947, zuerst unter Leitung von Dr. Schönenberg, nach seinem Fortgang unter der tatkräftigen und erfolgreichen Leitung von Dr. Diebel, den für kurze Zeit Dr. Schwan ablöste; im
Herbst 1949 nahm Dr. Diebel die Tätigkeit wieder auf und führte sie bis in die letzten Jahre fort. Die Gesamtleitung des Wiederaufbaus hatte bis 1949 Prof. Stille, von 1949 an Prof. Gross.

Nach der Wiederherstellung des Daches und des Dachgeschosses des Südflügels im Jahre 1947/48 wurden die ehemaligen Doktorandenzimmer wieder bewohnbar. Die Wiederherstellung des 2. Stockwerkes des Südflügels erfolgte 1948/49, im Sommer 1949 konnten die Zimmer des Südflügels wieder bezogen werden, darunter die Direktorenzimmer. Die Bibliothek wurde 1950 wieder eingeräumt. - Im Sommer 1949 konnte endlich das Notdach über dem Ostflügel durch ein neues Dach ersetzt werden, gleichzeitig erhielt der ehemalige große Hörsaal ein Dach, wenn auch an seine Wiederherstellung nicht zu denken war. Die Wiederherstellung der Dächer schuf die Voraussetzung zur Renovierung der darunter gelegenen Stockwerke und zur Beseitigung der im Laufe von fünf Jahren entstandenen großen Wasserschäden.

Die Wiederaufbauarbeiten mussten vom Institut selber geplant, organisiert und betrieben werden, wenn auch die Mittel von der Universität gestellt wurden und die Pläne von der Universitätsbauleitung genehmigt werden mussten. Das alles kostete unendlich viel Mühe und Sorge, weil es bald an Material, bald an Arbeitskräften oder wieder an Geld fehlte. Diese drei Voraussetzungen für den Wiederaufbau gleichzeitig zur Verfügung zu haben, war die große Kunst jener Jahre. Besprechungen mit Firmen und Bauführern, mit Handwerkern und Universitätsbehörden nahmen die volle Arbeitskraft der mit der Planung und Leitung des Wiederaufbaus beschäftigten Institutsmitglieder in Anspruch. Selbst die Beseitigung kleinerer Dach- und Mauerschäden erforderte zahlreiche Besprechungen, Besuche und Anträge, oft in vielfacher Wiederholung. Die finanzielle Unterstützung durch die Universität war in jeder Hinsicht großzügig.

Es ist nun notwendig, bei der Persönlichkeit Hans Stilles zu verweilen, der dem Institut in so vieler Hinsicht seinen Stempel aufgeprägt hat, der aus einem zwar geachteten, aber unmodernen Institut das erste geologische Institut Deutschlands gemacht hat, der noch im hohen Alter die Tatkraft aufbrachte, ohne Zögern sich sofort der Aufgabe des Wiederaufbaus zuzuwenden.

Die Lebensdaten und die akademische Laufbahn: geboren am 8.10.1876 in Hannover, gestorben am 26.12.1966 in Hannover; Dr. phil. 1899 in Göttingen bei von Koenen; 1900 bis 1908 
Geologe an der Preußischen Geologischen Landesanstalt; 1905 Habilitation in Berlin bei von Branco; 1905 bis 1908 Privatdozent in Berlin; 1908 bis 1912 Ordinarius für Geologie an der Technischen Hochschule in Hannover, 1912 bis 1913 an der Universität Leipzig, 1913 bis 1932 an der Universität Göttingen und von 1932 bis 1950 an der Universität Berlin; emeritiert am 1. 1.1950; vom 1.1.1950 bis 30.9.1950 Vertretung des Direktors in Berlin (Carlé 1967, 1988).

Hervorragend erfüllte Stille die drei Forderungen, die an einen Ordinarius und Institutsdirektor gestellt werden: als Wissenschaftler einer der bedeutendsten deutschen Geologen, als Lehrer meisterhaft und von seinen Schülern verehrt, als Direktor großartig. In jeder der drei Richtungen sind seine Verdienste gleich bedeutend.

Um die Jahrhundertwende stand die deutsche Geologie noch fast ganz im Zeichen der Paläontologie und Stratigraphie, wie man beim Durchblättern der damaligen Zeitschriften leicht feststellen kann. Auch in Berlin standen seit Beyrich die Paläontologie und die große Sammlung im Vordergrund. Von Branca und Pompeckj betrachteten es als die Hauptaufgabe der historischen Geologie, ein Bild von der Geschichte des Lebens $\mathrm{zu}$ entwerfen. Mittlerweile aber waren neue Forschungsrichtungen hervorgetreten, der Ausbau des biostratigraphischen Grundgerüstes hatte einen ersten Abschluss erreicht. Die historische Geologie sollte nun weniger die Geschichte des Lebens zum Inhalt haben als die Geschichte der Erde. Geschichte der Erde ist aber weitgehend nichts anderes als Geschichte des tektonischen Geschehens in Zeit und Raum. Wie kein zweiter hat Stille diese tektonische Forschung gefördert und in weltweiter Sicht ausgebaut und dem Abschluss entgegengeführt. Er konnte sich mit der Kontinentalverschiebungstheorie Wegeners nicht anfreunden und beharrte auf einer Konstanz der Kontinente. Unabhängig und doch in geistiger Verbindung mit ihm richteten andere bedeutende Geologen, vor allem Hans Cloos (Bonn) und Serge von Bubnoff (Greifswald) die Forschung auf die allgemeingesetzlichen Fragen und Bedingungen tektonischen Geschehens. Entgegen den Vorstellungen und Voraussagen v. Brancas und Pompeckjs verschob sich das Schwergewicht der Geologie auf die Seite der Tektonik; die reine Paläontologie und besonders die Paläontologie der Wirbeltiere traten in den Hintergrund, auch die historische Geologie. Die Paläontologie erhielt wieder den Charakter einer Hilfswissenschaft für chronologische Fragen. Sie wurde zwar voll anerkannt in ihrer praktischen Bedeutung als Grundlage für die zeitliche Einordnung aller Schichten und damit aller geologischen Geschehnisse, aber es waren nun eben die ,geologischen Geschehnisse“, denen die eigentliche Forschung der Geologen galt. Der Hauptinhalt der historischen Geologie wurde ein anderer. Chronologische Methodik konnte nicht der Inhalt der historischen Geologie sein.

Die Wendung in der Geologie führte auch zu einer neuen Wertung der Forschungseinrichtungen des Instituts und der Bedeutung des Museums. Dieser Wandel in der Geologie erinnert an den Wandel in der Zoologie um die Jahrhundertwende, von einzelnen Forschern sofort erfasst, von anderen gar nicht recht wahrgenommen: die Zeit intensiver systematischer, morphologischer und phylogenetischer Forschung wurde abgelöst von einer Zeit experimenteller physiologischer Forschung, von Entwicklungsmechanik, Vererbungslehre, Sinnesphysiologie und allgemeiner Biologie.

Viele Geologen betrachteten nicht mehr die Paläontologie als den Hauptgegenstand ihrer Forschung und auch nicht mehr die „Herrschaft über die Sammlung" - besonders über die Wirbeltiersammlung - als ihr Hauptanliegen, das v. Branca noch so leidenschaftlich verfochten hatte. Keine ,reinen Paläontologen" kamen daher, dieses Zepter den Geologen zu rauben, sondern dieses Zepter verlor in den Augen der Geologen seine Wertung und wurde fast achtlos beiseite gelegt.

Stille hat die Grenzziehung innerhalb der geologischen Wissenschaften anders gesehen als v. Branca und Pompeckj. Nach Stille soll sie zwischen der Geologie mit ihren drei großen Disziplinen einerseits und der Paläontologie andererseits verlaufen, nicht aber mitten zwischen der historischen und der allgemeinen Geologie. Reine Paläontologie und besonders Paläontologie der Wirbeltiere und der Gefäßpflanzen kann mit Erfolg nur von biologisch ausgerichteten Forschern betrieben werden. Der Paläontologe braucht keineswegs mit der Tektonik eng vertraut zu sein, um auf seinem Gebiet forschen zu können, aber auch der Geologe kann weitgehend von der reinen Paläontologie absehen, seine eigentlichen geologischen Disziplinen muss er aber beherrschen. Die historische Geologie darf nicht von der regionalen Geologie und der allgemeinen Geologie getrennt werden. Nur als angewandte Chronologie ist die Paläontologie für den Geologen unentbehrlich. - Den wahrhaft geologischen Inhalt hat Stille der histori- 
schen Geologie gegeben: erst die Erforschung der Zeitlichkeit tektonischer Vorgänge, den historischen Ablauf, dann die Verfolgung dieser Vorgänge als Bildungen im Raum über die ganze Erde, die Erforschungen des jeweiligen Anteils, den sie am Aufbau der Kontinente haben.

Mit dieser Arbeitsrichtung übernahm Stille das geologische Institut, in sie fügte er die Arbeit der jungen Geologen. Aus dem ein wenig vergessenen Institut, das im Schatten des Paläontologischen Museums stand, gestaltete Stille das größte geologische Institut Deutschlands, die bedeutendste Heranbildungsstätte junger Geologen. Die Bezeichnung „Stille-Schüler“" wurde fast zur Qualitätsbezeichnung.

Deswegen traten die Paläontologie und das Paläontologische Museum keineswegs in den Hintergrund. Zwar konnte sich Stille nicht unmittelbar persönlich um die paläontologischen Aufgaben kümmern, dazu lag ihm diese Wissenschaft zu fern, aber er unterstützte jede Kraft, die sich selbstständig ihre Ziele setzte und ihre Ziele zu erreichen strebte. Mit großer Energie förderte er die Ausgestaltung der Schausammlung und die Aufstellung des Riesensauriers $\mathrm{Bra}$ chiosaurus. Nie hat er sich den Wünschen der Paläontologen versagt, nur sollte die Initiative und die Tatkraft der Durchführung der Pläne von den Paläontologen selber kommen. Schon bei den Berufungsverhandlungen drang Stille auf eine gewisse Verselbstständigung der Paläontologie. 1937 gelang ihm die Errichtung einer beamteten außerordentlichen Professur für Paläontologie, die 1944 mit Prof. Gross besetzt wurde. Gleichzeitig mit dieser Berufung gewann Stille die zweite Kustodenstelle für das Museum. Nach dem Kriege war es wieder Stille, der die Berufung von Prof. Schindewolf und danach die Berufung von Prof. Gross und die Errichtung des Ordinariats für Paläontologie durchsetzte und alsbald auch die Paläontologische Abteilung und ihr selbstständiges Direktorat schuf.

Die Würdigung Stilles als Forscher und Gelehrter kann nicht Aufgabe dieses Beitrages sein; hervorragende Würdigungen seines wissenschaftlichen Lebenswerkes finden sich in verschiedenen bedeutenden wissenschaftlichen Zeitschriften (z. B. Carlé 1988). Dankbar spürt es ein Institut, wenn an seiner Spitze ein so bedeutender Wissenschaftler steht, jeder Angehörige des Instituts hat bewusst oder unbewusst Anteil an dem Ansehen, das einem solchem Direktor und seinem Werk gilt.

Stille war ein großartiger Direktor. Seine bis zum letzten Tage des Direktorats nie ermüdende
Energie schuf den Ausbau und den Wandel des Instituts im Jahre 1932 und auch den Wiederaufbau nach dem Kriege. Nie hat Stille Zeichen der Niedergeschlagenheit oder der Resignation gezeigt. Diese Sicherheit und Tatkraft strahlte auf das ganze Institut aus, jeder hatte die feste Überzeugung, dass Stille die Schwierigkeiten meistern würde, und wenn alles noch so sehr daniederlag. Dabei trug Stille auf seinen Schultern die Last höchster Ämter in der Akademie der Wissenschaften zu Berlin, an deren Wiederaufbau nach dem Kriege er entscheidenden Anteil hatte. Das hat niemals die Sorge für das Institut beeinträchtigt, eine Sorge, die sich auf jeden Angestellten und Mitarbeiter erstreckte. Stille kannte keine Sprechstunden, solange er im Institut war, hatte er für jeden Zeit und Gehör. Die Verwaltungsgeschäfte leitete er anscheinend mühelos und ohne zu zögern. - Ein sehr segensreicher Abstand $\mathrm{zu}$ allen Mitarbeitern wurde von ihm eingehalten. Diese fast unpersönliche Art, die niemand bevorzugte, schuf eine Atmosphäre der Zusammengehörigkeit. An der Spitze aller Sorgen stand die Ausbildung der Studenten. In Dankbarkeit und Verehrung gedenken alle Mitarbeiter und Schüler seiner Leistungen und seiner Sorge für sie.

Zur Zeit Stilles standen die wissenschaftlichen Veröffentlichungen auf Seiten der Geologen ganz im Zeichen der Tektonik und der allgemeinen Geologie. Große Werke erwuchsen, so das Buch von Stille „Einführung in den Bau Amerikas" (1940) und das Werk von F. Lotze „Steinsalz und Kalisalze, Geologie" (1938), ferner sehr zahlreiche Abhandlungen und Schriften Stilles und seiner Mitarbeiter und Schüler. Von paläontologischer Seite wurden besonders die fossilen Wirbeltiere in den Mittelpunkt der Forschung gestellt, entsprechend der alten Tradition des Instituts. Zahlreiche Arbeiten veröffentlichten W. Janensch über Reptilien, W. O. Dietrich über Säugetiere und W. Gross über niedere Wirbeltiere. W. Quenstedt verfasste wichtige Bände des „Fossilium Catalogus“ (Quenstedt \& Quenstedt 1936 und Quenstedt, Lambrecht \& Quenstedt 1938).

\section{Direktorat v. Bubnoff (1950 bis 1957)}

Im Oktober 1950 übernahm Prof. Dr. Serge von Bubnoff (Abb. 7) das Ordinariat für Geologie und das Direktorat über das Institut. Damit wurde die geotektonische Richtung des Instituts fortgesetzt. Im Vordergrund der Forschung standen 


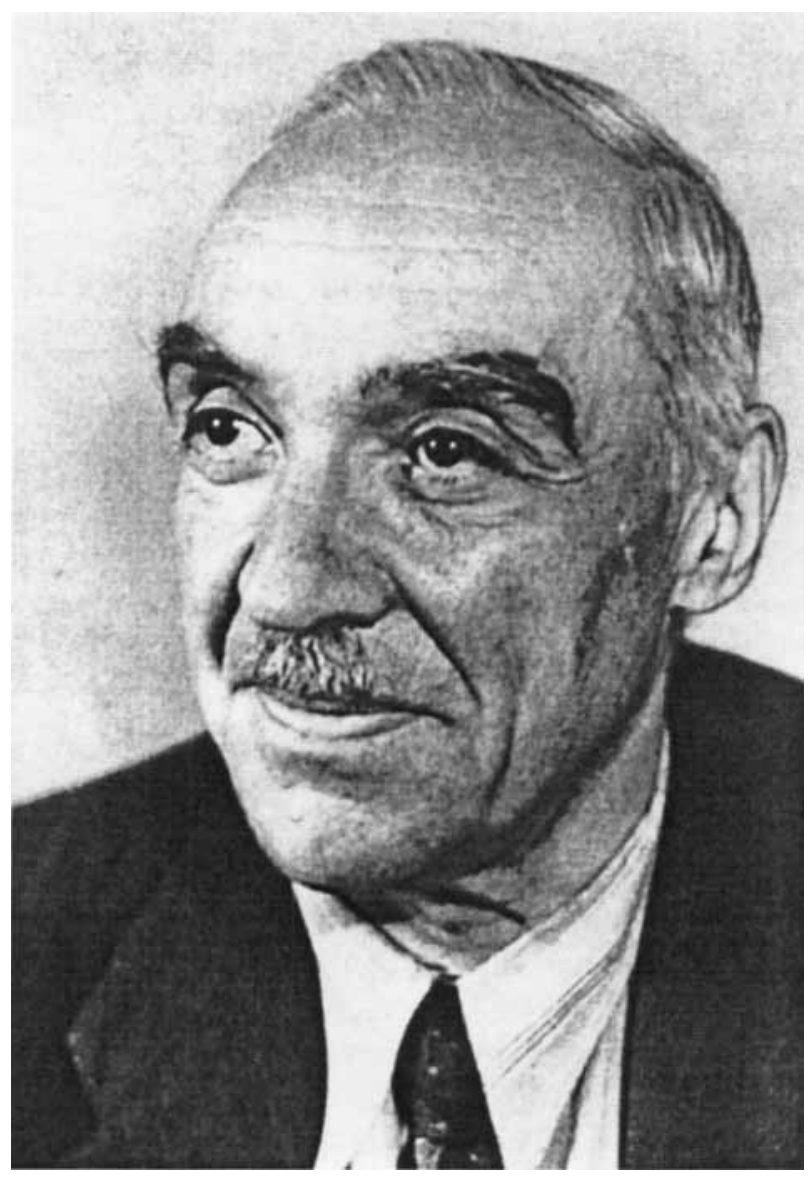

Abb. 7. Prof. Dr. S. von Bubnoff (Archiv des Museums für Naturkunde).

nun die Petrotektonik und die regionale Geologie. Praktisch war das Institut und Museum seit 1950 geteilt in eine paläontologische Abteilung unter Prof. Gross, der das Ordinariat für Paläontologie innehatte, und eine geologische Abteilung, die aber nach außen unter dem Namen Geologisch-Paläontologisches Institut und $\mathrm{Mu}-$ seum nicht hervortrat. In Wirklichkeit waren Leitung und Verantwortung, Haushalt und Personal fast gänzlich getrennt. Beide Direktoren vertraten sich bei Bedarf, was den Geschäftsgang sehr erleichterte. Die Leitung des Wiederaufbaus blieb bei Prof. Gross, der mit Kustos Dr. Diebel einen für diese Aufgabe denkbar geeigneten Mitarbeiter gefunden hatte. Verwaltungsaufgaben, praktische Fragen und Bauangelegenheiten blieben Prof. v. Bubnoff bis an sein Ende ein Gebiet, dem er kein rechtes Interesse abgewinnen konnte.

Bei der Übernahme des Direktorats durch Prof. v. Bubnoff waren folgende Herren als Lehrkräfte tätig: Ordinarius für Geologie Prof. Dr. v. Bubnoff; Ordinarius für Paläontologie und Direktor der paläontologischen Abteilung Prof. Dr. Gross; Professor mit vollem Lehrauftrag für $\mathrm{Pa}$ - läobotanik Prof. Dr. Gothan; Lehrbeauftragter für Hydrogeologie Prof. Dr. Denner. Erster Kustos war Prof. Dr. Janensch, der mit Ende des Jahres 1950 in den Ruhestand trat, und zweiter Kustos Prof. Dr. Dietrich. Assistent für Geologie war Dipl.-Geol. Dolezalek, Assistent für Paläontologie Dr. Diebel. Als Präparatoren waren tätig: Oberpräparator Siegert und Präparator G. Neubauer, als technische Institutsgehilfen F. Marquardt und R. Nicodem.

Im Wiederaufbau standen nun alle Dächer, es konnte mit dem Ausbau im dritten Stockwerk des Ostflügels begonnen werden.

Im Laufe der Jahre nach 1950 vollzogen sich folgende Änderungen im Lehrkörper: 1951 schied Prof. Dr. Denner aus und siedelte nach Koblenz über. 1952 wurde Prof. Dr. Fritz Deubel, Ordinarius für Geologie an der Universität Jena, als Professor für angewandte Geologie nach Berlin berufen. Einen Lehrauftrag für Mikropaläontologie erhielt 1952 Dr. Diebel, ein Lehrauftrag für Geophysik wurde an Prof. Dr. Gerhard Fanselau erteilt, der aber den Lehrauftrag nur in den Jahren 1952 und 1956 wahrnehmen konnte. An seiner Stelle erhielt den Lehrauftrag für Geophysik im Jahre 1953 Prof. Dr. Hans Martin, der seine Lehrtätigkeit bis 1955 ausübte. Im Jahre 1953 ließen sich die Professoren Gothan und Solger emeritieren, doch behielten sie ihre Lehraufträge. Ein Lehrauftrag für Sedimentpetrographie wurde 1953 an Dr. Gerhard Ludwig gegeben. 1954 schied Prof. Deubel aus, der sich auf das Ordinariat für Geologie an der Universität Jena beschränkte. An seiner Stelle erhielt Dr. Eberhard Kautzsch aus Eisleben einen Lehrauftrag für angewandte Geologie. Im Herbst 1954 habilitierte sich der ehemalige Assistent Dr. Schwan, dem 1955 die Dozentur verliehen wurde. Am 31.12. 1954 verschied Prof. Dr. W. Gothan, der weltbekannte Paläobotaniker, der sich die größten Verdienste um Forschung und Lehre in der deutschen Paläobotanik erworben hat (Potonié 1955). Der Unterricht der Paläobotanik wurde zunächst vertretungsweise von Dr. Winfried Remy und dann von Dr. Rudolf Daber, beide Schüler Gothans, durchgeführt; Dr. Daber erhielt alsbald Lehraufträge für Paläobotanik. Das Jahr 1955 brachte die Habilitationen von Dr. Remy und Dr. Kautzsch; eine Dozentur, die 1956 in eine Professur mit Lehrauftrag für angewandte Geologie umgewandelt wurde, erhielt indessen nur Dr. Kautzsch. Im gleichen Jahr schied Dr. Ludwig aus der Lehrtätigkeit. 1956 erhielten Lehraufträge: Dr. Günter Siemens für Geophysik, Dr. Klaus Schmidt für Gefügekunde 
und Dipl.-Geol. Siegfried Diener für Sedimentpetrographie. 1957 erfolgten die Habilitationen von Dr. Schmidt und Dr. Daber. Zum 1. 9.1957 ließ sich Prof. Dr. von Bubnoff emeritieren, aber er vertrat noch weiterhin das Ordinariat und Direktorat. Gänzlich unerwartet verstarb Prof. von Bubnoff am 16.11. 1957, ehe die Frage der Nachfolge geregelt war.

An Stelle des 1950 in den Ruhestand getretenen Kustos Prof. Janensch übernahm Dr. K. Diebel 1951 dieses Amt. Der nunmehr erste Kustos, Prof. Dietrich, ließ sich 1950 pensionieren, blieb aber weiterhin im Amt (bis 1959) (Gross 1964, Hennig 1965).

Mannigfaltig wie immer war der Wechsel der Assistentenstellen. Die zahlreichen Hilfsassistenten müssen unberücksichtigt bleiben. 1951 trat an die Stelle des nun Kustos gewordenen Dr. Diebel ein Hilfsassistent. In der geologischen Abteilung wurden 1952 Dr. Helmut Wegener und der Diplomgeologe Klaus Schmidt als Assistenten eingestellt. 1953 schieden die Assistenten Dr. Dolezalek und Dr. Wegener aus, im gleichen Jahr erhielten Assistentenstellen in der geologischen Abteilung Dipl.-Geol. Erich Schroeder und in der paläontologischen Abteilung Dipl.Geol. Klaus Fahlbusch. 1954 wurde der Assistent Dr. Schmidt zum Oberassistenten ernannt. 1955 schied der Assistent Dr. Fahlbusch aus; er wurde anschließend Assistent an der Technischen Hochschule Berlin-Charlottenburg und der Technischen Hochschule Darmstadt. 1956 erhielt Dipl.-Geol. Hermann Jaeger die Assistentenstelle in der paläontologischen Abteilung; in der geologischen Abteilung wurden die Dipl.-Geologen S. Diener und Hans-Jürgen Teschke Assistenten.

1953 wurde die Stelle einer Bibliothekarin geschaffen und mit der Dipl.-Bibliothekarin Anneliese Illner besetzt.

Nur geringe Veränderungen sind von den Präparatoren $\mathrm{zu}$ berichten. G. Neubauer wurde im Jahre 1955 Oberpräparator und F. Marquardt im Jahre 1954 Präparator. Neue Stellen wurden geschaffen für einen Fotografen (1950), einen Gesteinsschleifer (1952), einen Instituts- und Sammlungsgehilfen für die paläontologische Abteilung (1952), eine technische Hilfskraft für Mikropaläontologie (1953) und eine Stenotypistin für das Sekretariat.

Der von Stille begonnene Wiederaufbau und Ausbau des Museums wurde weitergeführt, und zwar fast ausschließlich unter Leitung von Prof. Gross und Kustos Diebel. Im Jahre 1951 erfolgte die Renovierung des Ostflügels im 2. Stock, wo- bei die früheren Oberlichte des großen Flurs und mehrere Zwischentüren zugemauert wurden. Der Ausbau des 1. Stockwerkes im Ostflügel wurde 1951 in Angriff genommen, anschließend an die Errichtung einer Dunkelkammer am Ende des Doktorandenflurs im 3. Stockwerk des Südflügels. Den Anfang machten der Ausbau eines Laboratoriums für Mikropaläontologie und mehrere kleinere Einzelzimmer. Für die geologische $\mathrm{Ab}$ teilung wurden zwei Räume zu einem Laboratorium für Schwermineralanalyse und Sedimentpetrographie ausgebaut und mit Geräten und Apparaten versehen. Sehr begrüßt wurde allgemein der Bau einer Duscheinrichtung für das Personal, das häufig Arbeiten ausführen muss, bei denen sich viel Gesteinsstaub entwickelt. Auf der Ostseite dieses Stockwerkes wurden neben mehreren Arbeitszimmern und Magazinräumen drei Werkstätten und Arbeitsräume für die Präparatoren gebaut und eingerichtet, anschließend an diese Räume ein Zeichensaal für die geologische Abteilung. Anfang 1953 war der Ausbau dieses Stockwerkes abgeschlossen, eine große Menge Räume war gewonnen worden, so dass sich die technischen Arbeiten viel günstiger ausführen ließen. Die Präparatoren kamen aus den dunklen Kellerräumen in helle Zimmer, gerade sie brauchen besonders günstige Lichtverhältnisse. Ein kleiner Raum wurde als Lichtpausanstalt eingerichtet und der Hochschul-Bildstelle der Universität unterstellt, die auch eine gewisse Oberaufsicht über das Photolabor ausübte.

Im Januar 1951 übergab der Geologische Dienst die Sammlung devonischer Fossilien und Gesteine der ehemaligen Preußischen Geologischen Landesanstalt an das Institut, um die Sammlung vor der Zerstreuung und Entwertung zu retten. Das Zoologische Institut stellte einen im Kriege ausgebrannten und sehr beschädigten Raum zur Verfügung, der nun ein Notfenster, einen Zementfußboden, Türen und Beleuchtung erhielt. Die Sammlung umfasste weit über hundert Doppelschränke, deren Inhalt teils geordnet, teils nur mit Feldetiketten versehen war. Die Schränke mussten in den folgenden Jahren zurückgegeben werden, so dass die Anschaffung neuer Schränke erforderlich wurde. Das Umsetzen der zahlreichen Schubladen verlangte nicht wenig Arbeit. Im Laufe der Jahre wurde die völlig verschmutzte Sammlung gereinigt, übersichtlich aufgestellt und in ein Verzeichnis aufgenommen. Diese beschwerliche und langwierige Arbeit der Ordnung führte vorbildlich Dipl.Geol. Jaeger durch. Gleichzeitig übergab der Geologische Dienst die paläobotanischen Samm- 
lungen (70 Schränke) an die Deutsche Akademie der Wissenschaften, wo 1952 die Arbeitsstelle für Paläobotanik gegründet wurde.

1952 konnte endlich an die Renovierung der Räume der Hauptsammlung gedacht werden, die in der Nachkriegszeit sehr unter den Einflüssen der Wassereinbrüche und der Witterung gelitten hatten. Wände und Decken mussten abgeklopft und neu verputzt werden, wobei die in den Schränken aufbewahrte Sammlung noch mehr verstaubte. Viel Arbeit und Mühe erwuchs in den folgenden Jahren aus der Aufgabe, die vielfach völlig zugequollenen Schränke zu renovieren und den Inhalt der Schubfächer zu säubern. Viele Etiketten mussten neu geschrieben werden, sofern sich die alten Etiketten überhaupt noch entziffern ließen.

Nach der Verglasung des Lichthofes im Jahre 1950, die im Zusammenhang mit der Unterbringung der großen Ausstellung „Unser Fünfjahresplan" in den damals noch teilweise leeren Räumen des Naturkundemuseums erfolgte, konnte an die Wiederherstellung des vielfach beschädigten und durch Jahre hindurch allen Witterungseinflüssen ausgesetzten Lichthofs geschritten werden. Im Jahre 1952 wurde der Lichthof an der Decke und am Gesims repariert, neu gestrichen und mit einem Staubdach versehen. Im Herbst 1952 stellten die Präparatoren Marquardt und Neubauer das Skelett des Riesensauriers Brachiosaurus in Rekordzeit wieder auf. Daran schlossen sich Restaurationsarbeiten am Gipsabdruck des Skelettes des Diplodocus und manche Änderungen in der Aufstellung der Vitrinen und der Platten aus dem Lias von Holzmaden. Der Lichthof konnte im Frühjahr 1953 wieder der Öffentlichkeit übergeben werden. Neu aufgestellt wurden in den folgenden Jahren im Lichthof: Skelett eines Nothosaurus aus dem Muschelkalk von Rüdersdorf bei Berlin, das aus dem Bestand des früheren Preußischen Geologischen Landesmuseums überwiesen worden war; ferner ein Skelett des Pareiasauriers Bradysaurus (1954, Leitung Prof. Janensch), Nachbildung des Kieferbogens des Riesenhaies Carcharodon megalodon (1954, Leitung Prof. Gross), Skelette von Plateosaurus und der ältesten Schildkröte, Proganochelys aus dem Keuper von Halberstadt (1956, Leitung Prof. Janensch). Im großen Schausammlungssaal des Paläontologischen Museums wurden die Skelette der Seekuh Halitherium aus dem Oligozän von Weinheim (1958, Leitung Prof. Dietrich) und des Bartenwals Balaenoptera aus dem Pliozän von Chile (1958, Leitung Prof. Dietrich) neu aufgestellt. Renoviert wurde 1954 der Knochenkeller, und das in ihm enthaltene Material wurde reduziert und neu geordnet.

Die geologische Abteilung ließ Renovierungsarbeiten in der Geologischen Schausammlung im Jahre 1953 durchführen. Im Auftrag von Prof. v. Bubnoff beendete Dipl.-Geol. Werner Neumann im Jahre 1954 die bereits 1937 begonnene Aufstellung des sogenannten „Tektonischen Zimmers", eines kleinen Nebenraums der Geologischen Schausammlung. Um dem weiterhin anhaltenden Platzmangel abzuhelfen, wurde 1956 der Boden des Südflügels als Sammlungsraum eingerichtet, wobei einige kleine Räume, z. T. mit Abzug versehen, zusätzlich für Laboratorien abgetrennt wurden. Auch für die Aufnahme der Wandkarten und Wandtafeln wurde ein kleiner Raum eingerichtet.

Leider konnte eine der wichtigsten Aufgaben der Wiederherstellung noch nicht durchgeführt werden, da die nötigen Mittel nicht freigegeben worden sind. Es handelt sich um den ausgebrannten großen Hörsaal des Instituts und seine Vorräume. 1953 wurde unter Leitung von Prof. Gross von Dr. Diebel, Dipl--Geol. Fahlbusch und Beauftragten der Universitätsbauleitung der Wiederaufbauplan bis zur letzten Schalterdose fertig gestellt und genehmigt. Der nach dem Kriege als Ersatzraum benutzte ehemalige Übungsraum war viel zu eng und akustisch sehr ungünstig, auch ist ein Hörsaal für die zahlreichen Vorlesungen und Übungen nicht ausreichend, ständig traten störende Überschneidungen auf.

Das Auseinanderstreben der beiden Abteilungen des Instituts und Museums in der Verwaltung und in der Arbeitsrichtung führte $1952 \mathrm{zu}$ Plänen einer verwaltungsmäßigen Trennung beider Abteilungen. Diese Pläne wurden in einer Denkschrift niedergelegt, jedoch entschloss sich Prof. v. Bubnoff erst 1957 zu ihrer Unterzeichnung. 1961 wurde diese Denkschrift dem Rat der Mathematisch-Naturwissenschaftlichen Fakultät vorgelegt und von ihm einstimmig gebilligt. Demnach sollen beide Abteilungen als selbstständige Institute gelten; ein Geologisches Institut und ein Paläontologisches Institut und $\mathrm{Mu}-$ seum.

Die Arbeitsrichtung, die v. Bubnoff persönlich verfolgte, war nicht an die besonderen Verhältnisse des Berliner Instituts gebunden. Viele seiner Berliner Schüler - der heutigen Studienordnung entsprechend weit mehr Diplomanden als Doktoranden - arbeiteten in der gleichen Richtung und haben sich mit den besonderen petrotektonischen Untersuchungsmethoden vertraut 
gemacht. Die Arbeitsrichtung der geologischen Abteilung war rein geologisch, besonders petrotektonisch.

In der paläontologischen Abteilung wurden nach wie vor besonders die Paläontologie der Wirbeltiere gepflegt: niedere Wirbeltiere, Säugetiere und Reptilien. Dazu traten intensive Untersuchungen an Graptolithen, an Conodonten und anderen Mikrofossilien, womit eine große $\mathrm{Zu}$ nahme des Sammlungsbestandes verbunden war. Das mikropaläontologische Laboratorium wurde modern und vielseitig ausgebaut, die Sammlung mikropaläontologischer Objekte, die nach der Stellung im System geordnet wurden, wuchs beträchtlich. Damit erweiterte sich zunehmend die Grundlage für das mühselige Bestimmen der Mikrofossilien aus den ständig anfallenden Proben. Die Anlage von Vergleichssammlungen, die Bildkarten und Literaturkarteien dienten ebenfalls diesem Zweck.

Eine kurze Würdigung v. Bubnoffs soll folgen. Die Lebensdaten und die akademische Laufbahn: geboren am 15.7.1888 in St. Petersburg, gestorben am 16.11.1957 in Berlin; 1912 Promotion in Heidelberg; 1921 Habilitation in Breslau; 1929-1950 Ordinarius für Geologie und Paläontologie in Greifswald; $a b \quad 1.10 .1950$ Ordinarius in Berlin; emeritiert am 1.9.1957 (Deubel 1958, Stille 1958).

Mit v. Bubnoff folgte einer der bedeutendsten Geologen Deutschlands der Berufung auf den Lehrstuhl für Geologie an der Berliner Universität. Seine zahlreichen Werke über regionale Geologie (z. B. Bubnoff 1930, 1952) haben seinen Namen weit über die Grenzen Deutschlands hinaus bekannt gemacht. Als Forscher hat sich von Bubnoff schon mit frühen Arbeiten nach dem ersten Weltkrieg über das von ihm immer behandelte Thema der Genese und Tektonik magmatischer Körper (z. B. Bubnoff 1928) einen hervorragenden Ruf erworben. Viele Schülerarbeiten hat er in dieser Richtung angeregt und gefördert. Zunehmende Schwerhörigkeit hinderte ihn immer mehr an Feldarbeiten und Geländeuntersuchungen. Sein Interesse wandte sich deswegen auch in zunehmendem Maße einer systematischen Betrachtungsweise und zugleich erwuchsen einerseits Werke größter Gelehrtenarbeit, die eine überreiche Stoffmenge mit Ideen erfüllte und einheitlich und persönlich darstellte, andererseits entstanden Arbeiten, die der Analyse der Grundfragen und der erkenntnistheoretischen Basis der Geologie galten. Die vielen Bücher über die regionale Geologie kennzeichnen die eine Seite seiner Arbeitsrichtung, das
Werk „Grundprobleme der Geologie“ die andere (Zusammenstellung der wissenschaftlichen Arbeiten siehe Illner 1958). Damit stellte sich v. Bubnoff mitten in die modernste deutsche Geologie, die er entscheidend beeinflusste, zu deren führenden Köpfen er gehörte. Dabei hat er immer engen Kontakt mit seinem Geburtsland Russland gehalten.

Als Lehrer interessierten v. Bubnoff vielfach Fragen des Unterrichtes. Diesem Interesse entsprang seine verdienstvolle Tätigkeit als Lehrbuchverfasser. Seine zweibändige ,Einführung in die Erdgeschichte" (Bubnoff 1949) ist nicht nur ein Lehrbuch für die Studierenden, sondern auch für die Dozenten. Sein Unterricht war didaktisch nicht ganz so ausgewogen wie der seines Vorgängers, die Fülle des Gebotenen verursachte den Aufnehmenden so manche Mühe. Besonders erwähnt sei v. Bubnoffs ungewöhnliche Vielseitigkeit, die in dem von ihm geleitetem Kolloquium immer wieder die Bewunderung der Teilnehmer hervorrief. Die neuartigsten Betrachtungsweisen und Untersuchungsmethoden waren ihm ebenso vertraut wie die neuesten Ergebnisse der Forschung. Die Literaturkenntnis war geradezu umfassend.

Als Institutsdirektor trat von Bubnoff wenig hervor. Alle Verwaltungsaufgaben, alle Sorgen um den Sach- und Personalhaushalt, um Bauen und Einrichten waren ihm fremd und unangenehm, besonders bei der zunehmenden Komplizierung dieser Aufgaben. Hier überließ er gerne weitgehend anderen das Feld der Betätigung und die Übernahme der Verantwortung. Prof. v. Bubnoff war menschlich und gütig, sobald ihm persönliche Schwierigkeiten der Schüler und Mitarbeiter vorgetragen wurden. Die Schwerhörigkeit behinderte das Wahrnehmen solcher Nöte und die unmittelbare Teilnahme. Als fast verschlossener, schweigsamer und bescheidener Vorgesetzter, der ein wenig über den Dingen schwebte, bleibt er im Gedächtnis der Kollegen, Mitarbeiter und Schüler. Von Bubnoff hat die Tradition der großen Geologen an der Spitze des Berliner Instituts würdig fortgesetzt und das Ansehen des Instituts erhalten.

\section{Direktorat Gross (i.V. 1957 bis 1961)}

Nach dem Tod von v. Bubnoff übernahm Prof. Dr. Gross kommissarisch die Leitung des gesamten Instituts, da sich die Suche nach einem Nachfolger für den Lehrstuhl für Geologie sehr schwierig gestaltete. Gross war mit dem Institut 
zeitlebens eng verbunden. Er war bestrebt der Paläontologie am Institut gegenüber der Geologie mehr Gewicht zu geben. So hat er 1952 ein Memorandum verfasst, das die Trennung der beiden Richtungen unter einem Dach vorsah. Dies wurde von v. Bubnoff 1957 gegengezeichnet und 1961 von der Mathematisch-naturwissenschaftlichen Fakultät befürwortet.

Die Lehre lief mit demselben Stab weiter. Prof. Dr. W. Gross vertrat weiterhin die Paläozoologie, Dr. R. Daber die Paläobotanik, Prof. Dr. E. Kautzsch die angewandte Geologie, Prof. Dr. M. Trénel die Bodenkunde und Dr. G. Siemens die Geophysik. Auch Prof. Dr. F. Solger setzte seine Lehrtätigkeit über das Quartär Europas fort. Dozent Dr. K. Schmidt übernahm die Hauptvorlesung in Geologie, später Dozent Dr. Schwan, der ein breites Spektrum an Vorlesungen anbot von der Mikropaläontologie bis zur Tektonik. Dr. Schwan wechselte mit den Studenten zwischen den Instituten in Ost- und WestBerlin (Freie Universität).

An der Besetzung des Instituts änderte sich wenig. Dr. K. Schmidt blieb Oberassistent, und die Dipl.-Geologen S. Diener, H. Jaeger, F. Schust und H.-J. Teschke, sowie Dr. E. Schroeder blieben Assistenten. Ende 1957 wechselten Dr. Schroeder und Dipl.-Geol. Teschke an das Geotektonische Institut der Deutschen Akademie der Wissenschaften und Ende 1958 Dipl.-Geologe F. Schust ins Zentrale Geologische Institut; neue Assistenten wurden die Dipl.-Geologen Siegfried Chrobok und Ernst Schlegel und 1960 Jochen Helms und Rudolf Meier, gleichzeitig wurde S. Chrobok Oberassistent. Im Jahre 1957 habilitierten Dr. K. Schmidt und Dr. R. Daber. Auch die Zahl der technischen Angestellten änderte sich nicht, obwohl zum Teil ein häufiger Wechsel durch Abwanderung in den Westen zu beobachten war.

Ein ganz besonderes Ereignis war die Rückkehr der paläontologischen Originale aus Leningrad Ende des Jahres 1958 (Diebel 1960). Es handelte sich um 38 Kisten mit etwa 7400 Fossilien. Die Fossilien befanden sich in gutem $\mathrm{Zu}-$ stand, sogar die Etiketten waren zum Teil restauriert. Es wurden dabei auch Originale, die ursprünglich in den Sammlungen des Preußischen Geologischen Landesamtes befanden, mit den Sammlungen (rheinisches Devon, Sedimentärgeschiebe und Säugetiere) vereint, die seit 1950 an das Paläontologische Museum übergeben worden waren.

1959 tagte die deutsche Paläontologische $\mathrm{Ge}$ sellschaft im Museum für Naturkunde (Abb. 8);

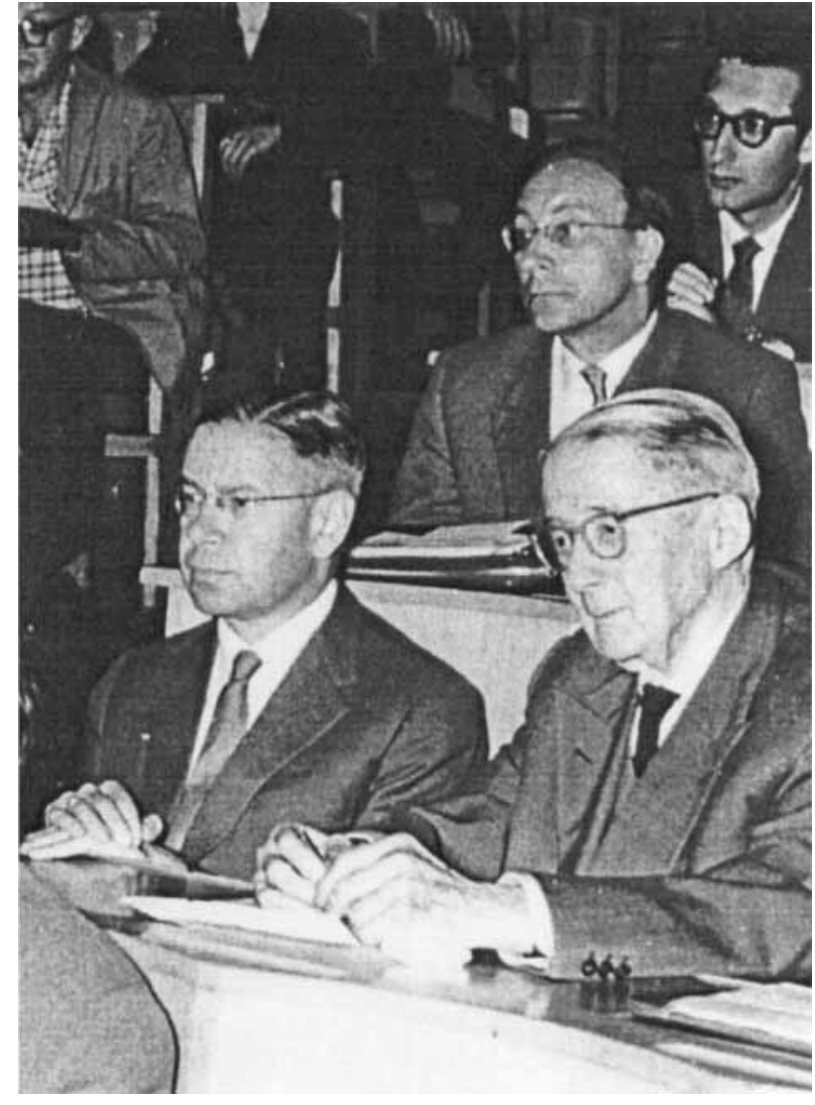

Abb. 8. Prof. Dr. W. Gross und Prof. Dr. H. Stille auf der Tagung der Paläontologischen Gesellschaft in Berlin im August 1959 (Aufnahme im Museum für Naturkunde).

dies war die letzte gemeinsame Tagung der deutschen Paläontologen für lange Zeit. Verbindungen mit Kollegen in Westdeutschland wurden bald danach untersagt. Erst kurz nach der Wiedervereinigung fand $1992 \mathrm{im}$ Institut wieder eine Tagung der deutschen Paläontologischen Gesellschaft im Hause statt.

Hier soll nur eine kurze Würdigung von W. Gross gegeben werden, eine ausführliche ist von Schultze (1996, siehe auch Schultze 1974) publiziert worden. Walter Roland Gross (Abb. 9): geboren am 20.8.1903 in Katlakaln bei Riga, gestorben am 9.6.1974 in Tübingen; Dr. phil. 1929 in Berlin bei Pompeckj; apl. Assistent 1932; 1934-1937 Assistent an der Universität Frankfurt a. M.; 1935 Habilitation und 1936 Dozent in Frankfurt; 1937 Rückkehr nach Berlin als Assistent und Dozent; 1943 a. o. Professor; 1944 Direktor der Paläontologischen Abteilung, 1943-1946 Offizier und Kriegsgefangener; ab 1950 o. Professor und Direktor der Paläontologischen Abteilung; 1957-1961 kommissarischer Direktor des Geologisch-Paläontologischen Instituts; 1961 während eines Besuchs der Ausgrabung am Monte San Giorgio, Tessin, abgeschnitten vom Institut durch den Bau der Mauer; ab 


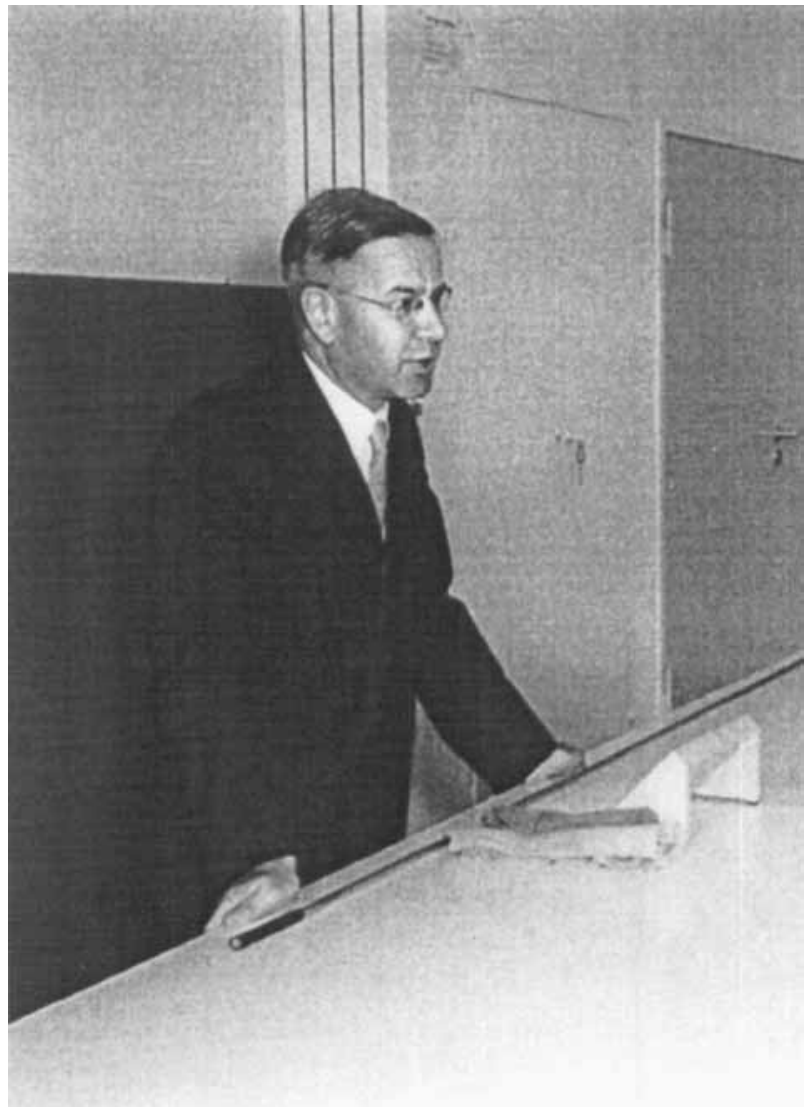

Abb. 9. Prof. Dr. W. Gross auf der Tagung der Paläontologischen Gesellschaft in Berlin am 26. 8.1959 (Aufnahme Prof. Dr. P. Siegfried $\dagger$, damals Münster).

1961 am Geologisch-Paläontologischen Institut in Tübingen, 1962-1969 als o. Professor für Wirbeltierpaläontologie und Direktor. Prof. Gross hatte ein breites Wissen nicht nur in der Paläontologie, sondern ebenfalls in der Zoologie, was in den Vorlesungen stark zu tragen kam. Er war für seine sachliche und unvoreingenommene Urteilskraft bekannt. So wies er auch Studenten auf Verhaltensweisen von Kollegen hin, damit sie nicht in Schwierigkeiten gerieten. Er selbst führte einen sehr geregelten Tagesablauf, hielt immer die gleichen Zeiten ein. Sein Arbeitstisch war immer übersichtlich geordnet und am Abend zum Arbeitsschluss völlig geleert. Während er der Ideologie des Dritten Reichs positiv gegenüber stand, lehnte er das kommunistische System ab. Als „Entschuldigung“" wurde ihm angerechnet, dass sein Vater von den Bolschewiki 1919 umgebracht worden war. Er versuchte, die Qualität des Instituts zu erhalten und Leute von der Abwanderung in den Westen abzuhalten. Als er dann selbst im Westen war, hatte er das Gefühl, seine Leute allein gelassen zu haben. Mit seinem Fortgang hatte das Institut seinen weltweit bekannten Paläontologen verloren.

\section{Die Zeit von 1961 bis 1994}

War schon nach dem Tode v. Bubnoffs kein neuer Ordinarius ernannt worden, so folgte auf den Mauerbau bis 1994 eine Zeit abwechselnder Leiter des Geologisch-Paläontologischen Instituts bzw. ab 1969 des Bereiches Paläontologisches Museum aus den Mitgliedern des Instituts.

Durch den Mauerbau 1961 waren die Mitglieder des Instituts, die im Westen Berlins wohnten, von ihrer Arbeitsstelle abgeschnitten. Neben Prof. Gross, der mit seiner Familie zu dem Zeitpunkt gerade in der Schweiz war, waren dies Prof. Dr. Schwan, der über Münster nach Erlangen ging, und die Präparatoren Marquardt und Neubauer. Erst 1964 konnte wieder ein Präparator, Hans-Hartmut Krueger, gefunden werden. Dr. Janensch konnte sein Lebenswerk (Gross 1970, Jaeger 1971) an den Dinosauriern von Tendaguru abschließen, da er einen Passierschein erhielt.

Eilig wurden alle Kräfte für die Lehre zusammengezogen, um die Ausbildung der Studenten aufrecht zu erhalten. Die promovierten und diplomierten Wissenschaftler des Instituts sprangen alle ein, so dass ein reichhaltiges Angebot präsentiert werden konnte. Die Dipl.-Geologen Ahrens und Beyer lasen im Herbstsemester 1961 die Allgemeine Geologie, Prof. Dr. Kautzsch die Ingenieurgeologie, die Lagerstättenkunde und in den folgenden Jahren auch die Allgemeine Geologie, Dr. Möbus die Geologie Mitteleuropas, Dipl.-Geologe Teschke die Geologie der Sowjetunion, Dr. Hyde die Geologie von Afrika, Dr. Schroeder Historische Geologie, Dipl.-Geologe Diener Sedimentpetrographie und Dipl.-Geophysiker Zeuch die Geophysik. Die Paläontologie wurde von Prof. Dr. Daber (Paläobotanik und Kohlenkunde), Dr. Helms (Paläontologie der Wirbellosen), Dr. Jaeger (Biostratigraphie), Dr. Diebel (Mikropaläontologie), und Dr. Peters, einem Zoologen aus dem Institut für Spezielle Zoologie und Museum, (Paläontologie der Wirbeltiere) vertreten. Vom Nachbarhaus, dem Zentralen Geologischen Institut, halfen aus: Dr. Krutzsch mit Sporenpaläontologie und Geologie der Braunkohle, Prof. Dr. Kölbel mit Geotektonik und Dr. Dittrich mit Geodäsie. Außerdem las Prof. Dr. Herneck Geschichte der Geologie und Paläontologie. Auch der über 80-jährige Prof. Solger erhielt einen Passierschein, so dass er weiterhin Quartärgeologie lesen und Exkursionen durchführen konnte.

Die Teilung des Geologisch-Paläontologischen Instituts und Museums in zwei selbstständige In- 
stitute, das Institut für Geologie mit Prof. Eberhard Kautzsch und das Institut für Paläontologie und Museum mit Prof. Rudolf Daber als Direktor, erfolgte 1962. Die beiden Institute existierten bis zur Auflösung der Geologie/Paläontologie als Ausbildungsfach der Humboldt-Universität mit der III. Hochschulreform der DDR im Jahre 1968. Geologie wurde als Nebenfach danach in der Sektion Geografie im Ortsteil Wendenschloß in Berlin-Köpenick weitergeführt.

Im Jahre 1968 wurde die Arbeitsstelle Paläobotanik der Deutschen Akademie der Wissenschaften aufgelöst und mit dem Paläontologischen Institut und Museum vereint. Damit kamen die großen Sammlungen aus den ehemaligen Steinkohlenrevieren von Schlesien bis zum Saarland ins Museum; diese waren bis 1951 im Zentralen Geologischen Institut, im Nachbarhaus, gewesen. Prof. Gothan hatte sie noch in die Akademie gerettet, wo sie von Herrn Dr. Remy von 1955 bis 1961 und von Prof. Dr. Daber von 1962 bis 1968 betreut worden waren. Es handelte sich um Sammlungen des Paläo-, Mesound Känophytikums. Aber bevor die Karbonpflanzen in den „Karbonsaal“, den zerstörten großen Hörsaal Stille's, einziehen konnten, musste dieser von den Resten der Übernahme der Haustiersammlung der ehemaligen Landwirtschaftlichen Hochschule (siehe oben: NehringSammlung) und der 1962 übernommenen Pleistozän-Sammlung aus dem Märkischen Museum geräumt werden. In den Jahren 1992 bis $1995 \mathrm{ka}$ men osteologische und quartäre Sammlungen aus dem Museum für Vor- und Frühgeschichte im Schloss Charlottenburg an das Institut.

Zwischen 1969 und 1970 wurde die Rühle von Lilienstern-Sammlung als Schenkung an das $\mathrm{Mu}-$ seum (Böhme 1993) übernommen. Der theropode Dinosaurier Liliensternus (= Halticosaurus) ist das herausragende Stück der Sammlung, Weiterhin umfasst die Sammlung Pflanzenfossilien aus dem Keuper, eine Fährtenplatte von Hildburghausen, einen Mastodonsaurus-Schädel, Plateosaurus, Ichthyosaurier, Branchiosaurier, Zechstein-Fische und zahlreiche Invertebraten. Nach der Wiedervereinigung wurde von der Familie Rühle von Lilienstern ein Antrag auf Rückübertragung der Sammlung gestellt. Dieser wurde nach mehreren Gerichtsverfahren vom Bundesverwaltungsgericht im Februar 2000 abgelehnt.

Nach der Auflösung des Lehrganges für Geologie und Paläontologie, und des Wechsels der Mineralogie in die Physik bestand für die Vertreter dieser Arbeitsrichtungen ein Vakuum, das durch die Gründung eines Museums für Natur- kunde am 25.2. 1969 aufgefangen wurde. Es war dies die zweite Gründung des Museums für Naturkunde nach 1889. Es bestand keine zentrale Verwaltung, nicht einmal Räumlichkeiten für einen Direktor und Sekretariat. All das musste erst geschaffen werden. Frühere Verwaltungsdirektoren des Museums waren jeweils Professoren der einzelnen Institute gewesen. Trotz der Gründung des Museums blieben durch die Aufteilung in Bereiche die alten Strukturen räumlich und mental erhalten. Direktoren des Bereiches Paläontologisches Museum waren 1969-1970 Rudolf Daber, 1970-1975 Hermann Jaeger, 1976-1978 Manfred Barthel, 1978-1986 Jochen Helms und 1987-1990 wieder Rudolf Daber. Im Jahre 1986 vertrat Dr. Böhme den schwer erkrankten Dr. Helms. Nach der Wiedervereinigung übernahm 1991 Hermann Jaeger bis zu seinem frühen Tod im Jahre 1992 die Leitung, danach von 1992 bis 1994 Wolf-Dieter Heinrich. Der Personalbestand des Bereiches Paläontologisches Museum umfasste 1969 (Abb. 10) unter der Leitung von Prof. Daber den Kustos und Dozenten Dr. Hermann Jaeger, den Kustos Dr. Diebel, die wissenschaftlichen Mitarbeiter (Kustoden) Dr. Karlheinz Fischer, Dr. Jochen Helms, Dr. Helmut Jähnichen und ab 1971 Dr. Rolf Herrmann als Kustos für die geologischen Sammlungen, außerdem die Aspiranten Dr. W.-D. Heinrich, Dr. S. Locker und Dr. E. Pietrzeniuk. H.-H. Krueger war der einzige Präparator. Dazu kamen aus der Arbeitsstelle Paläobotanik der Deutschen Akademie der Wissenschaften die wissenschaftlichen Mitarbeiter (Kustoden) Dr. Manfred Barthel, Dr. Reinhold Litke und Dr. Ludwig Rüffle.

1978 wurde Hans-Hartmut Krueger zum Chefpräparator ernannt; ihm unterstanden ab 1980 Frau Evelin Stenzel und Herr Lutz Berner als Präparatoren. Frau Stenzel war seit 1972 als technische Angestellte und Herr Berner seit 1975 als Sammlungspfleger am Museum. Beide nahmen an der Präparatorenausbildung, einer als Fernstudium am Museum über vier Jahre dauernden Präparatorenfortbildung, teil. Diese Präparatorenschule existierte bis zur Wiedervereinigung. Von Herrn Krueger wurden 1978 vor der Herstellung einer neuen Abgussform des Urvogels die Krallen der Vorderextremität freigelegt (Fischer \& Krueger 1979).

Außerdem waren im Bereich Paläontologisches Museum Joachim Steinmann als Photograph (ab 1975 Klaus Imlau), Karl Ix (1948-70), Karl-Hermann Haupt (1953-72), Renate Brauner (1969-81) und Ulrike Lange (1982-92) als 

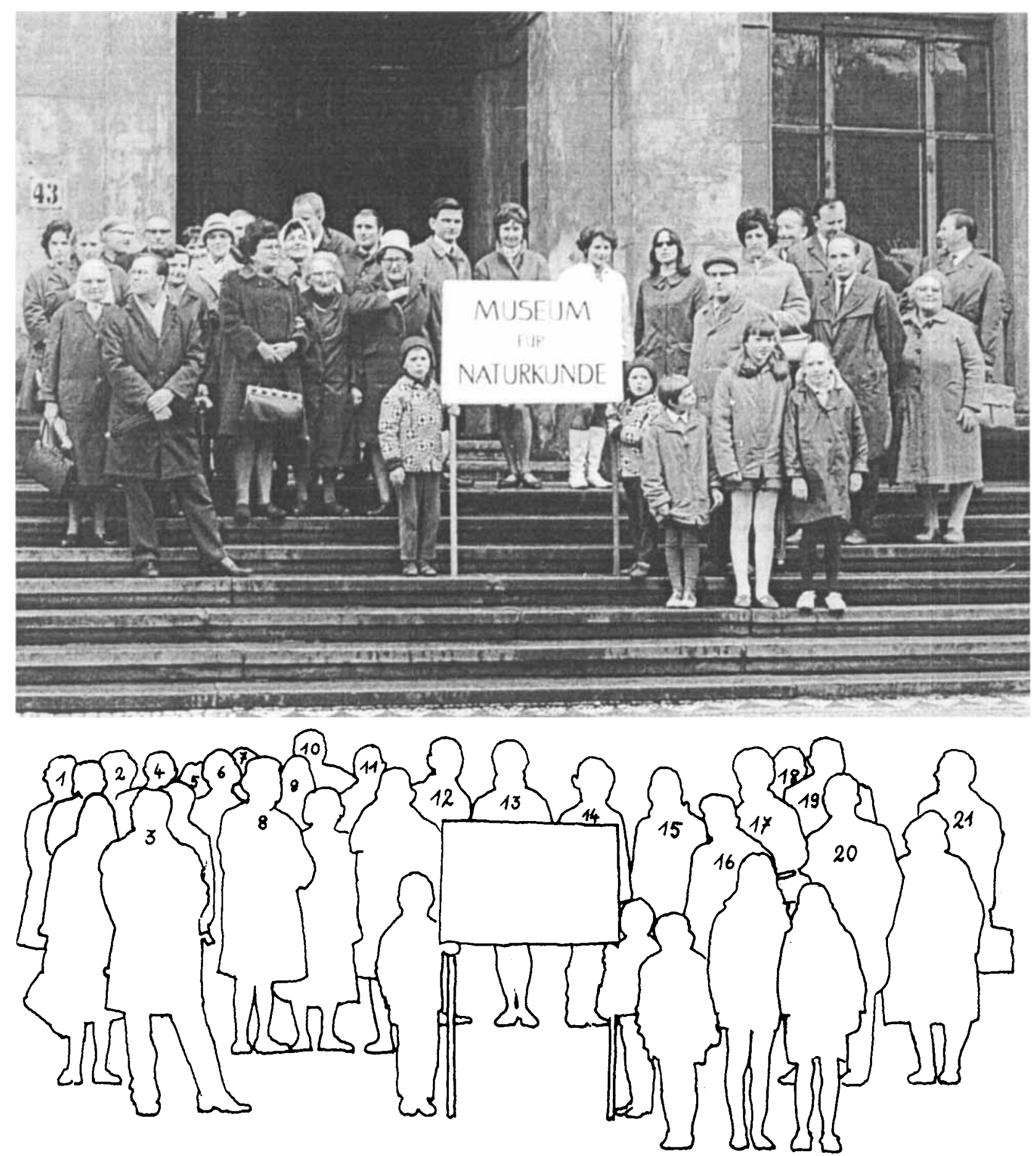

Abb. 10. Die Belegschaft des Bereiches Paläontologie mit Reinigungspersonal und Kindern am 1. Mai 1969 vor dem Haupteingang des Museums für Naturkunde. 1. R. Sanow (Laborangestellte Mikropaläontologie), 2. Dr. K. Diebel (Kustos Mikrofossilien), 3. Dr. M. Barthel (Kustos Paläobotanik), 4. H. Kroll (Laborant Paläobotanik), 5. Frau K. Paech (Mikropaläontologie), 6. Frau H. Kroll (Sammlungshelferin), 7. Dr. R. Litke (Kustos Paläobotanik, verdeckt), 8. Frau U. Strass (Sekretärin), 9. I. Schilling (Sammlungspflegerin), 10. Dr. W.-D. Heinrich (Aspirant Wirbeltierpaläontologie), 11. Dr. L. Locker (Aspirant Mikropaläontologie), 12. Dr. J. Helms (Kustos Invertebratenpaläontologie), 13. Frau Helms, 14. Frau R. Brauner (Graphikerin), 15. Frau Ch. Alten (Bibliothekarin), 16. Dr. L. Rüffle (Kustos Paläobotanik), 17. Frau Daber, 18. Dr. H. Jähnichen (Kustos Paläobotanik). 19. Prof. Dr. R. Daber (Direktor), 20. G. Böhme (wiss. Sekretär), 21. Dr. H. Jaeger (Kustos Invertebratenpaläontologie) (es fehlen: H.-H. Krueger, Präparator, Dr. Kh. Fischer, wiss. Mitarbeiter, und Dr. E. Pietrzeniuk, Aspirantin). (Aufnahme Fotograf Steinmann).

Graphiker, Emma Rogmann (1958-77), Helene Kroll (nur 1969), Serpentina Scheffel (1969-74, 1981-heute), Pia Rangnow (1972-90), Karola Ulrich (1977-99) und Cornelia Hiller (1987-heute) als Sammlungshelferinnen/Konservatoren und Jürgen Japs (1980-heute) und Klaus Klups $(-2000)$ als Konservatoren/Sammlungshelfer, Ruth Sanow (1954-92) und Frau 
Helga Voß (1963-91) als Laborantinnen und Ingeborg Schilling schon seit 1955 als technische Kraft und Ursula Straß als Sekretärin tätig. Bis in die siebziger Jahre hatte das Institut noch seine eigenen Reinigungskräfte, so dass täglich gereinigt wurde und die Vitrinen in den Sammlungsräumen geputzt wurden. Danach wurde die Arbeit von Reinigungsfirmen übernommen und reduziert bis auf ein Mal in der Woche in den Arbeitsräumen und auf ein Mal im Vierteljahr in den Sammlungen.

Die wissenschaftlichen Aktivitäten waren während dieser Jahre auf das Gebiet der DDR begrenzt und wurden durch zahlreiche politische Fortbildungskurse unterbrochen. Dennoch wurde international herausragende Arbeit geleistet, wie es das Beispiel Pisede zeigt. Nach Vorerkundungen in den Jahren 1966-1968 erfolgten vom Sommer 1968 bis 1971 die Ausgrabungen der fossilen Tierbauten in Pisede unter der Leitung von Dr. K. Diebel (1968-70) und Dr. W.-D. Heinrich (1971) in Mitarbeit mit den Paläontologen Dr. S. Locker und Dr. E. Pietrzeniuk, dem Quartärgeologen und Bodenkundler Dr. K.-D. Jäger, den Zoologen Prof. Dr. G. Peters und Dr. P. Beurton, den Präparatoren H.-H. Krueger und D. Matzke, der Photographin V. Kopske und den beiden Sekretärinnen K. Reineck und I. Schilling (Heinrich 1975). Die Füllungen der Tierbauten stammten aus dem späten Weichsel-Glazial und der holozänen Warmzeit. Die wissenschaftlichen Ergebnisse wurden in drei Sammelbänden der Wissenschaftlichen Zeitschrift der HumboldtUniversität $\mathrm{zu}$ Berlin, Mathematisch-Naturwissenschaftliche Reihe $[24$ (5, 1975), 26 (3, 1977) und $32(6,1983)$ ] publiziert.

Auch Dr. H. Jaeger, der international bekannteste Wissenschaftler des Bereiches, arbeitete hauptsächlich in der DDR, meist in Thüringen (Helms 1995). Da er ein weltweit bekannter Biostratigraph des oberen Silurs und unteren Devons war, hatte er aber die Möglichkeit zu vielen Reisen ins Ausland, die von Institutionen in Australien, Kanada, Schweden u. a. bezahlt wurden. Natürlich war er während dieser Zeiten von seiner Familie getrennt, die in Berlin zurückbleiben musste. Er brachte über die Jahre eine reichhaltige Graptolithen-Sammlung aus dem Silur/ Devon der ganzen Welt zusammen.

Daneben gab es für einige Mitarbeiter die Möglichkeit, in befreundete kommunistische Staaten zu reisen. 1967 unternahm Dr. Kh. Fischer mit Herrn H.-H. Krueger eine wirbeltierpaläontologische Expedition nach Kuba, wo sie pleistozäne Säuger (Fischer 1971) und Vögel (Fi- scher \& Stephan 1971) in Karsthöhlen von WestKuba (Pina del Rio) sammelten. In den Jahren 1983 bis 1986 war Prof. Daber mit seiner Frau in Mosambik.

Die Sammlungen des Museums waren Gästen aus dem Westen offen, eine inoffizielle interne Regelung. Dennoch war der internationale Austausch gering. So war die Organisation des Gedenkkolloqiums zum 100sten Geburtstag von W. O. Dietrich durch Dr. Heinrich vom 3.-5. 9. 1981 der Versuch, das Institut im Bewusstsein der internationalen Wissenschaftsgemeinschaft $\mathrm{zu}$ halten. Teilnehmer kamen aus Frankreich, Österreich, Polen, der Tschechoslowakei, der UdSSR, Ungarn und aus Westberlin und Westdeutschland. Die beiden Bände der Beiträge (Heinrich 1982, 1983) zeigen eine noch viel breitere internationale Resonanz.

Die Ausstellung wurde versucht im Sinne der Volksbildung zu gestalten. Das betraf vor allem die Entwicklung des Menschen. Dieser stark politisch ausgerichtete Ausstellungsteil wurde erst im Jahre 2000 durch eine moderne Darstellung der Entwicklung des Menschen ersetzt. Die Ausstellung „Tektonik" wurde Ende der 60er Jahre und die Ausstellung „Historische Geologie“" (siehe oben) nach dem Brand 1982 für immer geschlossen. Die Räumlichkeiten wurden im Jahre 2000 restauriert und mit einer Sonderausstellung der Vertretung Hessens in Berlin über die eozänen Fossilien von Messel (19.1.-29.4. 2001) wieder eröffnet, bevor sie in eine Nutzung als Cafeteria überführt wurden. Der Saal 2 (Paläontologie) erfuhr in den 70er und 80er Jahren einige Umgestaltungen. Im Mittelgang wurde eine Vitrinenreihe mit einer stratigraphisch angeordneten Paläobotanik-Ausstellung von den $\mathrm{Pa}$ läobotanikern des Bereiches, Barthel, Daber, Jähnichen, Rüffle und Süss 1983/84 eingefügt. Auf der Westseite des Saales (Wirbeltiere) wurde 1984 eine Präparationsvitrine eingerichtet, die die Arbeiten an der Grabungsstelle Pisede zeigt. In den Ausstellungen der fossilen Fische (ursprünglich von Prof. Gross in den 50er Jahren aufgebaut), der fossilen Amphibien und Reptilien wurden auch ab 1984 Änderungen vorgenommen. Hinzugefügt wurde 1971 von Dr. Heinrich, Dr. Jaeger und Herrn Krueger eine Darstellung der Pferdereihe und 1972/73 die Brontotherien und Nashörner. Es folgte der Aufbau der Artiodactylen (1976) und Elefanten (1978) an der Stirnseite des Saales. Davor blieb das 1958 von Dr. W. O. Dietrich und den Präparatoren G. Neubauer und E. Siegert aufgestellte Walskelett stehen. Das Gürteltier, 1904 
aufgestellt von Dr. Janensch, wurde in den 80er Jahren von Herrn Krueger neu montiert. Auf der Ostseite des Saales 2 wurde für die Torrell-Tagung 1975 (100 Jahre Glazialtheorie im Gebiet der skandinavischen Vereisungen; Veranstalter: Gesellschaft für Geologische Wissenschaften der DDR) eine Eiszeit-Ausstellung mit Fossilien aus Geschieben (verantwortlich Dr. Locker und Herr Krueger) und Fossilien des Rixdorfer Horizonts (verantwortlich Drs. Heinrich und Fischer) aufgebaut. Ein Teil der Geschiebeausstellung blieb erhalten, während die Vitrinen davor in den 80er Jahren von einzelnen Kustoden mit einer systematischen Ausstellung von Fossilien bestückt wurden. So war Dr. Jaeger für Trilobiten, Graptolithen, Brachiopoden und Bryozoen zuständig, Dr. Helms für Cephalopoden und andere Mollusken und Frau Dr. Pietrzeniuk für Echinodermen und Arthropoden. Entsprechend der Vielzahl der Gestalter entstand eine sehr unterschiedliche Ausstellung.

Während der Rekonstruktion der Heizung entstand am 3.2. 1982 ein Brand im dritten Obergeschoss des Paläontologischen Museums (Abb. 11). Arbeits- und Sammlungsäume sowie das Photolabor wurden zerstört, aber nur Teile der
Sammlungen (Gesteinsanschliffe von K. Schmidt und Teile der Pisede-Aufsammlungen) gingen verloren. Das Löschwasser gefährdete viele Sammlungsteile. Die Ehrenberg-Sammlung konnte noch an demselben Tag aus dem dritten Geschoss entfernt und die Schränke und Schubläden geöffnet werden, um der Feuchtigkeit Herr zu werden. Das Löschwasser war durch die Stockwerke hinunter bis in den Keller gelangt, so dass in allen Sammlungen gegen die Wassereinwirkungen vorgegangen werden musste. Der Abbruch und der Wiederaufbau begannen fast unmittelbar nach dem Brand, so dass einige Mitarbeiter sogar vor der offiziellen Bauübergabe am 9.11.82 in ihre Zimmer einziehen konnten. Weitere Restaurationsarbeiten im zweiten Stock und im Sauriersaal zogen sich bis Ende 1883 hin. Die Ausstellungen waren während der gesamten Zeit geschlossen.

Eine große Unruhe brachte der Beschluss, die Tendaguru-Dinosaurier und den Urvogel für eine Ausstellung in Japan außer Haus zu geben, in den Bereich Paläontologisches Museum. Dennoch wurde das Vorhaben ausgeführt. Bereits 1983 waren Prof. Barthel und Herr Krueger nach Japan gereist, um die Verträglichkeit von Konser-

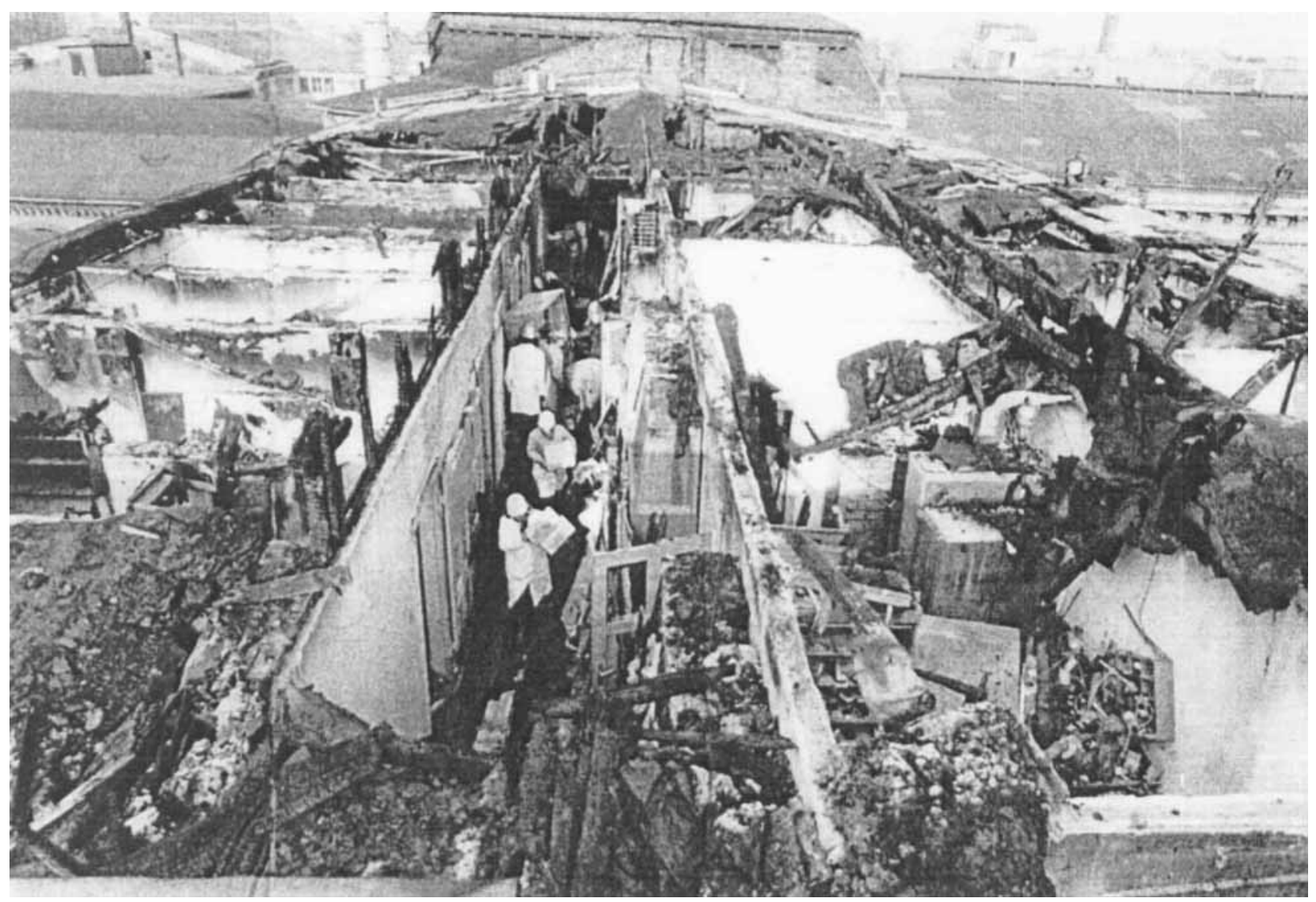

Abb. 11. Blick auf den Ostteil des dritten Obergeschosses nach dem Brand am 2. 2. 1982 (Blickrichtung nach Norden). (aus ..Neue Berliner Illustrierte" vom März 1982). 


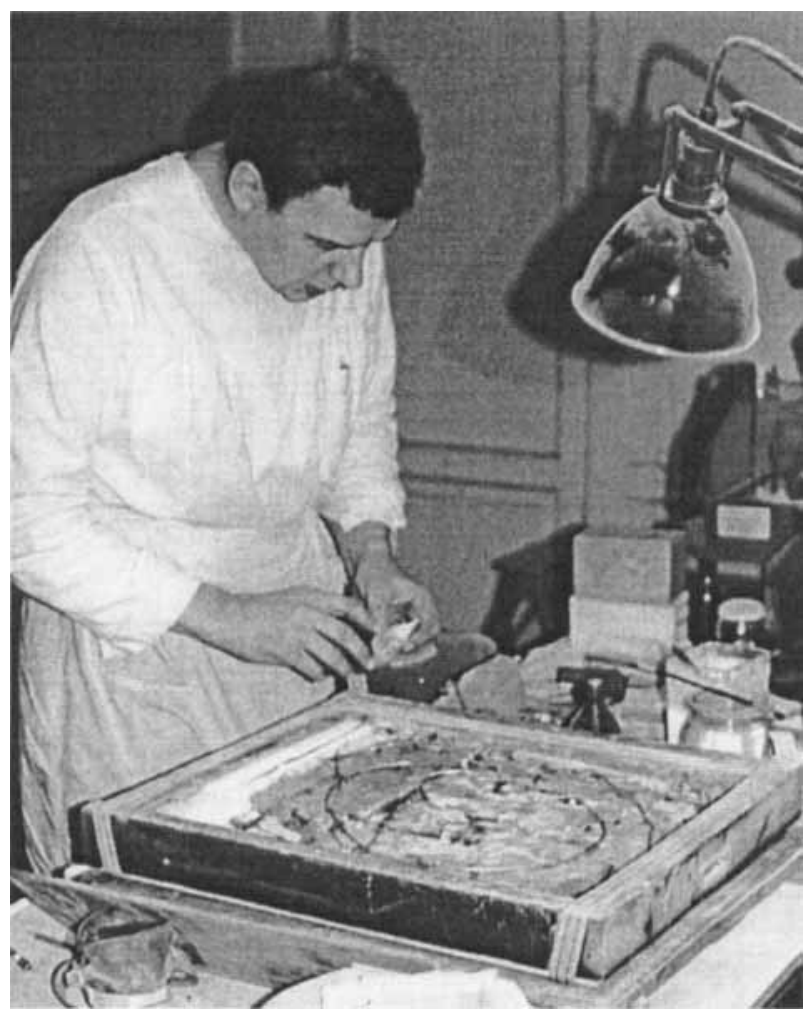

Abb. 12. H.-H. Krueger bei der Neukonstruktion des Gipsbettes des Urvogels, Archaeopteryx, Einlegen der Kupferspirale (März 1984). (Aufnahme Prof. Barthel).

vierungs- und Klebemitteln mit den früher für die Saurierknochen benutzten zu testen. Das Gipsbett der Archaeopteryx wurde für den Transport erneuert (Abb. 12) und verstärkt. Im März und April 1984 wurden die Fossilien dann verpackt und nach Japan verschifft. Anfang Mai flogen Dr. Böhme und Herr Krueger nach Tokyo, um den Aufbau zu überwachen. Die Ausstellung wurde am 7.7.84 eröffnet und lief bis zum 14. 10. 84. Es wurden 610915 Besucher gezählt. Dr. Böhme und Herr Krueger waren während der gesamten Zeit in Japan und flogen nach Abbau und Verpackung der Dinosaurier Anfang November nach Berlin zurück. Zu Beginn des Jahres 1985 wurden die Ausstellungen in Berlin wieder eröffnet, und die Dinosaurier waren wieder im Museum für Naturkunde zu sehen.

Die wissenschaftliche Arbeit war während der ganzen Jahre weitergegangen, oft unter sehr erschwerten Bedingungen, da keine Mittel für Restaurationsarbeiten der Räume und zur Anschaffung von Geräten zur Verfügung standen. Man gewöhnte sich daran, so lange die eigene wissenschaftliche Arbeit möglich war.

Nach dem Fall der Mauer 1989 und der Wiedervereinigung 1990 war Dr. H. Jaeger bestrebt, wieder ein geologisch-paläontologisches Institut aufzubauen. Diesem Vorhaben standen aber wis- senschaftspolitische Umstände entgegen. So bestanden in Westberlin zwei geologisch-paläontologische Institute, die die jetzt für geologische Forschung notwendigen Labore und Instrumente besaßen, die schon wegen des beengten Raumes im Museum nicht zu erstellen waren. Der Wissenschaftsrat empfahl eine Differenzierung der drei Berliner Institute in eine traditionelle Geologie/Paläontologie an der Freien Universität, eine angewandte Geologie an der Technischen Universität und eine biologisch ausgerichtete $\mathrm{Pa}$ läontologie an der Humboldt Universität. Eine Paläontologie in enger Verbindung zur Biologie ist eine für Deutschland einzigartige Situation. Dementsprechend wurden am Museum zwei Professuren, eine für Paläozoologie und eine für Paläobotanik, eingerichtet und ausgeschrieben.

Kurz nach der Wiedervereinigung versuchten Prof. Barthel, Prof. Daber und Dr. Krutzsch bereits ab 1991 die Lehre wieder aufzunehmen, obwohl es keinen etablierten Studiengang gab. Die Drs. Heinrich, Böhme und Fischer gaben im Sommersemester 1993 und Wintersemester 1993/94 eine Vorlesung zur Wirbeltierpaläontologie des Eiszeitalters für Archäologen. Offiziell las dann ab Wintersemester 1993/94 Prof. Mai Paläobotanik und ab Sommersemester 1995 Prof. Schultze vergleichende Anatomie und Wirbeltierpaläontologie jetzt für Biologen.

Kurz nach der Wiedervereinigung versuchte Dr. Jaeger auch erfolgreich, die Tagung der Paläontologischen Gesellschaft wieder nach Berlin zu holen. Diese fand vom 21.-26.9.1992 am Museum für Naturkunde in Berlin statt. Dr. Jaeger war erkrankt und starb zu Beginn der Tagung am 22.9.92, so dass Dr. Heinrich und Dr. Böhme die gesamte Organisation zu übernehmen hatten. Für viele Kollegen aus dem Westen der Bundesrepublik war es die erste Möglichkeit, die Schätze des Museums zu sehen.

1994 wurde zur Sicherung der Archaeopteryx ein Tresor angeschafft.

\section{Direktorat Schultze (1994 bis 2004)}

Im Jahre 1993 wurde Prof. Dr. Hans-Peter Schultze als Ordinarius für Paläozoologie und Direktor des Instituts für Paläontologie berufen; er trat die Stelle am 1. Juli 1994, aus Lawrence, Kansas, kommend, an. Es war für ihn eine persönliche Verpflichtung, das Institut, das sein Doktorvater Prof. Gross 1961 allein lassen musste, wieder aufzubauen. Ihm war die Möglichkeit gegeben, das Institut personell auszubauen, aber 
trotz vieler Versprechungen erfolgte baulich nur wenig. Ein Histologielabor und ein Essigsäurelabor wurden eingerichtet, das Flusssäurelabor und die Präparation modernisiert, und einige wenige Räume gestrichen, andere in Selbsteinsatz. Am 1.7.94 erfolgte die Gründung des Naturhistorischen Forschungsinstituts Museum für Naturkunde als Zentralinstitut der Humboldt-Universität. Diese Gründung war mit vielen Versprechungen und Hoffnungen auf eine Erneuerung des Gebäudes verbunden, diese wurden aber ebenfalls nicht erfüllt. Auch bei dieser Neugründung blieben im Museum wie schon 1889 und 1969 die alten Strukturen erhalten, vor allem blieb die Identifizierung des einzelnen mit seinem Institut oder gar nur mit seiner speziellen Sammlung und nicht mit dem Museum als ganzem bestehen.

Professor Dr. Dieter Mai trat bereits 1993 die C3-Professor für Paläobotanik an. Er wurde im Jahre 2000 pensioniert, seine Stelle wurde aber bisher nicht wieder besetzt, sondern nur vertretungsweise durch den Dozenten Dr. M. Prauss für zwei Jahre 2002 bis 2004. Aus der alten Garde konnten noch die Kustoden Dr. Böhme (Geologische Sammlungen), Dr. Fischer (Säugetiere), Dr. Heinrich (Reptilien, nach Pensionierung von Dr. Fischer zuständig für Säugetiere), Dr. Helms (Muscheln, Schnecken, Brachiopoden), Frau Dr. Pietrzeniuk (Arthropoden, Echinodermen, Graptolithen) und Herr Dr. Rüffle auf einer befristeten Mitarbeiterstelle für Paläobotanik übernommen werden. Auf die Stelle des verstorbenen Dr. Jaeger wurde 1995 Dr. R.-Thomas Becker als Kustos für die Trilobiten, Cephalopoden und Devon-Sammlungen eingestellt. Weiterhin wurden 1995 die Kustodien für Paläobotanik mit Frau Dr. B. Mohr (Mesophytikum) and Dr. S. Schultka (Paläophytikum) und die Assistentenstelle (C1) für Invertebratenpaläontologie mit Frau Dr. Hinz-Schallreuter besetzt. Neu geschaffen wurden die Kustodien Mikropaläontologie und $\mathrm{Pa}$ läoichthyologie, beide 1996 besetzt mit David Lazarus Ph.D. bzw. mit Prof. Dr. Gloria Arratia. Außerdem wurde eine befristete Bewährungsstelle für Wirbeltierpaläontologie eingerichtet und 1996 mit Dr. O. Hampe besetzt. Es existierten jetzt vier Kustodien für Wirbellose, drei für Wirbeltiere, zwei für fossile Pflanzen mit jeweils einer befristeten Stelle und eine Kustodie für die geologischen Sammlungen (Abb. 13). Dr. Fischer und Dr. Helms gingen 1997 in den Ruhestand und wurden 1998 durch David Unwin Ph.D. bzw. Dr. Martin Aberhan ersetzt. Dr. Christian Neumann übernahm 2001 die Stelle von Frau Dr.
Pietrzeniuk, die das Jahr zuvor in Ruhestand gegangen war. Nach dem Ausscheiden von Dr. Böhme übernahm Dr. Hampe die Kustodie für die geologischen Sammlungen. Mit dem Weggang von Frau Hinz-Schallreuter nach Greifswald wurden dann die beiden befristeten Stellen 2001 mit Dr. Rainer Schoch, der nur ein Jahr blieb, um dann nach Stuttgart zu wechseln, und Dr. Wolfgang Kießling besetzt. Auch Dr. Becker verließ das Institut 2001, um das Ordinariat für Paläontologie an der Universität Münster zu übernehmen. Auf seine Stelle kam 2002 Dr. Dieter Korn.

Als Sekretärin wurde 1994 Frau Christa Grothe eingestellt, die 2000 in Pension ging, und Frau Petra Ebber übernahm die Stelle. Herr Jörg-Peter Mendau (vorher Ulrike Lange) und als zweite Kraft Frau Elke Siebert wurden 1995 als Grafiker eingestellt. Frau Waltraud Harre war von 1994 bis 2000 die Photographin des Instituts, ihre Stelle wurde 2001 von Frau Carola Radke übernommen. Als Präparatoren waren Herr Lutz Berner, Herr Hans-Hartmut Krueger und Frau Evelyn Stenzel für die Paläozoologie, Frau Gudrun Humpohl von 1995 bis 1997 und ab 1997 Silvia Salzmann für die Mikropaläontologie und Frau Cornelia Hiller für die Paläobotanik angestellt. Im Jahr 2003 schied der Chefpräparator Krueger aus, und Herr Berner wurde Chefpräparator. Herr Jürgen Jabs (seit 1980) und Frau Serpentina Scheffel (seit 1981) waren als Sammlungskonservatoren für die Invertebraten- bzw. die Vertebratensammlungen zuständig. Außerdem gab es noch als Sammlungspfleger Herrn Klaus Klups von 1985 bis 2000 (danach Frau Claudia Kaatz), und Frau Karola Ulrich bis 1999 (ab 2000 Frau Manuela Tilling). Für die Paläobotanik standen zwei weitere technische Kräfte zur Verfügung, Frau Rosemarie Förster (vorher Heidrun Buder) von 1995 bis 2002 und Frau Catrin Puffert ab 1994. Frau Diane Raspe (vorher Annemarie Frederich) wurde für die Dateneingabe eingestellt, und Herr Andreas Schnock 1999 zur Betreuung der Computer. Die Bibliothek wurde weiter von Frau Seider, einer Diplompaläontologin, geleitet (ab 2001 von Frau Annegret Henkel).

Wie in den vorangegangenen Kapiteln soll hier ein kurzer Abriss der Lebensdaten des Leiters des Instituts, Hans-Peter Schultze, gegeben werden: geboren 13.8.1937 in Swinemünde auf Usedom, Pommern; Promotion 1965 in Tübingen bei W. Gross; 1971 Habilitation in Göttingen bei O. H. Walliser; 1972 Dozent und 1974 apl. Professor Universität Göttingen; 1978-1994 Mu- 

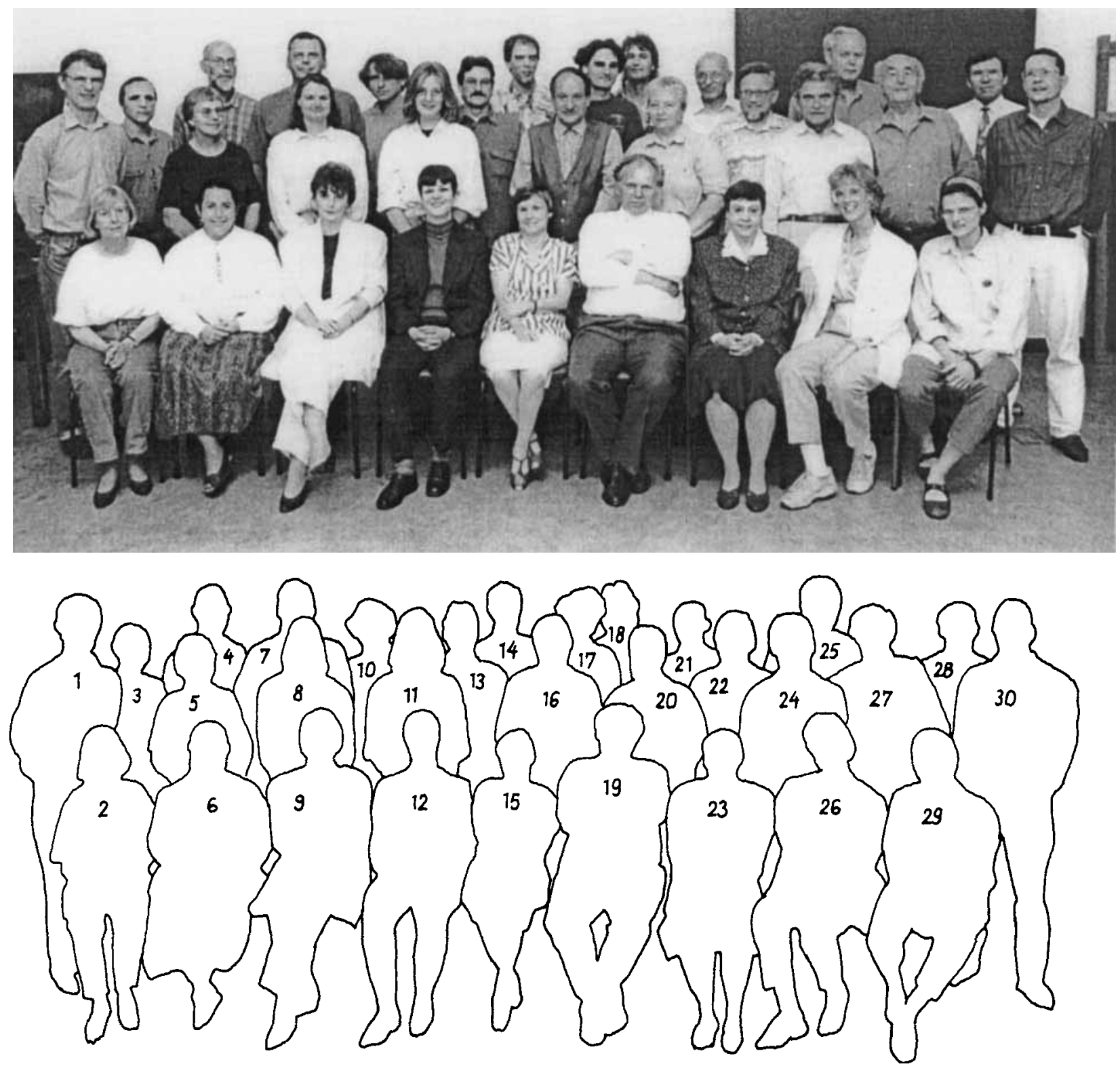

Abb. 13. Mitglieder des Instituts für Paläontologie im Jahre 1996 (3.9. 96): 1. Dr. St. Schultka, (Oberkustos Paläobotanik) 2. R. Förster (techn. Assistentin Paläobotanik), 3. K. Klups (Sammlungspfleger Wirbeltiere), 4. J.-P. Mendau (Graphiker), 5. Dr. E. Pietrzeniuk (Kustodin Arthropoden, Echinodermen u. a.), 6. Prof. Dr. G. Arratia (Kustodin Fische), 7. H.-H. Krueger (Chefpräparator), 8. E. Stenzel (Präparatorin), 9. S. Scheffel (Konservatorin Wirbeltiere), 10. J. Jabs (Konservator Wirbellose), 11. G. Humpohl (Präparatorin Mikrofossilien), E. Siebert (Graphikerin), 13. L. Berner (Präparator), 14. Dr. M. Otto (Postdoktorand), 15. C. Grothe (Sekretärin), 16. Prof. Dr. D. Mai (Leiter Paläobotanik), 17. G. Mayr (Doktorand), 18. Dr. R.-T. Becker (Oberkustos Wirbellose), 19. Prof. Dr. H.-P. Schultze (Direktor), 20. Dr. G. Burmann (DFG-Stipendiatin), 21. Dr. G. Böhme (Kustos Geologie), 22. Dr. Kh. Fischer (Kustos Säugetiere), 23. Dr. B. Mohr (Kustodin Mesophytikum), 24. Dr. J. Helms (Kustos Mollusken u. a. ), 25. Dr. W.-D. Heinrich (Oberkustos Wirbeltiere), 26. Dr. A. Hinz-Schallreuter (Assistentin), 27. Dr. H. Jähnichen (Pensionär Paläobotanik), 28. E. Kahlert (wiss. Mitarbeiter Paläobotanik), 29, C. Hiller (Präparatorin Paläobotanik), 30. Dr. O. Hampe (Assistent); (es fehlen D. Lazarus Ph.D., Kustos für Mikropaläontologie, und K. Ulrich, Sammlungshelferin Wirbellose). (Aufnahme Fotografin W. Harre).

seum of Natural History und Department of Systematics \& Ecology, University of Kansas, Lawrence, Kansas, 1988-1990 Chairman des Departments of Systematics \& Ecology; 1994-2004 Professor und Direktor Institut für Paläontologie; 2000-2004 Direktor Museum für Naturkunde (Cloutier 2002, 2004).

In diesem Zeitraum wurden die Sammlungen durch Kauf und Expeditionen weiter vergrößert. H.-P. Schultze ging 1995 und 1997 zusammen mit dem kanadischen Kollegen Dr. Steve Cumbaa vom Museum of Nature in Ottawa in die kanadische Arktis (etwa $300 \mathrm{~km}$ östlich des Mackenzie-Deltas), wo sie unterdevonische Knochenfische aufsammelten (Schultze \& Cumbaa 2001, Schultze 2001). Anfang 1998 wurde die Edinger Sammlung mit Hilfe von Lottomitteln aufgekauft (Sonderausstellung 5.5.-30.9.98); es handelte sich vor allem um devonische Fischfossilien aus Deutschland und Schottland, aber auch aus an- 
deren Zeitaltern. Mit einem weiteren kanadischen Kollegen, Dr. M. Wilson von Edmonton, ging H.-P. Schultze in die südlichen Mackenzie Mountains und brachte Agnathen aus dem Silur/DevonGrenzbereich nach Berlin. Ebenfalls mit Unterstützung der Deutschen Lottogesellschaft Berlin konnten 1999 Fossilien, vornehmlich Pflanzen und Insekten, aus der Unterkreide Brasiliens (Araripe, Provinz Céara) aufgekauft werden (Mohr \& Friis 2000, Mohr \& Rydin 2002). Ein Schwerpunkt der Sammlungsarbeit lag auf der Katalogisierung vor allem der Originale und auf der Dateneingabe, da die Sammlungen nur ganz sporadisch katalogisiert waren. Dazu lud Herr Kießling 2002 eine internationale Gruppe von Wissenschaftler zu einem Symposium im Frühjahr 2003 ein (,The International Paleobiology Database Symposium" vom 13.-14. 3. 2003).

Die geologischen Sammlungen wurden zusammengeführt und in einem Gebäude der Humboldt Universität in der Prenzlauer Promenade 149-152 untergebracht. Zu Zeiten Beyrichs bestanden enge Beziehungen zwischen den Sammlungen des Preußischen Geologischen Landesamtes im Nachbargebäude Invalidenstr. 44 und den Sammlungen des Geologisch-Paläontologischen Instituts. So war es nur natürlich, dass Teile der Sammlungen 1951 vom Museum bzw. auf dem Umweg über die Deutsche Akademie der Wissenschaften (siehe oben) vom Geologisch-Paläontologischen Institut übernommen wurden. Die Sammlungen des Nachbarhauses machten mehrere Umzüge mit, bis sie in einer KavallerieKaserne in Spandau eine gute Unterkunft fanden. Im Jahr 2000 wurde zwischen der Humboldt Universität und der Bundesanstalt für Bodenforschung ein vorläufiges Übereinkommen über die Übernahme der Sammlungen der ehemaligen Preußischen Geologischen Landesanstalt durch das Museum für Naturkunde getroffen. Dieser Vorvertrag wurde von der Bundesanstalt 2003 aufgekündigt, da die Humboldt Universität bis dahin aus finanziellen Gründen keine Personalmittel für die Übernahme der Sammlungen vorgesehen hatte.

Ein besonderes Anliegen von Prof. Schultze war es, die Forschung an dem Tendaguru-Material zu reaktivieren. Dr. Heinrich hatte bei der Aufarbeitung von Gestein der alten Ausgrabungen interessante Säugerzähne gefunden (Heinrich 1998, 1999, 2001). In einem Sammelband der Geowissenschaftlichen Reihe (Band 2, 1999) wurden neueste Ergebnisse zusammengetragen, ein Sammelantrag wurde bei der Deutschen Forschungsgemeinschaft gestellt und bewilligt. So konnte im Jahre 2000 wieder eine Tendaguruexpedition des Instituts organisiert werden, die die Untersuchung von Mikroinvertebraten, Mikround Makrovertebraten, Pflanzenfossilien und der Sedimentologie zum Ziel hatte (Heinrich et al. 2001). An dieser Deutsch-Tansanischen Expedition nahm der Kanadier Gerhard Maier teil, der danach ein umfangreiches Buch über die Ausgrabungen am Tendaguru und die Bearbeitung der Funde publiziert hat, wo die Tätigkeit der Mitarbeiter des Instituts sehr positiv dargestellt wird (Maier 2003).

Durch Vermittlung des neuen Ordinarius für systematische Zoologie, Prof. Dr. U. Zeller, konnte 1998 eine neue geologische Zeitschriftenreihe, ,Mitteilungen aus dem Museum für Naturkunde der Humboldt-Universität in Berlin, Geowissenschaftliche Reihe", gegründet werden. Die drei Reihen des Museums für Naturkunde erscheinen seitdem mit ähnlichem Layout beim Verlag Wiley-VCH. Auf Initiative von Prof. Zeller wurde das Graduiertenkolleg "Evolutive Transformationen und Faunenschnitte" beantragt und 1998 genehmigt. Diesem Kolleg gehörten Doktoranden und Postdoktoranden aus der Paläontologie an. So haben hier als Postdoktoranden Dr. Wolfgang Kießling von 1999 bis 2000, Frau Dr. Stefanie Schumacher von 2001 bis 2003, Herr Henning Scholz von 2002 bis 2004 und Herr Alexander Schmidt ab 2004 gewirkt. Es wurden drei internationale paläontologisch ausgerichtete Symposien abgehalten: 1. „Origin and evolutionary transformation of mammals Using biological signals in understanding earth history" 29.--31. 5. 2000. 2. „Coleoid cephalopods through time: neontological approaches to their palaeobiology in the light of the fossil record" 16.-19. 9. 2002. 3. „Mesozoic-Cenozoic Bioevents: Possible links to impacts and other causes" 21.-23.11.2002 (Kiessling \& Lazarus im Druck).

Im Frühjahr 2000 musste Prof. Schultze die Leitung des Museums für Naturkunde übernehmen, nachdem er den Mineralogen Prof. Stöffler schon länger vertreten hatte. Ihm wurde die Leitung auch noch angetragen, als er sein Pensionsalter erreicht hatte, da die Universitätsleitung bis zur Einsetzung eines Generaldirektors keinen Wechsel in der Führung des Museums wünschte. Prof. Schultze verblieb dadurch wenig Zeit für die Leitung des Instituts für Paläontologie, er durfte Führungen für besondere Gäste wie am 20. 11. 2001 für den Bundespräsident Rau (Abb. 14) durchführen. Es war nach dem Kaiserbesuch im Jahre 1912 der zweite Besuch eines Staats- 


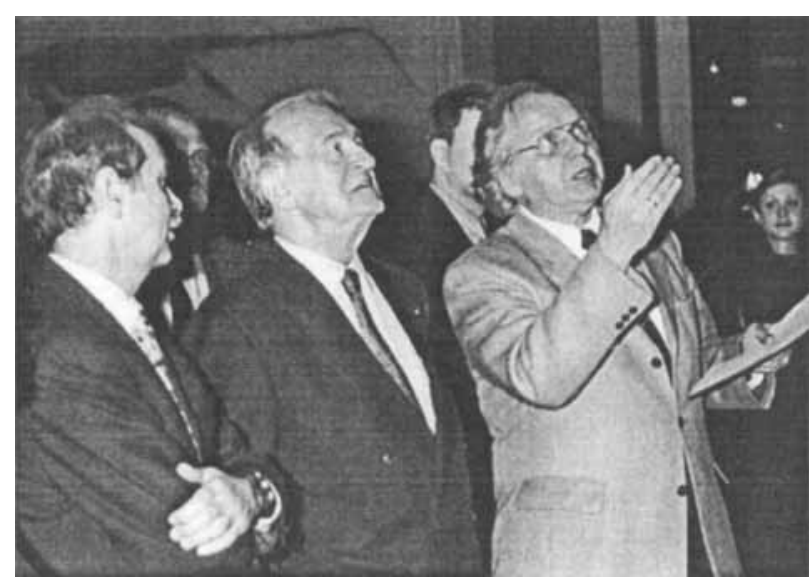

Abb. 14. Besuch des Bundespräsidenten Johannes Rau am 20. 11. 2001. v. 1. n. r.: Prof. Dr. Jürgen Mlynek, Präsident der Humboldt-Universität, Bundespräsident Johannes Rau, Prof. Dr. Hans-Peter Schultze, Direktor des Museums, vor dem Brachiosaurus. (Aufnahme Fotografin C. Radke).

oberhauptes im Museum für Naturkunde. Im letzten Amtsjahr von Prof. Schultze erfolgten einige überraschende positive Entwicklungen. So bot die Senatsverwaltung dem Museum EU-Mittel, so genannte EFRE-Mittel (,Europäischer Fonds für Regionale Entwicklung"), an, wozu die Deutsche Lottogesellschaft Berlin die Gegenfinanzierung bewilligte. Mit diesen Mitteln soll der Sauriersaal neu gestaltet werden und ein neuer Saal der Geschichte des Lebens eröffnet werden. Außerdem wurde eine Aktion gestartet, um private Mittel zur Unterstützung der Sammlungen in Form von Patenschaften für die Sammlungsstücke einzuwerben. Auf Initiative des Direktors beteiligte sich das Museum für Naturkunde zusammen mit dem Botanischen Garten und Museum an einem EUAntrag von CETAF (,Consortium of European Taxonomic Facilities", einer Vereinigung großer Naturkundemuseen Europas). Dieser Antrag, „Synthesys", wurde genehmigt, so dass dem Museum über 500000 Euro in den nächsten Jahren für die Unterstützung von Wissenschaftlern, die in den Sammlungen arbeiten wollen, zur Verfügung stehen.

Im Jahre 1996 war das Museum für Naturkunde vom Wissenschaftsrat zur Aufnahme in die Wissenschaftsgemeinschaft Gottfried Wilhelm Leibniz („Blaue Liste") vorgeschlagen worden, aber erst im Herbst 2003 war die Senatsverwaltung daran interessiert, einen Antrag auf Aufnahme zu stellen. Dieser Antrag ist von der Bund-Länder-Kommission Anfang März 2004 behandelt, aber nicht endgültig entschieden worden. Die Aufnahme in die „Blaue Liste“ nähme das Museum aus den Kürzungen heraus, die der Senat den Universitäten Berlins auferlegt hat.

\section{Rückschau}

Wenn man die Geschichte einer Institution beschreibt, verfällt man leicht dem Versuch, sie oder einige ihrer Zeiten zu glorifizieren. Wir hoffen, dass dies hier nicht geschehen ist. Natürlich hat das Geologisch-Paläontologische Institut Zeiten erlebt, in denen es größere Ausstrahlung hatte als in anderen. Diese Zeiten lassen sich aber nicht durch Wiederherstellung der alten Strukturen zurückholen. Die Voraussetzungen personeller und institutioneller Art haben sich geändert. Man sollte mit der Zeit gehen und Änderungen bewusst anstreben.

Prof. v. Branca vertrat die alte allumfassende Form der Geologie des 19ten Jahrhunderts. Er lehnte eine Trennung von Geologie und Paläontologie ab, wie sie Anfang des 20sten Jahrhunderts von Prof. Jaekel vehement gefordert, in Berlin in der Nachfolge v. Branca's nicht, aber z. B. von Prof. Abel in der Nachfolge Stille's in Göttingen durchgeführt wurde. Prof. Pompeckj hat das Institut im Sinne v. Branca's weitergeführt. Prof. Stille hat dann die Trennung - wenn auch nicht institutionell - vorgenommen und ein geologisches Institut geschaffen, das von v. Bubnoff so weitergeführt wurde. Danach konnte die Geologie auf der qualitativen Höhe nicht mehr weitergeführt werden und endete 1968 ganz mit der Hochschulreform in der DDR.

Der Paläontologie gab Prof. Stille ihr eigenes Dasein als Abteilung. Diese Trennung wurde von Prof. Gross, einem von der Zoologie kommenden Paläontologen, weiter betrieben. Prof. Gross hatte als Wirbeltierpaläontologe die Situation am Naturhistoriska Riksmuseet in Stockholm (Prof. Stensiö, ursprünglich Mediziner) und in den Vereinigten Staaten vor Augen, wo sich die Wirbeltierpaläontologie von der Geologie ganz getrennt hatte und in enger Verbindung mit der vergleichenden Anatomie betrieben wurde. Nach 1968 verblieb im Museum für Naturkunde nur noch die Richtung Paläontologie erhalten. Nur sie konnte nach der Wiedervereinigung in Verbindung mit der Biologie als Hochschulfach reaktiviert werden. Gegen eine Wiederaufnahme der Geologie sprachen die neuen hochschulpolitischen (Geologie-Paläontologie an der Freien Universität und Angewandte Geologie an der Technischen Universität in Berlin) und die räumlichen Gegebenheiten (Fehlen von Platz und Labors im Museum). So hat eine ursprünglich allumfassende geowissenschaftliche Institution sich im 20sten Jahrhundert über ein Zentrum der geologischen Forschung zu einem Schwerpunkt 
in der paläontologischen Forschung entwickelt. Außerdem ist das Institut von einem Universitätsinstitut zu einer Einheit des Museums für Naturkunde geworden, somit liegt das Gewicht heute mehr auf der Betreuung der und Forschung an den Sammlungen und weniger auf der Lehre und Ausbildung von Studenten.

\section{Danksagung}

Verschiedene Mitglieder und ehemalige Mitglieder des Instituts für Paläontologie haben durch ihre Informationen bei der Zusammenstellung des Manuskriptes geholfen, vor allem die Herrn Drs. Böhme und Heinrich. Außerdem dankt der Juniorautor ehemaligen Mitgliedern des ZGI, Dr. J. Gersemann von der Bundesanstalt für Geowissenschaften u. Rohstoffe. Frau A. Wolff, Universitätsarchiv der Humboldt Universität, Frau A. Henkel, Museum für Naturkunde, Daniel Brinkmann und Barbara Narendra, Yale Peabody Museum, für Angaben, die in der Tabelle Eingang fanden. Die Aufnahmen zu den Abbildungen 10 und 12 stellten Herr Prof. R. Daber und Prof. M. Barthel zur Verfügung. Herr Prof. F. Thiedig, Hamburg, und Herrn Prof. H. Miller, München, halfen beim Auffinden von Nachrufen. Für die kritische Durchsicht des Manuskripts sei den Herren Professoren Drs. G. Hoppe, Berlin, und M. Guntau, Rostock, gedankt.

\section{Literatur}

Anonym 1962. Mitteilungen. Informationen aus den Hochschulen. Personalia. - Berichte der Geologischen Gesellschaft in der Deutschen Demokratischen Republik für das Gesamtgebiet der Geologischen Wissenschaften 7, 3: $440-441$.

Asen, J. 1955. Gesamtverzeichnis des Lehrkörpers der Universität Berlin. I. 1810-1945. 279 pp., Harrassowitz, Leipzig.

Böhme, G. 1989. Otto Jaekel und das Museum für Naturkunde der Berliner Universität. - Wissenschaftliche Zeitschrift der Ernst-Moritz-Arndt-Universität Greifswald, Mathematisch-naturwissenschaftliche Reihe $38(1-2): 18-21$.

- 1993. Die paläontologische Sammlung H. Rühle von Lilienstern - Bedeutung und Schicksal. - Fundgrube. Populärwissenschaftliche Zeitschrift für Geologie, Mineralogie, Paläontologie, Bergbaugeschichte 29 (3-4): 108-11.

Branca, W. von. 1910a. Das geologisch-paläontologische Institut und Museum an der Königl. Friedrich-WilhelmsUniversität in Berlin. In Lenz, M.: Geschichte der königlichen Friedrich-Wilhelms-Universität zu Berlin III: 319-343. Verlag der Buchhandlung des Waisenhauses, Halle.

- 1910b. Über die Abtrennung der Paläontologie von der Geologie. - Naturwissenschaftliche Wochenschrift. Neue Folge IX (8): 113-115.

- 1913. Über das Verhältnis der Geographie zur GeologiePaläontologie und die Frage einer Teilung der GeologiePaläontologie. - Zeitschrift der Deutschen Geologischen Gesellschaft 65 (11): 1-10.

- 1916a. Ein Säugetier?-Unterkiefer aus den TendaguruSchichten. - Archiv für Biontologie 4 (1): 137-140.

- 1916b. Über Paläontologische Hypothesen: Zwei gleichberechtigte Wege paläontologischer Forschung und Die Frage einer Teilung der Geologie - Paläontologie. Centralblatt für Mineralogie, Geologie und Paläontologie Jg. 1916: 243-336.

Branco, W. 1879. Beiträge zur Entwicklungsgeschichte der fossilen Cephalopoden. Theil I: Die Ammoniten. - Palaeontographica N.F. $6(1 \& 2)$ : $15-50$.
- 1880. Beiträge zur Entwickelungsgeschichte der fossilen Cephalopoden. Theil II: Die Goniatiten, Clymenien, Nautiliden, Belemnitiden und Spiruliden. - Palaeontographica N.F. 7 (1): $12-81$.

- 1894. Schwabens 125 Vulkan-Embryonen und deren tufferfüllte Ausbruchröhren, das größte Gebiet ehemaliger Maare auf der Erde. Teil I. - Jahreshefte des Vereins für vaterländische Naturkunde in Württemberg 1894: 505-997.

- 1895. Schwabens 125 Vulkan-Embryonen und deren tufferfüllte Ausbruchröhren, das größte Gebiet ehemaliger Maare auf der Erde. Teil II und III. - Jahreshefte des Vereins für vaterländische Naturkunde in Württemberg 1895: $1-280$.

Bubnoff, S. von 1928. Der Werdegang einer Eruptivmasse. Geologisch-petrographische Analyse der Intrusionstektonik im Schwarzwalde. - Fortschritte der Geologie und Paläontologie 7 (20): -239 .

- 1930. Geologie von Europa. Zweiter Band: Das außeralpine Westeuropa. Erster Teil: Kaledoniden und Varisciden. XII + 690 S., Gebrüder Borntraeger, Berlin.

- 1949. Einführung in die Erdgeschichte (2. Auflage). I. Teil: Voraussetzungen - Urzeit - Altzeit. VII + 344 S. II. Teil Mittelzeit. - Neuzeit - Synthese. VIII + $345-772$ S. Mitteldeutsche Druckerei und Verlagsanstalt, Halle.

- 1952. Fennosarmatia. Geologische Analyse des europäischen Kerngebietes. XI + 450 S. Akademie-Verlag, Berlin.

Carlé, W. E. H. 1967. Hans Stille 1876-1966. - Jahresberichte und Mitteilungen des oberrheinischen geologischen Vereins 49: 17-19.

- 1988. Werner - Beyrich - von Koenen - Stille. Ein geistiger Stammbaum wegweisender Geologen. - Geologisches Jahrbuch, Reihe A, Heft 108: 1-499.

Cloutier, R. 2002. Hans-Peter Schultze, a great paleoichthyologist for whom work is synonymous with enjoyment. Mitteilungen aus dem Museum für Naturkunde in Berlin, Geowissenschaftliche Reihe 5: 5-17.

- 2004. Hans-Peter Schultze's contribution to our understanding of lower vertebrate evolution. In Arratia, G., Wilson, M. V. H. \& Cloutier, R.: Recent Advances in the Origin and Early Radiation of Vertebrates: 9-26. Verlag Dr. Friedrich Pfeil, München.

Daber, R. 1987. Geologie und Berliner Universität. - Fundgrube. Populärwissenschaftliche Zeitschrift für Geologie, Mineralogie, Paläontologie, Bergbaugeschichte 23 (4): 102-117.

- 1994. Auf der Suche nach Werten, die das Leben lebenswert machen - Berliner Paläobotanik - Geschichte 1945 bis 1994. - Sitzungsberichte der Gesellschaft Naturforschender Freunde zu Berlin (N. F.) 33: 197-205.

- 2002. Fachrichtung oder Museum? - Geohistorische Blätter 5: 109-116.

Deubel, F. 1958. Nachruf für Serge von Bubnoff. - Geologie 7: 100-101.

Diebel, K. 1960. Die paläontologischen Originale der Berliner Museen. - Paläontologische Zeitschrift 34: 59-60.

Dietrich, W. O. 1931. Joseph Felix Pompeckj 10.5.1867-8.7.1930. - Geologische und paläontologische Abhandlungen N. F. 18 (3): I-X.

- 1960. Geschichte der Sammlungen des Geologisch-Paläontologischen Instituts und Museums der Humboldt-Universität zu Berlin. Ein Beitrag zur Paläontologie-Geschichte. - Berichte der Geologische Gesellschaft der DDR 5 (4): 247-289.

Erben, K. H. 1971. Otto Heinrich Schindewolf, 7.6.1890-10. 6. 1971. -- Paläontologische Zeitschrift 45: 94-96.

Faden, E. 1967. Friedrich Solger 1877-1965. - Jahrbuch für Brandenburgische Landesgeschichte 18: 142-147.

Fischer, Kh. 1971. Riesenfaultiere (Megalonychidae, Edentata, Mammalia) aus dem Pleistozän der Pio-Domingo-Höhle in Kuba. - Wissenschaftliche Zeitschrift der Humboldt-Universität zu Berlin, Mathematisch-Naturwissenschaftliche Reihe 20 (4/5): 609-673. 
Fischer, Kh. \& Krueger, H.-H. 1979. Neue Präparation am Berliner Exemplar des Urvogels Archaeopteryx lithographica H. v. Meyer, 1861. - Zeitschrift für geologische Wissenschaften Berlin 7: 575-579.

Fischer, Kh. \& Stephan, B. 1971. Ein flugunfähiger Kranich (Grus cubensis n.sp.) aus dem Pleistozän von Kuba - Eine Osteologie der Familie der Kraniche (Gruidae). Wissenschaftliche Zeitschrift der Humboldt-Universität zu Berlin, Mathematisch-Naturwissenschaftliche Reihe $\mathbf{2 0}$ (4/5): 541-607.

Gross, W. 1964. Wilhelm Otto Dietrich (1881-1964). - Neues Jahrbuch für Geologie und Paläontologie Monatshefte, Jahrgang 1964: 385-387.

- 1970. WERnER JANENSCH †. 10. 11. 1878-29. 10. 1969. - Paläontologische Zeitschrift 44: 1-2.

Heck, H.-L. 1966. Friedrich Solger zum Gedenken. - Berichte der deutschen Gesellschaft für geologische Wissenschaften, Reihe A, Geologie und Paläontologie 11 (6): 745-746.

Heinrich, W.-D. 1975. Anlaß und Ablauf der quartärpaläontologischen Ausgrabungen und Untersuchungen bei Pisede (Kr. Malchin). - Wissenschaftliche Zeitschrift der Humboldt-Universität zu Berlin, Mathematisch-Naturwissenschaftliche Reihe 24 (5): 575-578.

- (Hrsg.) 1982. Wilhelm Otto Dietrich 1881-1964. - Zeitschrift für Geologische Wissenschaften Jahrgang 10 (7): 883-1057.

- (Hrsg.) 1983. Wirbeltier-Evolution und Faunenwandel im Känozoikum. - Schriftenreihe für Geologische Wissenschaften 19/20: $1-384$.

- 1998. Late Jurassic mammals from Tendaguru, Tanzania, East Africa. - Journal of Mammalian Evolution 5 (4): 269-290.

- 1999. First haramiyid (Mammalia, Allotheria) from the Mesozoic of Gondwana. - Mitteilungen aus dem Museum für Naturkunde der Humboldt-Universität in Berlin, Geowissenschaftliche Reihe 2: 159-170.

- 2001. New records of Staffia aenigmatica (Mammalia, Allotheria, Haramiyida) from the Upper Jurassic of Tendaguru in southeastern Tanzania, East Africa. - Mitteilungen aus dem Museum für Naturkunde der Humboldt-Universität in Berlin, Geowissenschaftliche Reihe 4: 239-255.

Heinrich, W.-D., Bussert, R., Aberhan, M., Hampe, O., Kapilima, S., Schrank, E., Schultka, St., Maier, G., Msaky, E., Sames, B. \& Chami, R. 2001. The German-Tanzanian Tendaguru Expedition 2000. - Mitteilungen aus dem $\mathrm{Mu}$ seum für Naturkunde der Humboldt-Universität in Berlin, Geowissenschaftliche Reihe 4: 223-237.

Helms, J. 1995. Hermann Jaeger † 22. 2. 1929 - 22. 9. 1992. Paläontologische Zeitschrift 69 (3/4): 303-312.

Hennig, E. 1928. Geh. Bergrat Prof. Dr. Wilhelm von Branca. - Jahreshefte des Vereins für vaterländische Naturkunde in Württemberg 84. Jg.: XXV-XXIX.

- 1930. Josef Felix Pompeckj †. Centralblatt für Mineralogie Geologie und Paläontologie, Abteilung B 1930: 353--366.

- 1965. Wilhelm Otto Dietrich. Paläontologischer Forscher. - Jahreshefte des Vereins für vaterländische Naturkunde in Württemberg 120. Jg.: 55-58.

Hoppe, G. 2003. Zur Geschichte der Geowissenschaften im Museum für Naturkunde zu Berlin. Teil 5: Vom Mineralogischen Museum im Hauptgebäude der Universität $\mathrm{zu}$ den zwei geowissenschaftlichen Institutionen im Museum für Naturkunde -1856 bis 1910 . - Mitteilungen aus dem Museum für Naturkunde der Humboldt-Universität in Berlin, Geowissenschaftliche Reihe 6: 3-51.

Illner, A. 1958. Wissenschaftliche Arbeiten von SERGE VON BUBNOFF. - Geologie Jg. 7 (3-6): 251-256.

Jaeger, H. 1971. WERNER JANENSCH 1878-1969. - Berichte der deutschen Gesellschaft für geologische Wissenschaften 16: $149-154$.
- 1992. 62. Jahrestagung der Paläontologischen Gesellschaft in Berlin. - Paläontologie aktuell 25: 13-22.

Janensch, W. 1930. Joseph Felix Pompeckj $\dagger$. - Sitzungsberichte der Gesellschaft Naturforschender Freunde zu Berlin 1930: 281-286.

Kiessling, W. \& Lazarus, D. (eds) (im Druck). Mesozoic-Cenozoic bioevents. -- Paleogeography, Paleoclimatology, Paleoecology.

Kohring, R. 1998. Große Paläontologen: Joseph Felix Pompeckj (1867-1930). - Fossilien Jg. 1998, 2: 121-124.

Lenz, M. 1910. Geschichte der königlichen Friedrich-Wilhems-Universität zu Berlin. Dritter Band: Wissenschaftliche Anstalten. Spruchkollegium. Statistik. VIII + 536 S., Verlag der Buchhandlung des Waisenhauses, Halle.

Lotze, F. 1938. Steinsalz und Kalisalze. Geologie. In Stutzer, O.: Die wichtigsten Lagerstätten der "Nicht-Erze“. Band III, Teil 1: XXVI + 936 S. Gebrüder Bornträger, Berlin.

Maier, G. 2003. African Dinosaurs Unearthed. The Tendaguru Expeditions. 380 S., Indiana University Press, Bloomington und Indianapolis, Indiana.

Mohr, B. A. R. \& Friis, E. M. 2000. Early angiosperms from the Lower Cretaceous Crato Formation (Brazil), a preliminary report. - International Journal of Plant Science 161 (6 Supplement): S155-S167.

Mohr, B. A. R. \& Rydin, C. 2002. Trifurcatia flabellata n. gen. n. sp., a putative monocotyledon angiosperm from the Lower Cretaceous Crato Formation (Brazil). - Mitteilungen aus dem Museum fuir Naturkunde in Berlin, Geowissenschaftliche Reihe 5: 335-344.

Mutschlechner, G. 1961. Werner Quenstedt †. - Verhandlungen der geologischen Bundesanstalt Wien 1961: 1-5.

Pompeckj, J. F. 1928. Gedächtnisrede auf Wilhelm von Branca. - Sitzungsberichte der preußischen Akademie der Wissenschaften zu Berlin 1928: CXIV-CXXXX

Potonié, R. 1955. Walter Gothan †. - Geologisches Jahrbuch 70: XXVII-LIII.

Quenstedt, W. \& Quenstedt, A. 1936. Hominidae fossiles. In Quenstedt, W. (ed.): Fossilium Catalogus I: Animalia. Pars 74: 1-456. Dr. W. Junk, 's-Gravenhage.

Quenstedt, W., Lambrecht, K. †, Quenstedt, A. 1938. Palaeontologi. Catalogus bio-bibliographicus. In Quenstedt, W. (ed.): Fossilium Catalogus I: Animalia. Pars 72: 1-495. Dr. W. Junk, 's-Gravenhage.

Reck, H. 1929. Wilhelm von Branca. - Zeitschrift für Vulkanologie 12: 1-7.

Schultze, H.-P. 1974. Walter Robert Gross 20. 8. 1903-9. 6. 1974. - Paläontologische Zeitschrift 48 (3/4): 143-148.

- 1996. Walter R. Gross, a palaeontologist in the turmoil of 20th century Europe. - Modern Geology 20: 209-233.

- 2001. Melanognathus, a primitive dipnoan from the Lower Devonian of the Canadian Arctic and the interrelationships of Devonian dipnoans. - Journal of Vertebrate Paleontology 21 (4): 781-794.

Schultze, H.-P. \& Cumbaa, S. L. 2001. Dialipina and the character of basal actinopterygians. In Ahlberg, P. E. (ed.). Major Events in Early Vertebrate Evolution. Palaeontology, Phylogeny and Development. - Systematics Association Special Volume Series 61: 315-332. Taylor \& Francis, New York.

Stille, H. 1940. Einführung in den Bau Amerikas. XX + 717 S. Gebrüder Bornträger, Berlin.

- 1958. Serge von Bubnoff $\dagger$. - Forschungen und Fortschritte 32 (6): $188-189$.

Weisbach, W. W. 1961. In Memoriam Werner Quenstedt 1. 1. 1893-25. 10. 1960. In Westphal, F. (ed.): Fossilium Catalogus. I: Animalia. Pars 98: 2-6. Dr. W. Junk, 's-Gravenhage. 